\title{
CHANGEABILITY OF ARC FLASH \\ PARAMETERS AND ITS IMPACT ON \\ HAZARD MITIGATION IN LOW VOLTAGE POWER SYSTEMS
}

by

\author{
Abdeslem Kadri \\ Bachelor of Engineering, Boumerdes University INELEC, 1996
}

A thesis

presented to Ryerson University

in partial fulfillment of the requirements for the degree of Master of Applied Science in the Program of Electrical and Computer Engineering

Toronto, Ontario, Canada, 2016

CCAbdeslem Kadri, 2016 


\section{AUTHOR'S DECLARATION FOR ELECTRONIC SUBMISSION OF A THESIS}

I hereby declare that I am the sole author of this thesis. This is a true copy of the thesis, including any required final revisions, as accepted by my examiners.

I authorize Ryerson University to lend this thesis to other institutions or individuals for the purpose of scholarly research.

I further authorize Ryerson University to reproduce this thesis by photocopying or by other means, in total or in part, at the request of other institutions or individuals for the purpose of scholarly research.

I understand that my thesis may be made electronically available to the public. 


\title{
CHANGEABILITY OF ARC FLASH PARAMETERS AND ITS IMPACT ON HAZARD MITIGATION IN LOW VOLTAGE POWER SYSTEMS
}

\author{
Master of Applied Science 2016 \\ Abdeslem Kadri \\ Electrical and Computer Engineering \\ Ryerson University
}

\section{Abstract}

Arc flashes in power system result in a huge amount of incident energy that can injure human workers. Strict safety measures have to be applied in the work place for safety of technical personnel. Computation of the incident energy is imperative to determine the corresponding safety requirements. Arcing current, and hence incident energy, is a function of some system parameters which may vary due to different reasons.

This research work considers the problem of parameter variability in arc flash calculations and its effect on hazard mitigation. A mathematical basis is set forth for the impact of the variation in gap between electrodes and system voltage on the incident energy value. Findings of this work emphasize that small variations in system parameters can yield inaccurate values of incident energy and misleading hazard categories. Therefore, parameter variation has to be carefully accommodated in the arc flash calculations to result in the proper hazard mitigation precautions. 


\section{Acknowledgement}

The completion of this thesis would not have been possible without the consistent help and support of Dr. Farah Mohammadi and Dr. Kaamran Raahemifar, who gave me the opportunity to serve as a Research Assistant under their supervision in the department of Electrical and Computer Engineering at Ryerson University. Their belief in me and my believe in them throughout the difficult times of my research and my graduate studies is what still keeps me motivated to this day.

I also wish to thank all the members of Ryerson Lab research group for their constructive guidance and advice. Moreover, I would like to thank the lab technicians for their technical support.

Lastly, I would like to thank my wife. Her constant encouragement made the completion of this degree possible. 


\section{Dedication}

Dedicated to the memory of my mother. 


\section{Table of Contents}

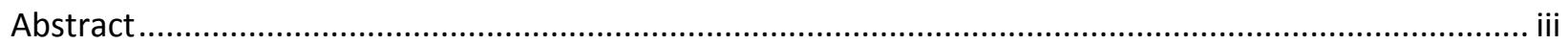

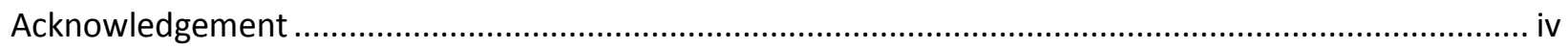

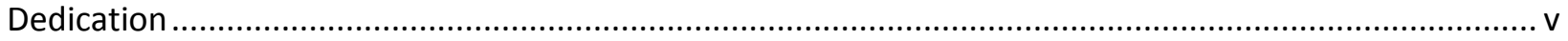

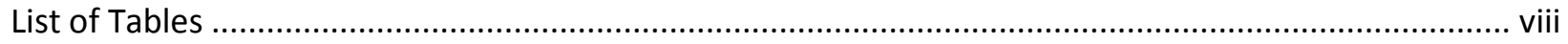

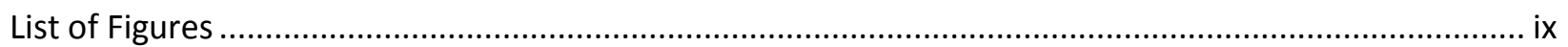

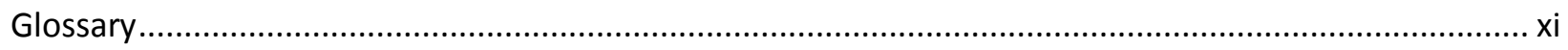

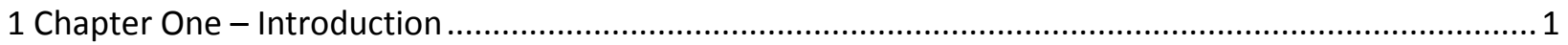

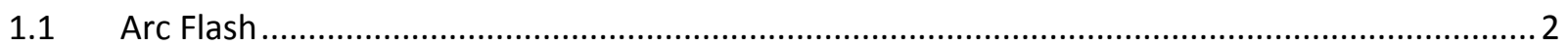

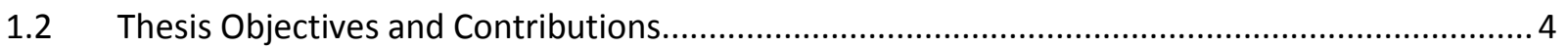

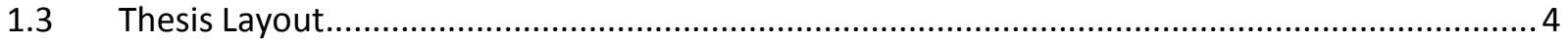

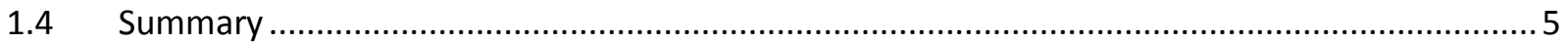

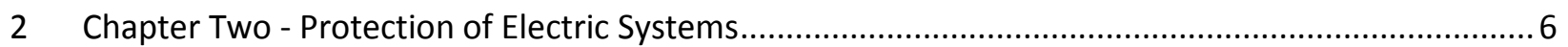

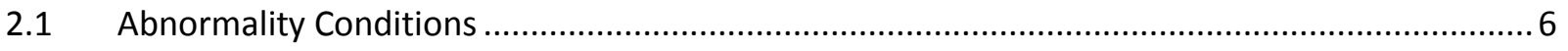

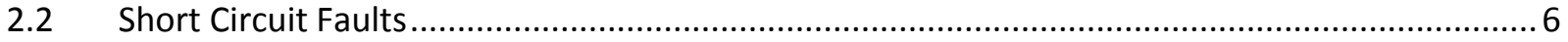

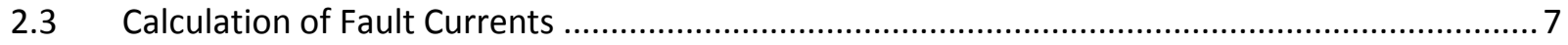

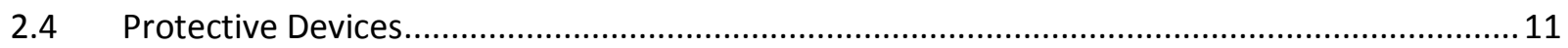

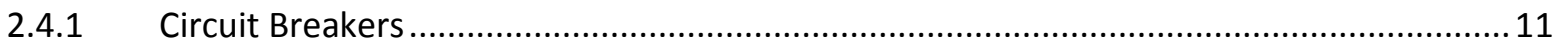

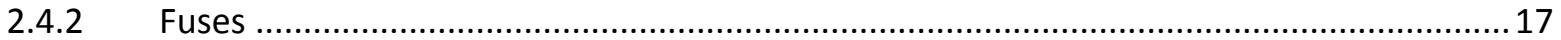

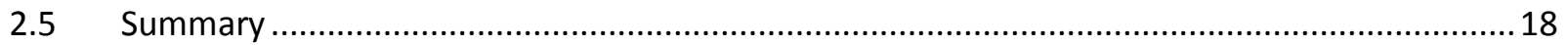

3 Chapter Three - Arc Flash Calculation and Power Systems Studies.................................................19

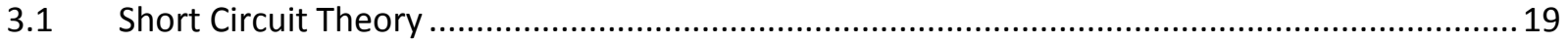

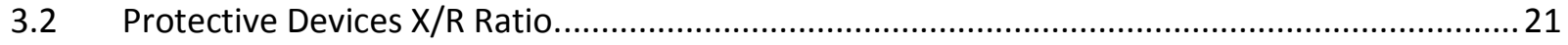

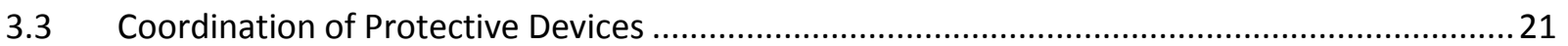

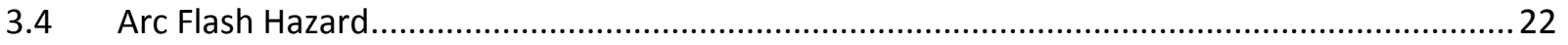

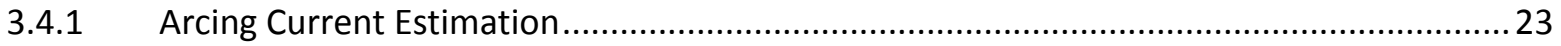

3.4.2 Normalized Incident Energy Estimation......................................................................... 24

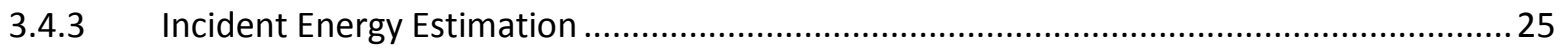

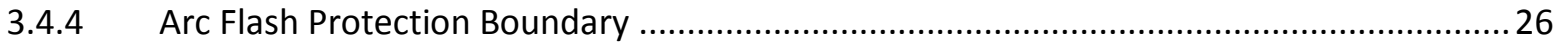

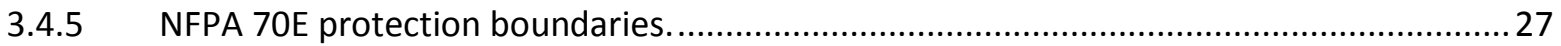

3.4.6 Energy Levels and Arc Flash Hazard Categories ...........................................................2

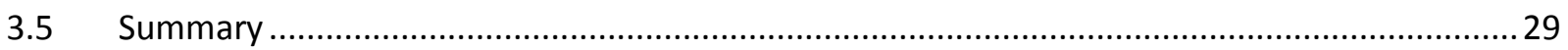


4 Chapter Four - Changeability of Arcing Parameters and Proposal for Arc Flash Calculation

4.1 Arcing Current Analysis Based on Clearing Time and Incident Energy ....................................30

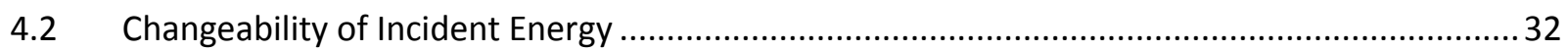

4.3 Changeability of the Gap between Electrodes and its Effect on Arcing Current.......................33

4.4 Changeability of the voltage between electrodes and its effect on arcing current and time....37

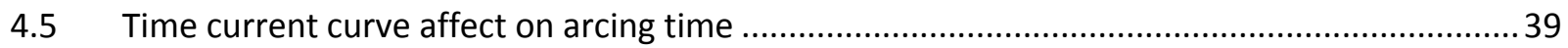

4.6 A proposed steps and flowchart of calculating arc flash hazard ........................................... 40

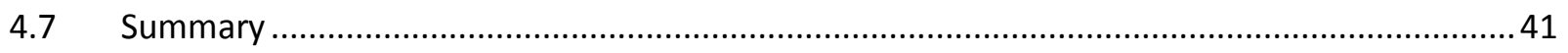

5 Chapter Five - Simulation Results and Observations ................................................................ 42

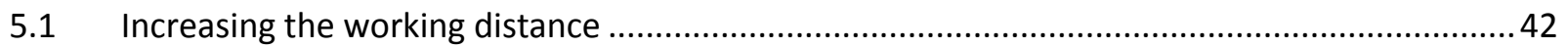

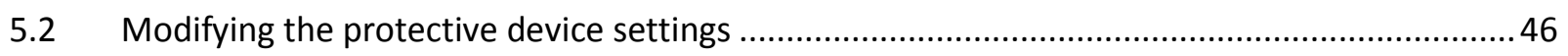

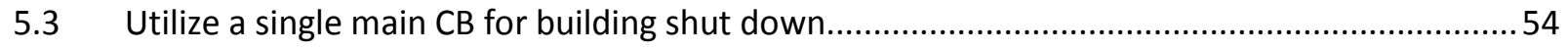

$5.4 \quad$ Install LVPCB instead of the fused disconnect mean before the MDP ...................................61

5.5 Install (LVPCB) in front of the step down transformers rated above 125KVA........................68

5.6 Transformers large than 125 KVA should be replaced with smaller size transformers .............75

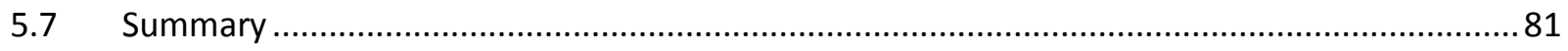

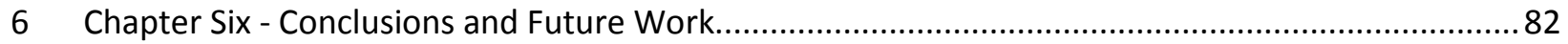

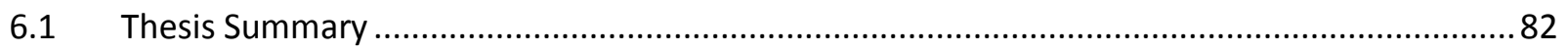

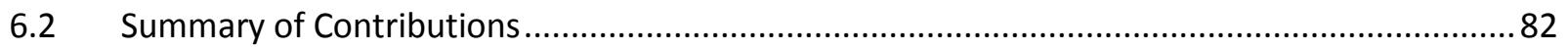

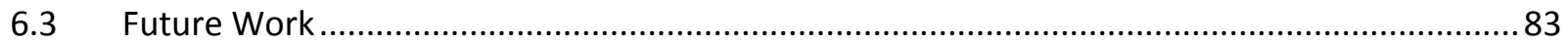

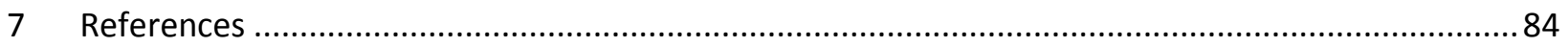




\section{List of Tables}

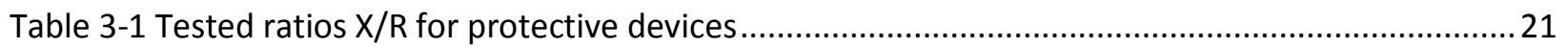

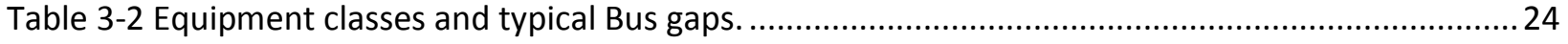

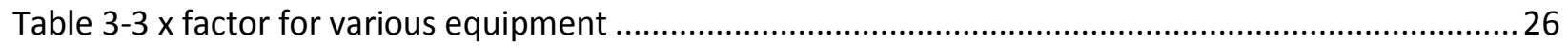

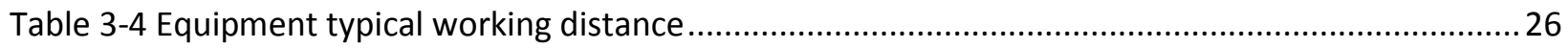

Table 3-5 The level of incident energy associated with each category NFPA70E2000 ..........................28

Table 3-6 The level of incident energy associated with each category NFPA70E2004 .........................28

Table 3-7 The level of incident energy associated with each category NFPA70E2009 ..........................29

Table 3-8 The level of incident energy associated with each category NFPA70E2012 ..........................29

Table 4-1 Min and Max likely changeability in LV arcing currents [39] ................................................... 31

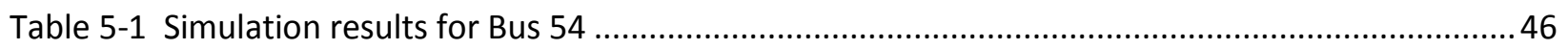

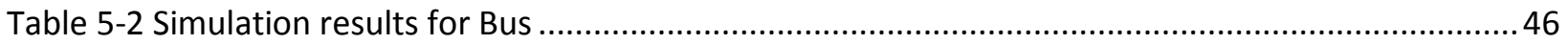

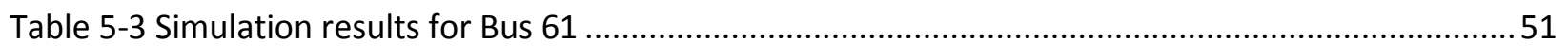

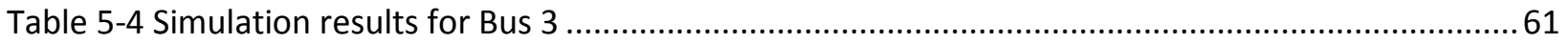

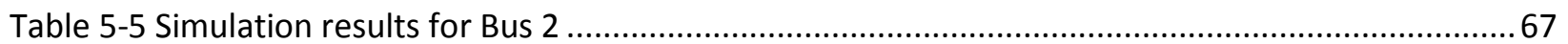

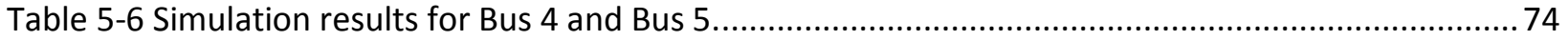

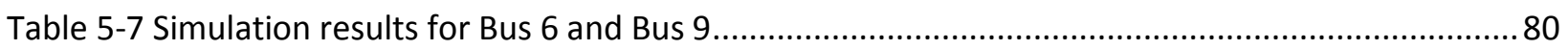




\section{List of Figures}

Figure 1-1 Arc Flash and Blast (arc current > 25KA). ........................................................................ 3

Figure 2-1 Current in RL circuit with AC voltage source [18]............................................................. 8

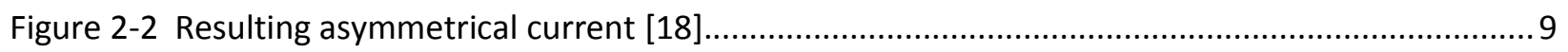

Figure 2-3 Asymmetrical fault current for X/R ratio 6 (simulation) ...................................................... 10

Figure 2-4 Response curve of CB generated from ETAP .................................................................. 11

Figure 2-5 Thermal action trip of CB generated from ETAP ................................................................. 12

Figure 2-6 Magnetic action Instantaneous trip of CB generated from ETAP.......................................... 13

Figure 2-7 TCC curve for adjustable MCCB generated from ETAP ........................................................ 14

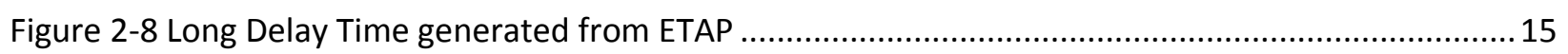

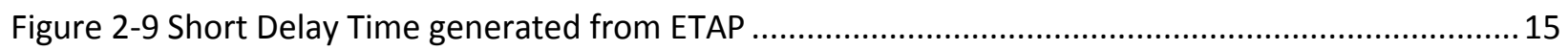

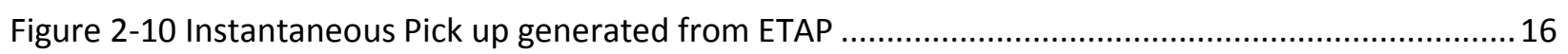

Figure 2-11 Long Delay Pick up generated from ETAP.......................................................................... 16

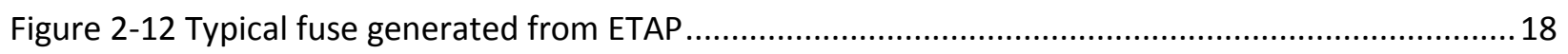

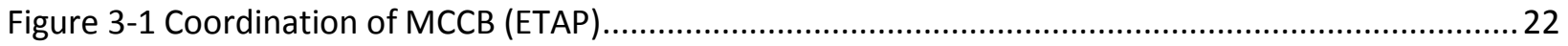

Figure 4-1 Histogram of LV arc current calculation error ................................................................... 31

Figure 4-2 Frequency distribution of deviation of measured incident from calculated one.....................33

Figure 4-3 Changeability of arc current as a function of gap for $\mathrm{Ib}=36 \mathrm{KA}$ and $\mathrm{V}=208 \mathrm{~V}$..........................35

Figure 4-4 Arc current as a function of gap for different fault currents with $\mathrm{V}=208 \mathrm{~V}$............................36

Figure 4-5 Changeability of arc current as a function of electrodes gap and $\mathrm{Ib}=70 \mathrm{KA}$.............................36

Figure 4-6 Changeability of arc current as a function of voltage for $\mathrm{Ib}=70 \mathrm{KA}$ and $\mathrm{G}=32 \mathrm{~mm} \ldots \ldots \ldots \ldots \ldots . . . . . . .38$

Figure 4-7 Arc current as a function of voltage for different fault currents with $\mathrm{G}=32 \mathrm{~mm}$.................... 39

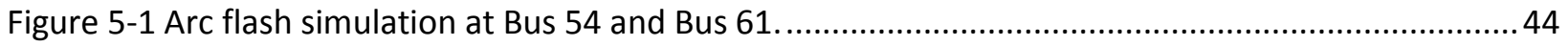

Figure 5-2 Arc flash simulation at Bus 54 at working distance of 48 inches........................................... 45

Figure 5-3 Arc flash simulation at Bus 61 at working distance of 24 inches.......................................... 45

Figure 5-4 Simulation of the power system with the High Instantaneous setting of CB57 .......................47

Figure 5-5 Arc flash factors affected from the High Instantaneous setting of CB57 ...............................48

Figure 5-6 Simulation of the power system with the Low Instantaneous setting of CB57 ......................49

Figure 5-5-7 Arc flash factors affected from the Low Instantaneous setting of CB57 .............................50

Figure 5-8 The response of CB57 at High Instantanious setting ..........................................................5 52

Figure 5-9 The response of CB57 at High Instantanious setting .......................................................5

Figure 5-10 Power system without single main CB before the MDP ...................................................55

Figure 5-5-11 Arc flash factors affected from the delay response of the Fuse at Bus 1.........................56

Figure 5-12 The response of the fuse to the arcing current ................................................................57 
Figure 5-13 The previous Power system with single main CB before the MDP …...............................58

Figure 5-5-14 Arc flash factors affected by the fast response of the CB ahead MDP ...........................59

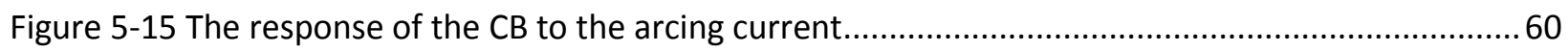

Figure 5-16 Power system with fused disconnect switch before the MDP ..........................................62

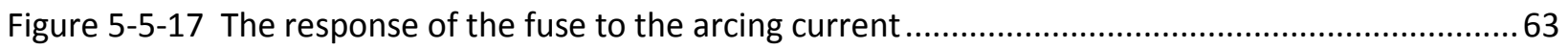

Figure 5-5-18 Arc flash factors affected by the response of the fuse ahead MDP .................................64

Figure 5-19 Power system with LVCB instead of fused disconnect switch before the MDP ....................65

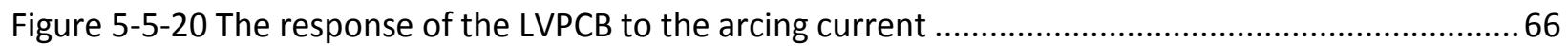

Figure 5-5-21 Arc flash factors affected by the response of the LVPCB ahead MDP ...............................67

Figure 5-22 Power system with thermal magnetic CB before transformer...........................................69

Figure 5-23 Arc flash factors at Bus 4 (Primary of Transformer T2) ....................................................... 70

Figure 5-24 Arc flash factors at Bus 5 (Secondary of Transformer T2) .................................................. 70

Figure 5-25 The response of the thermal CB1 to the arcing currents. .................................................... 71

Figure 5-26 Power system with LSI CB before the transformer ......................................................... 72

Figure 5-27 Arc flash factors at Bus 5 (Secondary of Transformer T2) using LSI CB ............................... 73

Figure 5-28 The response of the LSI CB to the arcing currents at primery and secondary of T2 ..............74

Figure 5-29 Power system with large Transformer T2 feeding 120/208 loads. ..................................... 75

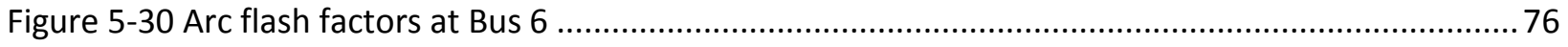

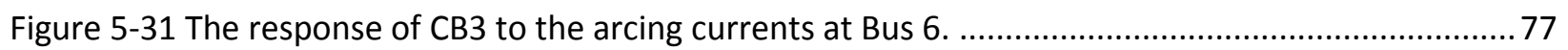

Figure 5-32 Power system with small size Transformers (T6, T13, and T12) instead of T2 in 5-29...........78

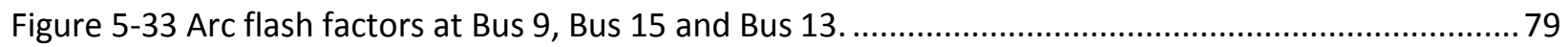

Figure 5-34 The response of CB's 6, 12 and 14 to the arcing currents at Bus's 9, 15 and $13 \ldots \ldots \ldots \ldots \ldots \ldots . . . . . . . .80$ 


\section{Glossary}

\begin{tabular}{|l|l|}
\hline AC & Alternating current \\
\hline AFB & Arc Flash Boundary \\
\hline AFC & Available Fault Current \\
\hline AFHA & Arc Flash Hazard Assessment \\
\hline AIC & Available Interrupting Current \\
\hline ASY & Asymmetrical \\
\hline Cf & Calculating Factor \\
\hline COPS & Critical Operating Power Systems \\
\hline D & Working Distance \\
\hline Eb & Incident Energy at Boundary Distance \\
\hline Ei & Incident Energy \\
\hline En & Normalized Energy \\
\hline FLA & Full Load Current \\
\hline FPB & Flash Protection Boundary \\
\hline G & Gap between conductors \\
\hline Ia & Arcing Current \\
\hline Ibf & Bolt Fault current \\
\hline ICBB & Insulated Case Circuit Breaker \\
\hline IT & Instantaneous Time \\
\hline LAB & Limited Approach Boundary \\
\hline LSI & Long Short Instantaneous \\
\hline LT & Long Time \\
\hline LVPCB & Low Voltage Power Circuit Breaker \\
\hline MCCB & Molded Case Circuit Breaker \\
\hline MDP & Main Distribution Panel \\
\hline PAB & Prohibited Approach Boundary \\
\hline PPE & Personnel Protective Equipment \\
\hline RAB & Restricted Approach Boundary \\
\hline SLD & Single Line Diagram \\
\hline ST & Short Time \\
\hline TCC & Time Current Characteristics \\
\hline x & Distance exponent \\
\hline
\end{tabular}




\section{Chapter One - Introduction}

The most important factor that has to be taken into consideration in the electrical systems design is safety. In recent years, electric injuries have represented a serious workplace health and safety issue. The seriousness of electric injuries is primarily due to their ability to cause serious complications including sudden cardia arrest, irregular heartbeat, hypoxia, renal failure, and sepsis [1], [2]. Further, it can also produce long term neurological complications and can greatly influence the quality of life [1], [2]. The main injury circumstance related to electric hazard are electric shocks, and arc flash and blast [2]. Since the beginning of the use of the electric power, the electric shock has been a concern. Over the last few decades, significant attention has been paid to develop and regulate the safety standards in the industry. Improper installations may cause fatal injury, fire or damage to the property and equipment. This leads to the necessity of development of the electric guidance and codes. In USA, the National Fire Protection Association (NFPA): National Electric Code (NEC) was first published in 1897 [4], [5] and it is used as a guide for the electric installations design. The Occupational Safety and Health Administration (OSHA) was formed to address the concerns of health and safety in the workplace. As a result of the collaboration between OSHA and NFPA a standard called NFPA 70E (Standard for Electrical safety in the Workplace) was developed. This standard provides guidance for a safe workplace in the electric installations industry. Primarily, it addresses the electric shock and arc flash. In Canada, the Canadian Electric Code (CEC) is the standard published by Canadian Standard Association (CSA) as guidance for electrical installations and maintenance of electrical equipment. And the CSA Z462, Workplace Electrical Safety Standard is the Canadian standard for workplace electrical safety, and was first published in January 2009 [3]. It is based on and harmonized with the NFPA 70E. Bill C45 (also known as Westray Bill) was created and introduced as a result of 1992 Westray coal mining disaster in Nova Scotia. In March 2004, Statute 217.1 established a duty under Criminal Code of Canada for employers, managers, and supervisors to ensure workplace health and safety. There is no specific limit on fines against a corporation that is found guilty, and individual representatives of a corporation can receive a maximum sentence of life imprisonment [4]. Due to this law, safety has become the primary concern for companies and many have invested to eliminate or reduce the electric shock and arc flash. Both NFPA70E and CSA Z462 are the key standards that outline electrical safety required for employees and electrical safety programs that the employers must 
implement. They provide guidance on how to protect workers that perform energized electrical work tasks. The standards also give guidance for the selection of Personal Protective Equipment (PPE), such as protective clothing and equipment to protect workers from electric arc flash and shock hazards. In addition, the standard also provides the working and safety distances and boundaries from energized equipment, along with the different energy levels. According to the Canadian Center for Occupational Health and Safety, CSA Z462 is a reasonable measure for an employer to follow to protect its employees [5]. CSA Z462 has been revised and we are now following the $3^{\text {rd }}$ edition, which was published in January 2015.

\subsection{Arc Flash}

In low voltage, shock injuries happen due to direct contact with electric current. However, a high voltage can create an arc that carries electric current without any direct physical contact [1], [9], [10]. It is created when an abnormal condition exists on energized electrical equipment, and an arc fault occurs that leads to an arc flash. There are many factors that can cause and increase the probability for arc flash, such as human interaction, deficiency in human performance and lack of electrical equipment maintenance. An arc flash is tremendous release of electrical energy to the air when a breakdown occurs between conductors. It can also appear when an energized conductor comes in contact with another energized conductor or with the ground, resulting in either a small spark or big explosion. This explosion is known as arc flash and it gives off thermal radiation, thermal heat and can cause burns or serious injuries to workers that are several feet away. Temperature has been recorded as high as $35000 \mathrm{~F}$ and may cause serious burns, hearing loss, eye injuries, skin and lung damage [6]. Strong arc flash also creates considerable pressure waves that heat the surrounding air, causing a blast that can hit the worker and the equipment with strong

pressure. "This pressure is about ten times the value of wind resistance that walls are normally built to withstand, so such an arc could readily destroy a conventional wall at a distance of about $40 \mathrm{ft}(12 \mathrm{~m})$ or less. A $25-\mathrm{kA}$ arc could similarly destroy a wall at a distance of $9.5 \mathrm{ft}(3 \mathrm{~m})$ " [7]. 


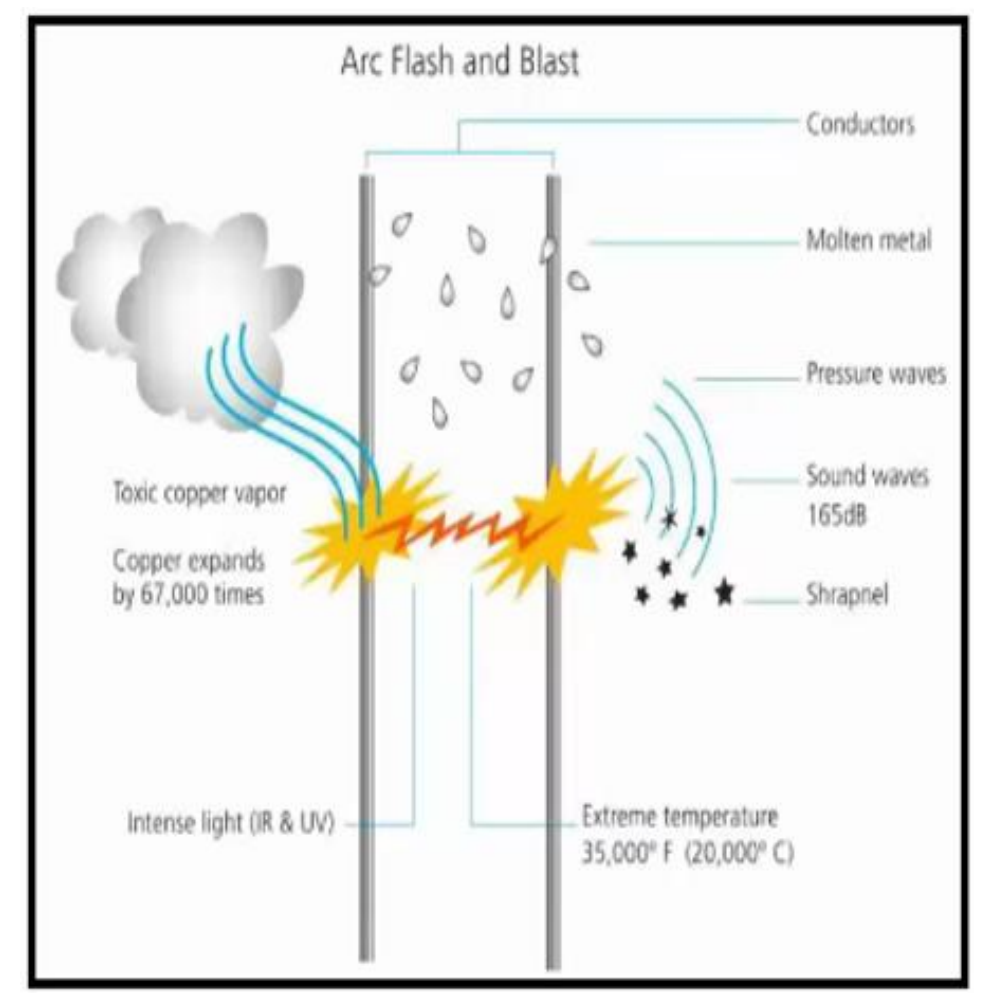

Figure 1-1 Arc Flash and Blast (arc current > 25KA).

One of the first papers concerning the arc flash quantified the incident energy released, and was written by Ralph Lee. Lee's paper developed a relationship between the heat transfer and distance and its effect on human skin. This paper highlighted some of the dangers of an arc flash, resulting in many in the industry seeking more information regarding the proper protective equipment that should be used at each particular level of exposure.

Now, the focus starts on measurement and calculation of incident energy that an arc flash may produce. A paper by Doughty, Neal and Floyd discussed the measurement and prediction of the incident energy based on two factors: the available fault current, and the distance from the arc source. An important result was that incident energy is bigger when the arc source is located in an enclosure with an open door versus a source in open air with the same distance [8]. Tests were done by using manikins to understand and mimic how humans can be affected by arc flash [9]. Arc flash hazard was first considered in 1995 by NFPA 70E standards and the Personnel Protective Equipment (PPE) and Hazard Risk Table was thus introduced. The standard used 5 categories (0- 
4) with different PPE requirement and classified by task and not by the hazard level or the incident energy. In 2002, Institute of Electrical and Electronics Engineering (IEEE) published the IEEE1584 "guide for performance arc flash hazard calculations". This standard was the basis of evaluating the arc flash hazard based on incident energy calculation in the location required at the electric installation. It became the standardized way of hazard calculation and is still used as the primary method today. Therefore, it is possible to calculate the incident energy at any point in the installation and consequently, the related thermal exposure and the selection of the relevant PPE. Gammon and Matthews published a paper in 2005 that highlighted the comprehensive statistical analysis of the IEEE 1584 test data [10]. In 2011, Curtis Thomas discussed and suggested a few techniques used in the industry to reduce arc flash hazards [11]. The results of Curtis show important reduction of arc hazards.

\subsection{Thesis Objectives and Contributions}

This thesis focuses on the variation of arc flash parameters such as voltage, gap between electrodes and arcing time. Examine the challenge of reducing the risk of injury, minimizing the arc flash hazard and improving the safety of workers at electric equipment.

This work simulate those techniques used to mitigate arc flash and investigate the impact of arc parameters variation on them. Further, we propose calculation procedure that may lead to adequate results.

\subsection{Thesis Layout}

In chapter 2, protection of electrical systems is discussed. Short circuit calculation and the different protective devices along with their characteristics and their use are investigated.

In chapter 3 the method of fault current calculation is described. The options of protective devices are also discussed. Lastly, the arc flash hazard calculation methodology is presented.

The chapter 4 is dedicated to changeability in arcing parameters such as voltage and gap. Their effect on arcing current and arcing time is discussed.

The chapter 5 will focus mainly on the results and observations. Simulation of the scenarios used to mitigate the arc flash hazard using IEEE 1584 standard is performed. The same scenarios 
are carried out with the consideration of voltage and gap variation. The results is compared and analyzed. Furthermore, the impact of voltage and gap between electrodes variation on incident energy and hazard category is shown.

The conclusions, final thoughts and future works are presented in chapter 6. Finally, the reference section covers all the sources used in this endeavor.

\subsection{Summary}

This Chapter gives an introduction to the topic of the research work. Arc flash is defined highlighting its causes and impacts. Historical development of industry standards related to arc flash in North America is stated. A quick literature review on the topic of arc flash is presented. The objectives of this research are stated along with the contributions of the work. Finally, the layout of this thesis report is given. 


\section{Chapter Two - Protection of Electric Systems}

The purpose of electrical systems is to provide electrical energy to equipment in a reliable and safe way. The equipment will convert the delivered energy to the form that is needed by the user. These electrical systems must be capable of delivering the required electric energy in a continuous form, which must be protected against any outage or damage in case of any abnormal circumstances. However, equipment may fail by nature, resulting in serious influx of energy, putting the users, installation and equipment in danger. The protection system is used to isolate the faults as quickly as possible and save the users from harm, and equipment from fire and damage.

\subsection{Abnormality Conditions}

There are many situations that abnormal conditions may occur. Events such as overloads, short circuits, under voltage, single phasing of three phase systems, overvoltage and transient surges, incorrect synchronizing of frequencies, incorrect phase sequence and reverse power flow are some of the common causes of abnormality. Amongst these, the most common abnormalities in low voltage power systems are overloads and short circuits. Therefore, our focus will be on these two. Overload is caused by an extra demand from the equipment, but is not the result of any failure in the system itself. On the other hand, a fault, such as a short circuit or ground fault, is not an overload [12]. In fact, fault is caused by an electric failure and the resulting current can be huge compared to the normal operating current. As such, it must be isolated as quickly as possible in order to minimize the risk of damage and harm.

\subsection{Short Circuit Faults}

Faults occur in normal electric installations, and an unintentional electric path will be created. As a result, the voltage will collapse and a high influx of current will flow toward the fault location from all parts of the electrical system. Fault current are reduced with distance from the source due to system impedance [13]. In power systems, there are four types of faults: (i) single line to ground, (ii) line to line, (iii) double line to ground and (iv) balanced three phase fault [14]. Line to ground faults start from few percentage to $125 \%$ of the three phase value. Line to line faults 
are approximately $87 \%$ of three phase fault current. The probability of line to ground fault current value to exceed the three phase value is very low [15]. It is a well-known fact that line to line faults

in equipment and cables turn into three phase faults very quickly [16]. The three phase fault is used because it gives the maximum and conservative value [15].

\subsection{Calculation of Fault Currents}

All currents used in arc flash simulation and modeling are three phase because three phase faults produce the maximum and conservative values. It is crucial to calculate the maximum fault current that can flow at any given point on the electrical installation to ensure the correct selection of equipment. The electric codes require that equipment intended to break current at fault level must have an interrupting rating that is sufficient enough that it can clear the fault without any damage. As we discussed before, the maximum fault current in low voltage installations occurs in three phase bolted faults. Therefore, calculations are held on this basis. It is important to mention that the fault current may not be symmetrical depending on the time at which the fault happens during the cycle. Therefore, the resulting current can be offset from the normal current axis and become asymmetrical [17]. Power systems are highly inductive (transformers and the like) [17] Figure 2-1 shows a theoretical circuit with resistance and inductance. The closing of the switch mimics a fault on the system and the current flow represents the fault current. For simplicity and conservative results, we assume zero fault impedance (bolted fault). Writing KVL:

$$
\frac{L d i(t)}{d t}+R i(t)=2 V \sin (\omega t+a) \quad \text { where } t \geq 0
$$

Solving 2.3.1 result in:

$$
\begin{aligned}
i(t) & =i_{a c}(t)+i_{d c}(t) \\
& =\frac{\sqrt{2} V}{Z}\left[\sin (\omega t+\alpha-\theta)-\sin (\alpha-\theta) e^{-\frac{t}{T}}\right] A
\end{aligned}
$$




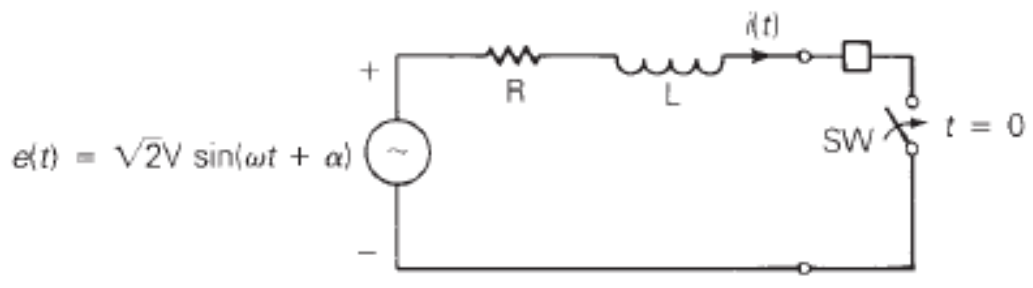

Figure 2-1 Current in RL circuit with AC voltage source [18].

$$
\begin{array}{r}
i_{a c}(t)=\frac{\sqrt{2} V}{Z} \sin (\omega t+\alpha-\theta) A \\
i_{d c}(t)=-\frac{\sqrt{2} V}{Z} \sin (\alpha-\theta) e^{-t / T} A \\
Z=\sqrt{R^{2}+(w L)^{2}}=\sqrt{R^{2}+X^{2}} \Omega \\
\theta=\tan ^{-1} \frac{\omega L}{R}=\tan ^{-1} \frac{X}{R} \\
T=\frac{L}{R}=\frac{X}{\omega R}=\frac{X}{2 \pi R} s
\end{array}
$$

The fault current in equation 2.3.2 is called the asymmetrical fault current. The AC fault current given by equation 2.3.3 is called symmetrical or steady state current and the DC offset current is given by equation 2.3.4.

The total fault current is the sum of its two components: the symmetrical fault current and the DC offset, which decays exponentially with a time constant $\mathrm{T}=\mathrm{L} / \mathrm{R}$ as shown in Figure 2-2. 


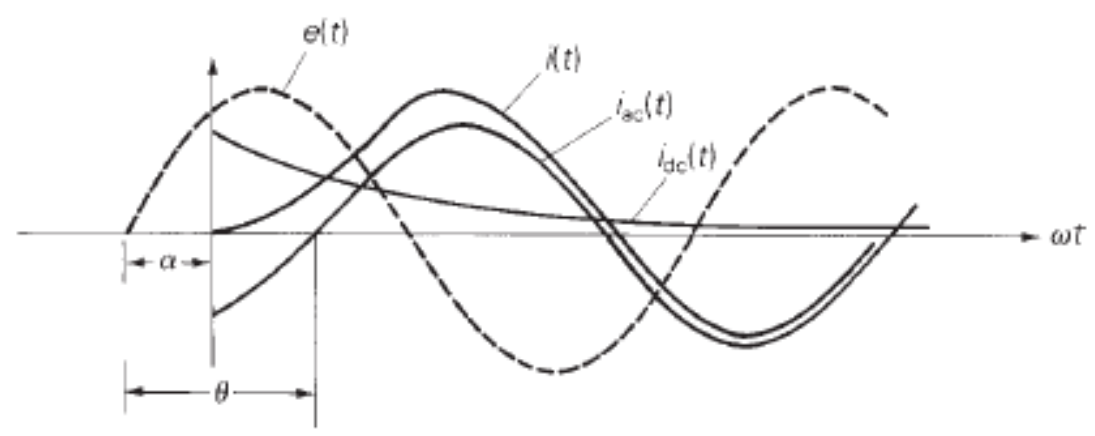

Figure 2-2 Resulting asymmetrical current [18].

From equation 2.3.4, the maximum value of the DC offset is $\frac{\sqrt{2} V}{Z}$ when $\sin (\alpha-\theta) e^{-t / T}=1$ and $\alpha=\theta \pm \frac{\pi}{2}$. Since the fault may happen at any instant during the cycle of the source, we are interested in the maximum possible value of the fault current.

$$
i(t)=\frac{\sqrt{2} V}{Z}\left[\sin \left(\omega t-\frac{\pi}{2}\right)-e^{-\frac{t}{T}}\right] A
$$

From equation 2.3.3, $\frac{V}{Z}$ is the RMS value of $i_{a c}(t)$. So, $I_{a c}=\frac{V}{Z} A$.

From equation 2.3.2, we treat the exponential term as a constant and we apply the concept of rms to the asymmetrical fault $i(t)$ with maximum DC offset.

$$
\begin{gathered}
I_{A S Y}=\sqrt{\left(I_{a c}\right)^{2}+\left(I_{d c}\right)^{2}} \\
I_{A S Y}=I_{a c} \sqrt{1+2 e^{-\frac{2 t}{T}}} A
\end{gathered}
$$

Using $\mathrm{T}=\mathrm{X} /(2 \pi f \mathrm{R})$ and $\mathrm{t}=\tau / f$, this implies:

$$
I_{A S Y}=K(\tau) I_{a c} A
$$

Where:

$$
K(\tau)=\sqrt{1+2 e^{-4 \pi /\left(\frac{x}{R}\right)}} \text { p.u }
$$


The $\mathrm{K}(\tau)$ is called the asymmetry factor. It is clear that the asymmetrical fault can have a maximum value of $\sqrt{3} I_{a c}$ when $\tau=0$ and reach $\quad I_{a c}$ when $\tau$ is very large. Note that a higher $\mathrm{X} / \mathrm{R}$ value gives a higher $I_{A S Y}$ value. It is very convenient to consider the fault current as asymmetrical current consisting of two components: (i) symmetrical AC current alternating or superimposed on (ii) a DC current [19] [17]. The peak value of this asymmetrical fault current appears in the first half cycle of the fault known as the Available Fault Current (AFC). Note that electrical systems are generally inductive circuits, meaning the resistance is negligible. With this in mind, if we consider $I_{a c}$ as $1 \mathrm{pu}$, then $I_{A S Y}=\sqrt{\left(I_{a c}\right)^{2}+\left(I_{d c}\right)^{2}}=\sqrt{(1.0)^{2}+(\sqrt{2})^{2}}=\sqrt{3}$

This means that the rms value of the asymmetrical current is 1.73 times the symmetrical current. This will result in significant mechanical and thermal stress on the electrical installation as these stresses are proportional to the square of the rms value of the current [17]. The system conditions play a serious role on the decay of the offset DC component. The rate at which the DC component decays depends on the ratio of the system X/R Figure 2-3 shows a typical low voltage electric systems with $\mathrm{X} / \mathrm{R}=6$ as simulated in MATLAB.

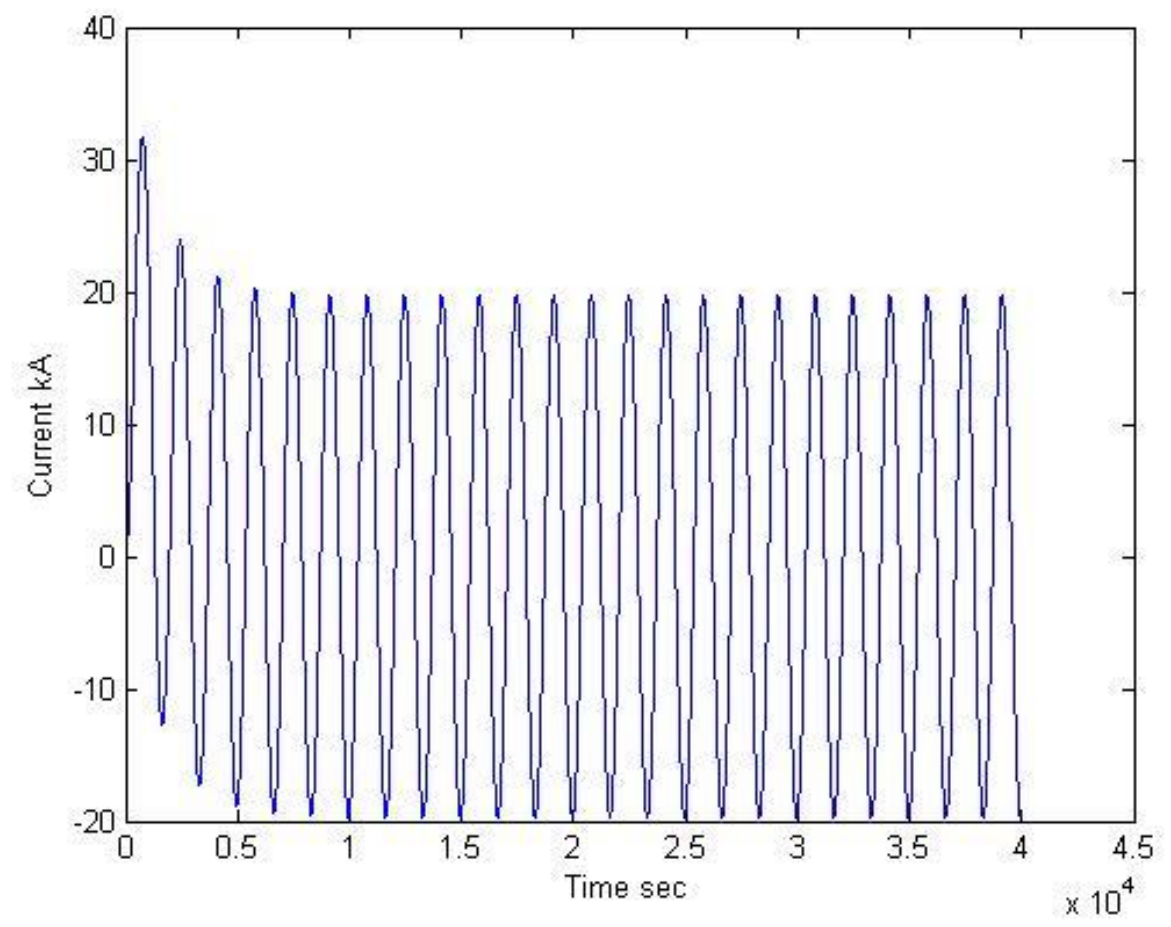

Figure 2-3 Asymmetrical fault current for $\mathrm{X} / \mathrm{R}$ ratio 6 (simulation) 


\subsection{Protective Devices}

\subsubsection{Circuit Breakers}

The main function of protective devices is to detect any abnormal situation or fault and disconnect it automatically and safely from the system. Protective devices are rated for the following parameters:

1. Maximum continuous voltage

2. Maximum continuous current

3. Interrupting rating

4. Short time current rating

These are the ratings applied to the basic protective device mechanisms and there are separate ratings for the detection units incorporated into the protective device. The detection units of the protective device respond quickly to large fault currents and respond slowly for overloads. This characteristic is known as inverse time characteristic. Figure 2-4 shows a circuit breaker curve that has both the inverse time element and the instantaneous element.

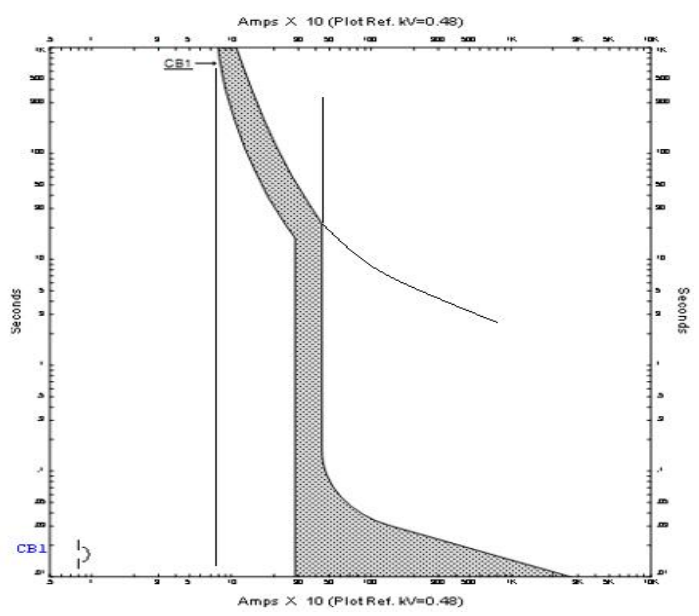

Figure 2-4 Response curve of CB generated from ETAP

Circuit breaker parameters such as available interrupting capacity and rated continuous current are very crucial in design of the electric systems. The interrupting capacity, or the breaking capacity, 
is the maximum fault current the $\mathrm{CB}$ can interrupt with fixed voltage. This interrupting capacity is expressed in rms current magnitude [20].

There are two types of tripping units: (i) the series and (ii) the solid state type. The series are thermal and magnetic connected in series with each power line. The thermal action provides respond to overloads that is way less than short circuit current and it trips the breaker after some delay. On the other hand, the magnetic action provides instantaneous tripping and it respond quickly to short circuit currents. Figure 2-5 shows the thermal action of MCCB, the time delay tripping and the graph of typical inverse time current response. Figure 2-6 shows the magnetic action and the instantaneous tripping of MCCB. And Figure 2-7 shows the combined thermalmagnetic action.

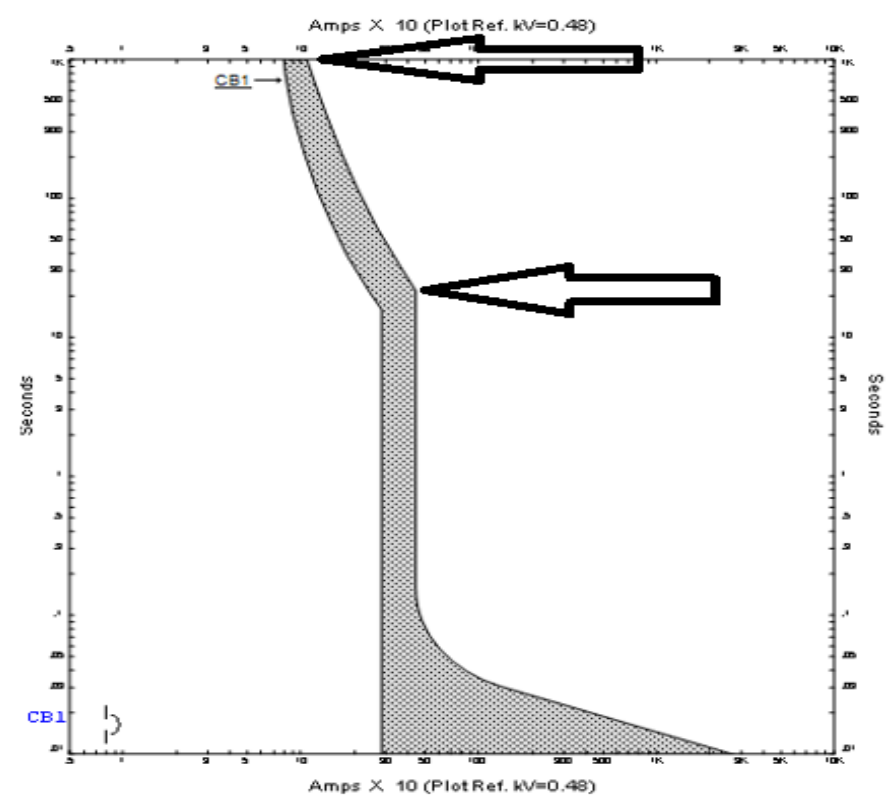

Figure 2-5 Thermal action trip of CB generated from ETAP 


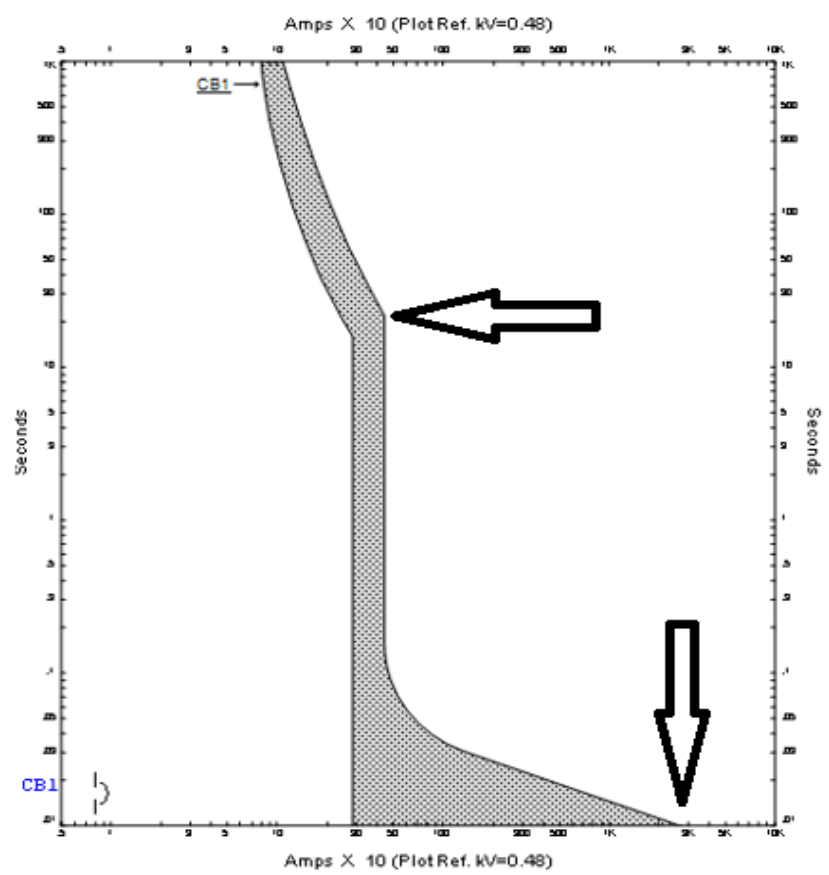

Figure 2-6 Magnetic action Instantaneous trip of CB generated from ETAP

Circuit breakers are analyzed graphically from their Time Current Curves (TCC) and they are available with adjustable magnetic trip. Figure 2-6 shows non-adjustable thermal magnetic MCCB. Note that the graph showing minimum and maximum values represent the boundaries of the operating band. Regardless of the precision of the circuit breaker, there will be small differences between the individual breakers of the same type.

Figure 2-7 shows a thermal MCCB and its TTC curve with adjustable magnetic trip setting. In this type of MCCB's, we can adjust the pickup of the fault current. 


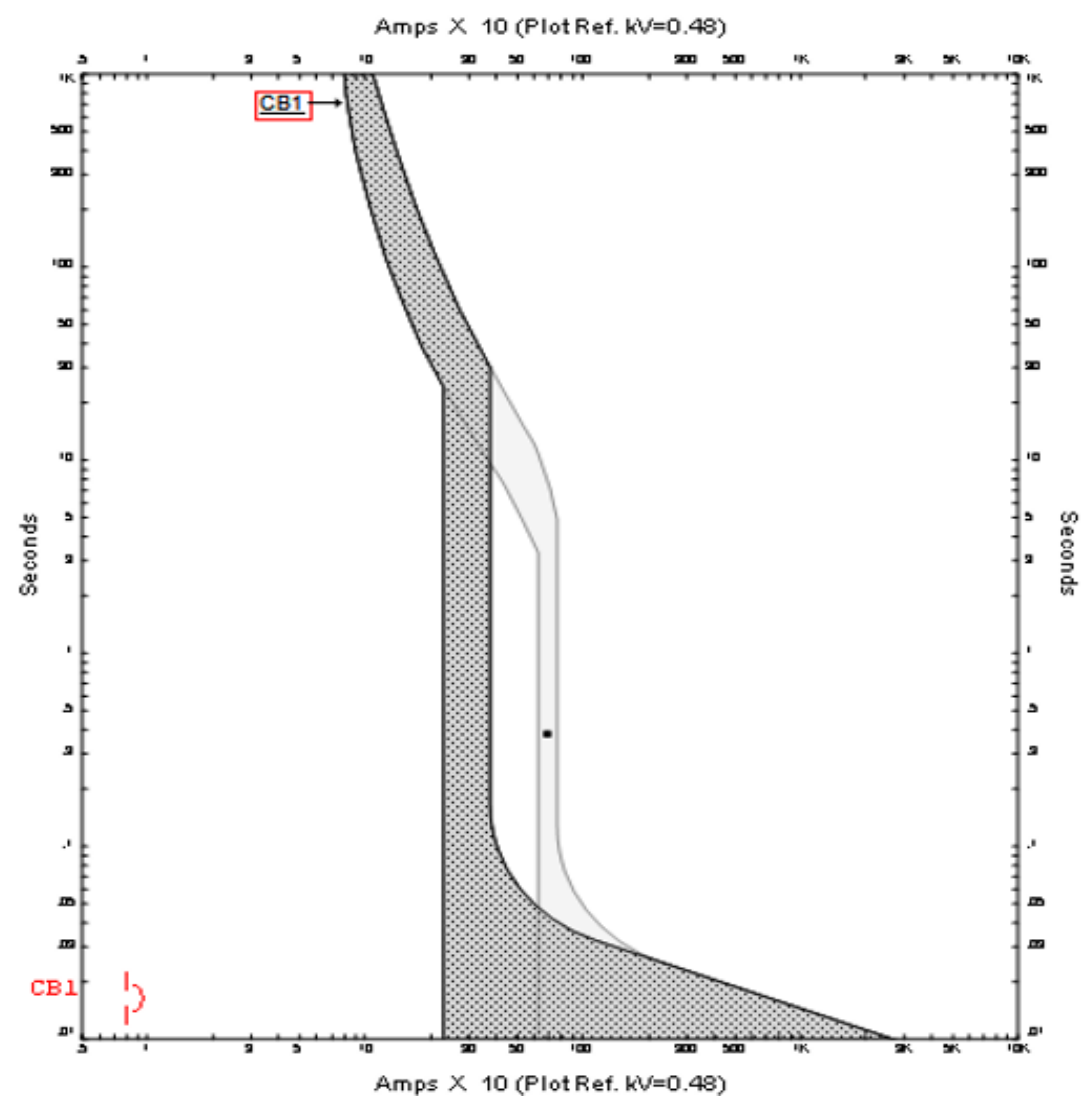

Figure 2-7 TCC curve for adjustable MCCB generated from ETAP

The other circuit breaker used in the industry of electrical power distribution is the low voltage power circuit breaker (LVPCB). It is more flexible and has a higher rating than MCCB. In fact, it is generally called power circuit breaker to be distinguished from the MCCB. The national Electrical Manufacturers Association defines the low voltage power circuit breaker "as one for use on circuits rated 1000 volts alternating current and bellow, but not including molded-case circuit breakers". These breakers handle large amounts of power, up to $4000 \mathrm{amp}$ at 600 volts. These breakers are heavier and larger than MCCBs. Power circuit breakers have thermal-magnetic trip for overload tripping; however, they have 30 cycle short time current rating as per the ANSI standard [21]. These features or settings are used for coordination purpose and they are called Long-time, Short-time and Instantaneous (LSI). Most of the power circuit breakers today are of the solid state type. The solid state type mimics the TCC of the thermal magnetic type and provides more flexibility, features and precision. Several settings are provided for LVPCBs. 
Figures 2-8, 2-9, 2-10 and 2-11 show a typical TCC with the different possible settings in the four time domain (long delay time, short delay time, instantaneous pick up, long delay pick up, respectively).

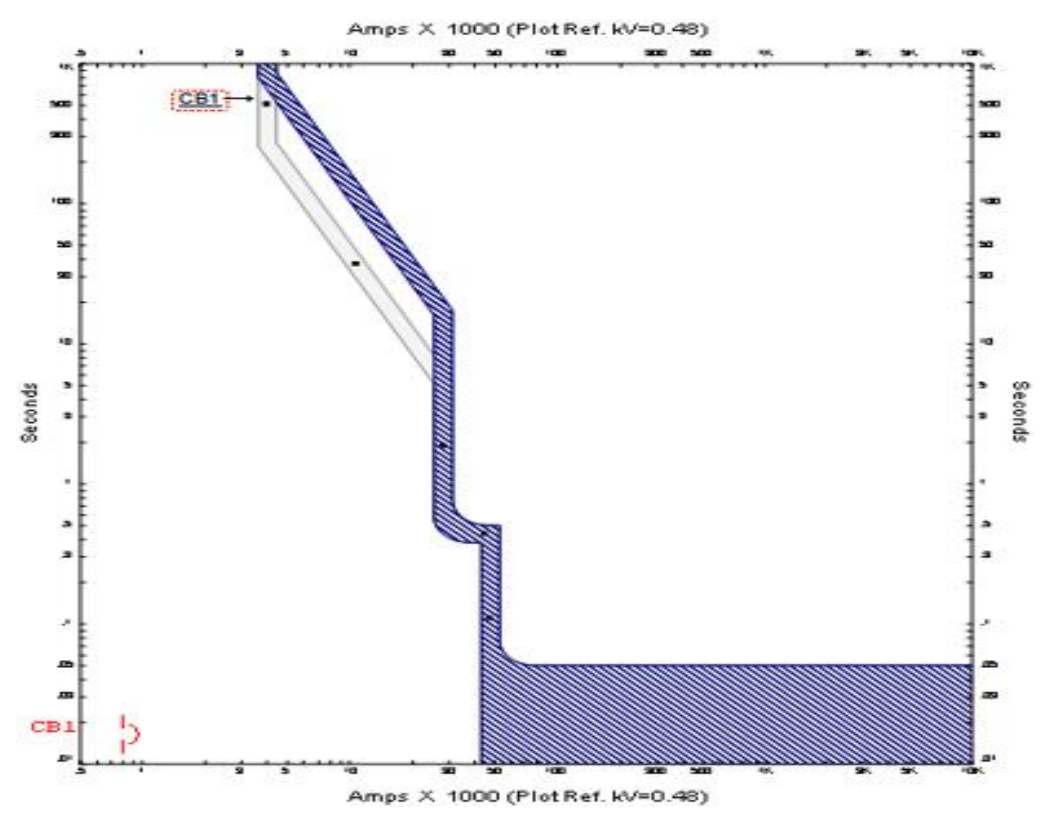

Figure 2-8 Long Delay Time generated from ETAP

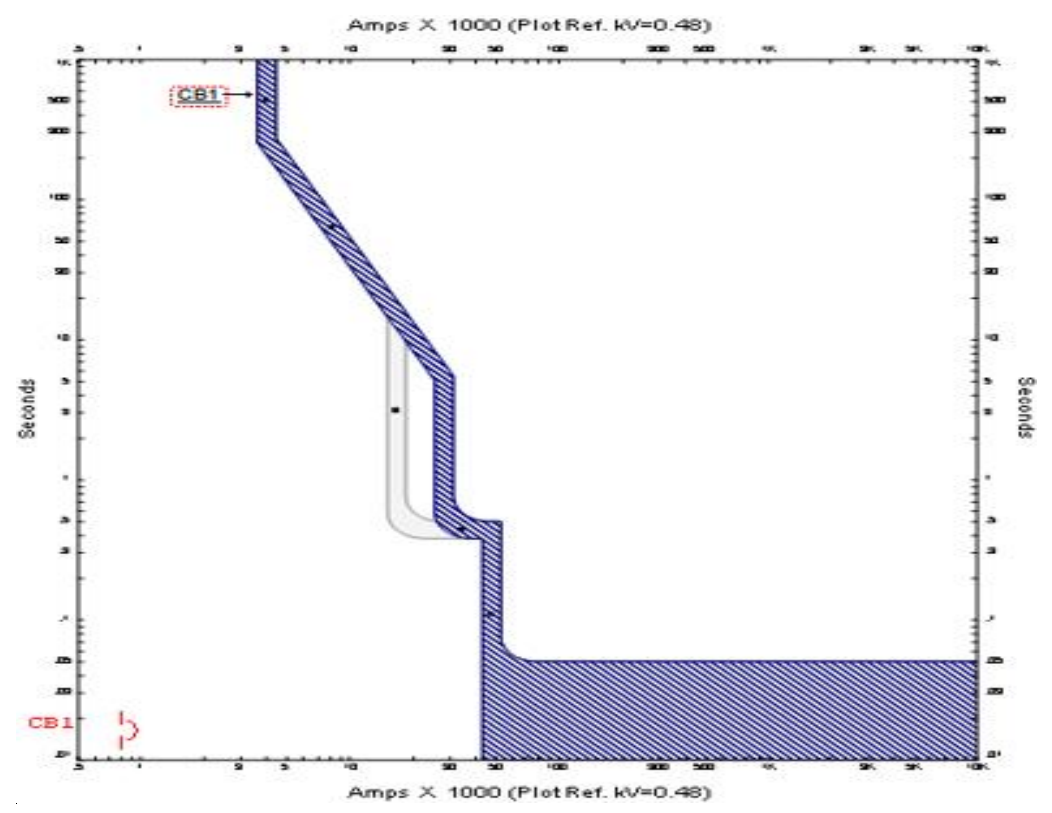

Figure 2-9 Short Delay Time generated from ETAP 


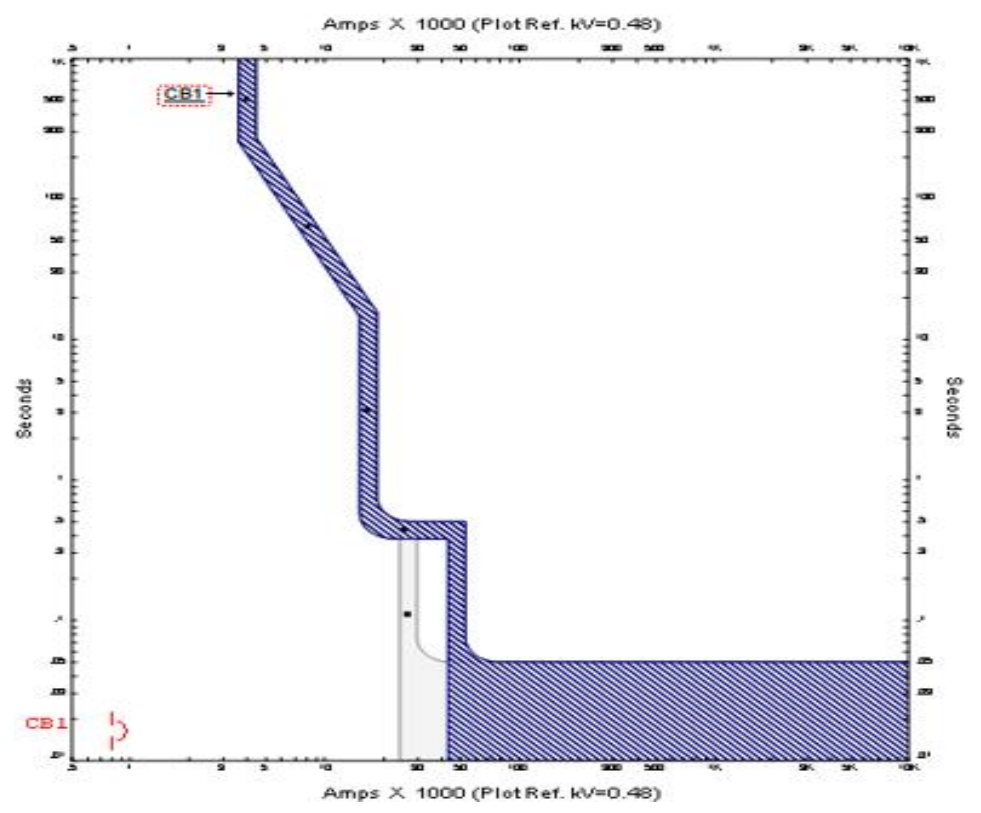

Figure 2-10 Instantaneous Pick up generated from ETAP

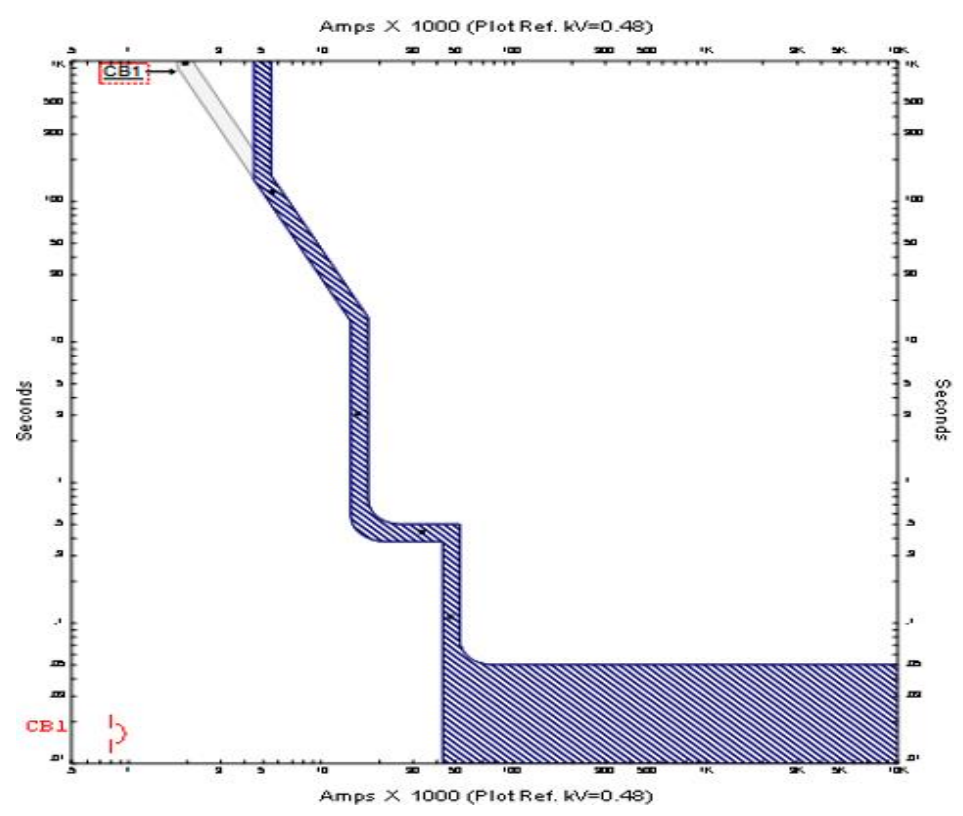

Figure 2-11 Long Delay Pick up generated from ETAP 
Over time, the distinction between molded case breakers (MCCB) and power circuit breakers disappeared because of the development of large frame MCCB's with solid state trip units. These new MCCBs are known as hybrid circuit breakers.

Insulated circuit breakers are molded case circuit breakers which have some features of low voltage power circuit breakers LVPCB [20] [22]. "The industry recognizes three types of circuit breakers - molded-case circuit breakers (MCCB), insulated-case circuit breakers (ICCB), and low-voltage power circuit breakers LVPCB). Insulated-case circuit breakers are designed to meet the standards for molded-case circuit breakers" [23]

\subsubsection{Fuses}

The national electric code defines the fuse as "an overcurrent protection device with a circuit opening fusible part that is heated and severed by the passage of current through it" [24]. Fuses have amp rating, voltage rating and interrupting ratings. In low voltage systems, they are used to protect from overload and short circuit currents. These fuse respond to thermal energy, causing it to melt when sufficient current pass through it [25]. The heat is a function of $I^{2} t$. So the fuse automatically has an inverse time current response TCC. Figure 2-12 shows a typical fuse response curve. The two boundaries in the graph represent the minimum melt time and the total clearing time of the fuse. The American National Standards Institute (ANSI) standards allow a maximum tolerance of $+/-10 \%$ in the melting current for any given time. The area between the two lines in the graph is the operating band of the fuse. 


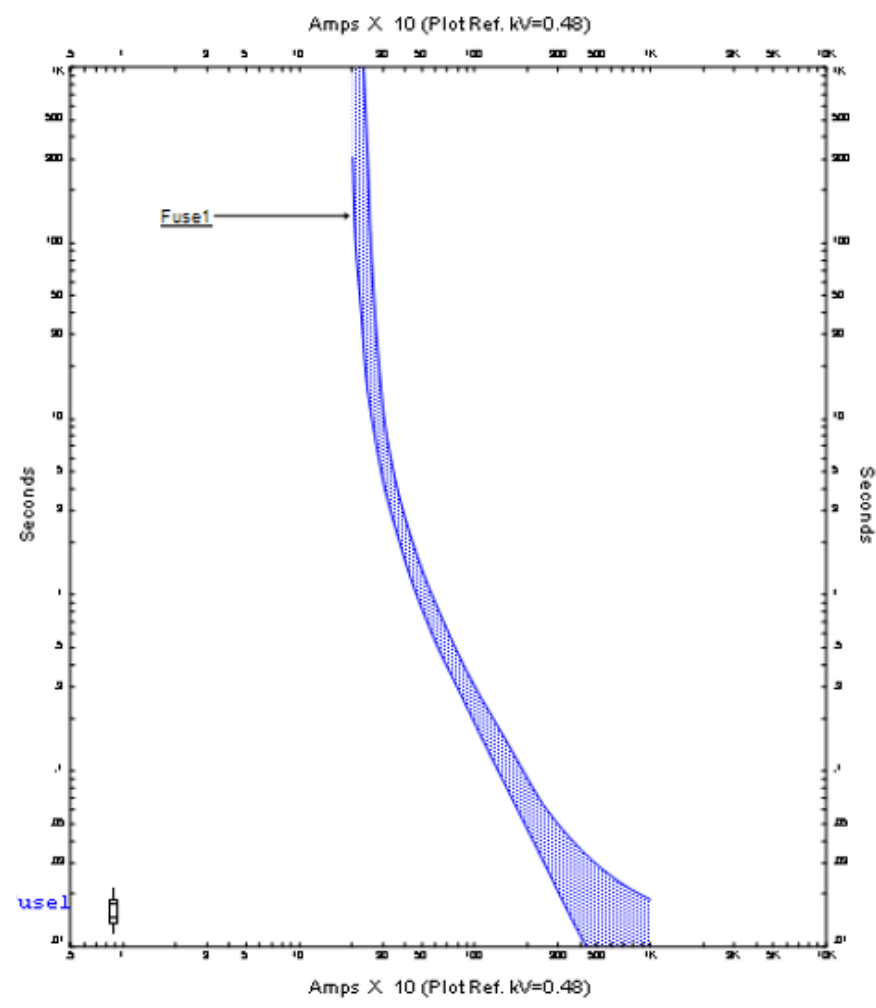

Figure 2-12 Typical fuse generated from ETAP

\subsection{Summary}

This Chapter presents a few concepts of electric power system protection as related to the problem of arc flash. Abnormal operation conditions in power systems are introduced with focus on short circuit faults. Then, fault current calculations are addressed, in particular three-phase faults which give conservative results. The effects of power system components parameters (resistance and reactance) on short circuit faults are summarized. Operation of power system protective devices, especially circuit breakers, is explained. Distinction is made between circuit breaker behaviours under overload and short circuit conditions as related to their function in protecting power system components. 


\section{Chapter Three - Arc Flash Calculation and Power Systems Studies}

As part of a risk assessment procedure, an arc flash risk assessment would be required in order to reduce severity or harm. In order to do so, a fault current analysis, protective device coordination, a short circuit analysis and arc flash calculations must be carried out. By conducting the short circuit analysis, we will figure out the available fault current and consequently, the interrupting rating of the protective devices and the equipment withstand. The protective devices coordination will show the possibilities of reducing the risk through fault time reduction. Finally, the arc flash study will help us to measure the incident energy at different locations within the system.

\subsection{Short Circuit Theory}

As discussed in sections 2.1, 2.2 and 2.3, electric fault may occur due to many reasons, whether intentionally or unintentionally. In most cases, it will be developed to three phase fault.

The short circuit value at that location is called the available fault current (AFC). The equipment installed at that location must have withstand rating that is higher than the available fault current, in order to support the corresponding mechanical and thermal stresses. The protective devices must also have an available interrupting capacity (AIC) or breaking capacity higher than the AFC in order to interrupt the fault without any damage [26]. Protective devices such as fuses and circuit breakers must be capable of interrupting the biggest possible fault that may happen. All other parts of the system such as bus bars, feeders, cables must be capable of handling the faults and supporting the associated stresses. At the time of the fault in the installation, sources such as utility system, generators and all motors (both synchronous and induction) contribute to the value of the fault. The components that impede the fault current are the cables and transformers. The process of calculating the fault currents is documented in IEEE standard [19] and [32]. A point to point fault calculation method is presented here [32].

$$
F=\frac{1.732 * L * A F C}{C * n * V}
$$


Where:

$L: \quad$ Length of the conductor

AFC: $\quad$ Available Fault current at the beginning of the run

$C: \quad$ Constant representing conductor type

$n: \quad$ number of conductors parallel runs

V: $\quad$ Voltage Line to Line

The available fault current AFC or the available short circuit capacity at the service entrance is provided by the local utility. Since we always prefer to take conservative values with the intention to assess the system during the worst case high fault current scenario, we consider the infinite bus calculation. This assumption not only simplifies the calculation but also gives us the maximum possible fault current that can be seen in the secondary of the service transformer.

This results in the following calculation procedure: [32].

Step 1: calculate the Full Load Current at the secondary of the transformer

$$
F L A_{\text {secondar }}=\frac{K V A_{3 P H}}{\sqrt{3} K V_{L L}}
$$

Step 2: calculate the Available Fault Current at the secondary of the transformer

$$
A F C_{\text {secondar }}=\frac{F L A_{\text {secondary }} * 100}{\% Z}
$$

As we discussed in Section 2.3 and shown in Figure 2-3, the peak value of the first cycle is strongly related to the DC exponential decay value. The rate at which the DC component decays depends on the ratio of the system reactance and resistance $\mathrm{R}$ under fault conditions. In most power systems, the DC component decays to an insignificant value within 0.1 seconds [19]. Electrical installations are mostly resistive and inductive components due to cables, transformers and utility source. The factor $\mathrm{X} / \mathrm{R}$ has a significant effect on the selection of protective devices and power distribution equipment. Once the fault happens, the current is no longer sinewave and it is a combination of symmetrical part and a decaying DC component. As shown in Section 2.3, the larger the X/R ratio, 
the longer the DC part exist [33] and [34]. Therefore, the selection of the protective devices depends on the AFC as well as the X/R of the system. In case the tested X/R of the protective device is less than the $\mathrm{X} / \mathrm{R}$ of the system, a de-rated factor is applied to go for higher value of AIC [35].

\subsection{Protective Devices X/R Ratio.}

Protective devices (circuit breakers) are tested as per ANSI and UL standards [21], [36], [37], and [38]. X/R parameter, also called DC decay factor, is of our interest. Circuit breakers used in low voltage power system installations are tested at previously determined ratios as shown below [35].

Table 3-1 Tested ratios X/R for protective devices

\begin{tabular}{|l|c|}
\hline \multicolumn{2}{|c|}{ Test X/R ratios for protective devices } \\
\hline \multicolumn{1}{|c|}{ Protective Device } & Test X/R \\
\hline LVPCB & 6.6 \\
\hline MCCB rated <10K AIC & 1.7 \\
\hline MCCB rated between 10K and 20K AIC & 3.2 \\
\hline Fuses, ICCB, MCCB rated > 20K AIC & 4.9 \\
\hline
\end{tabular}

The AIC and the X/R ratio are crucial parameters derived from the short circuit analysis of the system to decide whether or not the panel boards and the protective devices are suitable at a specific location in the installation.

\subsection{Coordination of Protective Devices}

The goal from protective devices coordination is to minimize the damage to personnel and equipment at the time when the fault occurs. IEEE clearly stated "coordination is basic ingredient of a well-designed electrical distribution system and is mandatory in certain healthcare and continuous industrial systems" [32]. Coordination is applied to all series protective devices from 
utility to the equipment using the power. Both fuses and circuit breakers have to be coordinated by the use of their time current curves (TTC). An example shown in Figure 3-1 below explains the process and the goal of coordination [17]. With fault at location A, the breaker with 100A trip will clear the fault before the main breaker of 300A trip and shut down the power from all the circuits. The circuit breakers are more flexible than the fuses in protection coordination because they contain adjustable settings. Circuit breakers with long time (LT), short time (ST) and instantaneous (I) settings are called LSI protective devices. Those adjustments in the three time domain allow for a circuit breaker curve to be coordinated and custom fitted for any specific application.

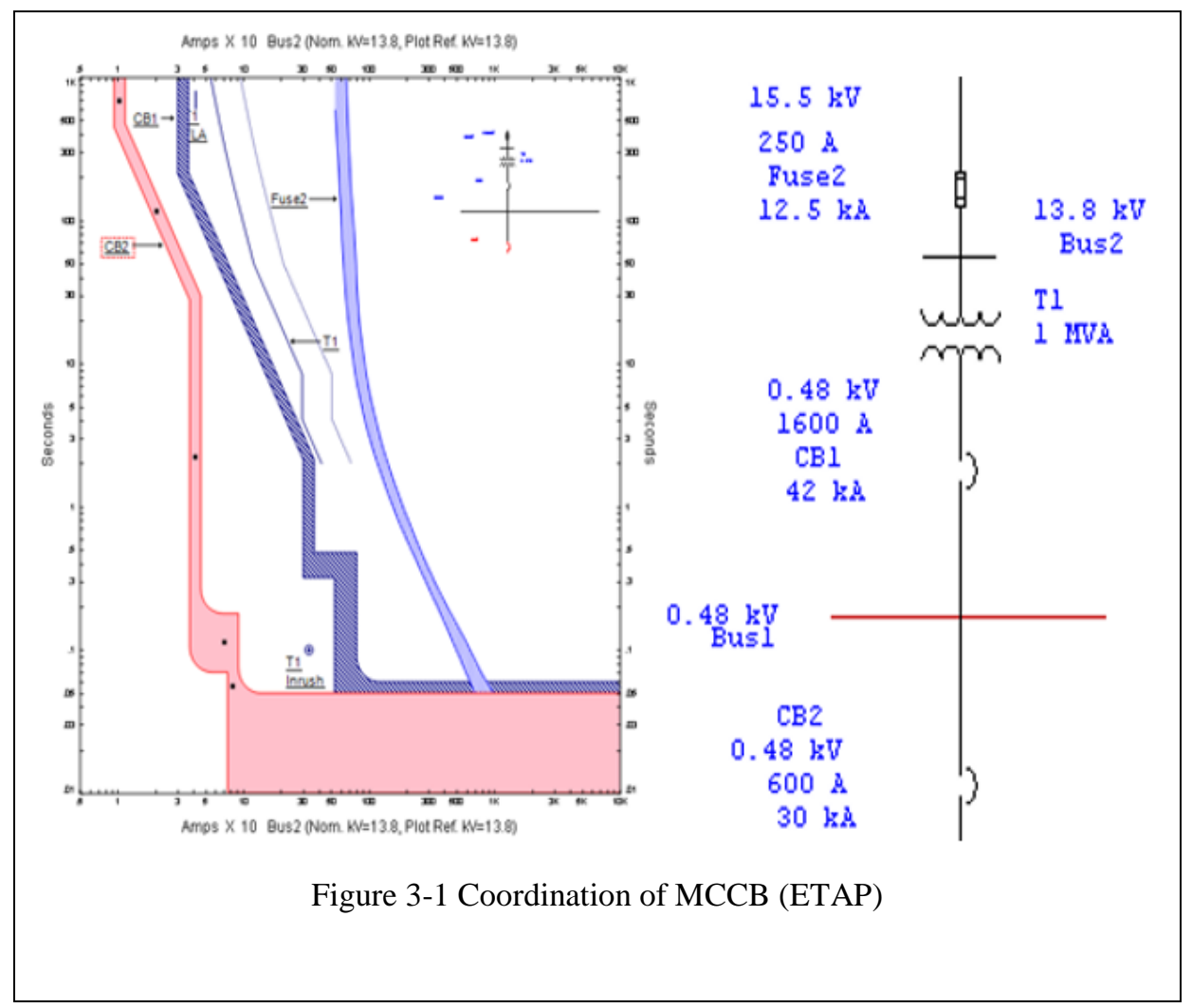

\subsection{Arc Flash Hazard}

The procedure which will be described here about the arc flash calculation methods is recommended by IEEE standard 1584-2002. The empirically derived equations were developed by IEEE working group on arc flash. The conditions for which the IEEE 1584 equations are applicable are: 
1- System voltage: $0.208 \mathrm{kV}$ to $15 \mathrm{kV}$

2- Frequencies: 50 or $60 \mathrm{~Hz}$

3- Bolted fault current: 0.7 to $106 \mathrm{kA}$

4- Gap between electrodes: 13 to $153 \mathrm{~mm}$

5- Equipment enclosure type: Open air, box, MCC, panel, Switchgear, cables

6- Grounding type: Ungrounded, grounded, high resistance grounded

7- Phases: 3 phase faults

The results from short circuit analysis and protective device coordination are used to perform the arc flash hazard. And the arc flash hazards results are used to indicate or name the flash protection boundary and the incident energy level. The IEEE-1584 estimates the incident energy from the arc due to heat [16]. The procedure includes the calculation of the arcing current, followed by the incident energy and finally, concludes the arc flash boundary.

\subsubsection{Arcing Current Estimation}

For low voltage systems (less than 1000V), the arc current is given by the following equation [16].

$$
I_{a}=10^{K+0.662 \log \left(I_{b f}\right)+0.0966 V+0.000526 G+0.5588 V * \log \left(I_{b f}\right)-0.00304 G * \log \left(I_{b f}\right)}
$$

Where:

$I_{a}$ is the arcing current (KA)

$\mathrm{K}=-0.153$; open configuration

$=-0.097 ;$ box configuration

$I_{b f}=$ bolted fault current for three phase faults symmetrical RMS in KA

$\mathrm{V}=$ voltage system $\mathrm{KV}$

$\mathrm{G}=$ Gap between conductors, $\mathrm{mm}$

For medium voltage system $(>1000 \mathrm{~V})$, the arc current is given by this equation 
$I_{a}=10^{0.00402+0.983 \log \left(I_{b f}\right)}$

In our study we focus on low voltage systems (industrial or commercial buildings). Therefore, the voltage is three phase $480 \mathrm{~V}$ and the factor $\mathrm{K}$ is -0.097 for electric panels. The factor $\mathrm{G}$ is the gap between electrodes or bus bars. In our case, $\mathrm{G}$ will be represented by the gap between electrodes in panels or switchgears. In low voltage systems, the value of $\mathrm{G}$ for these panels will be $25 \mathrm{~mm}$ or $32 \mathrm{~mm}$ as per the IEEE- 1584 [16] as can be seen from the following table:

Table 3-2 Equipment classes and typical Bus gaps.

\begin{tabular}{|l|c|}
\hline \multicolumn{2}{|c|}{ Typical Bus gaps as per IEEE-1584 } \\
\hline \multicolumn{1}{|c|}{ Equipment class } & Bus gap \\
\hline 15 KV switchgear & $152 \mathrm{~mm}$ \\
\hline 5 KV switchgear & $104 \mathrm{~mm}$ \\
\hline Low voltage switchgear & $32 \mathrm{~mm}$ \\
\hline Low voltage MCCs and Panel boards & $25 \mathrm{~mm}$ \\
\hline Cable & $13 \mathrm{~mm}$ \\
\hline
\end{tabular}

In case of the switchboards equation 3.1 becomes:

$$
I_{a}=10^{-0.034+0.833 \log \left(I_{b f}\right)}
$$

\subsubsection{Normalized Incident Energy Estimation}

Normalized incident energy is based on $610 \mathrm{~mm}$ (24 inch) distance from the arc in duration of 0.2 seconds and it is given by the following equation:

$$
E_{n}=10^{K_{1}+K_{2}+1.081 * \log \left(I_{a}\right)+0.0011 G}
$$

Where

$E_{n}=$ Incident energy normalized for time and distance $(\mathrm{J} / \mathrm{cm} 2)$ 
$I_{a} \quad=$ arcing current from Equation 3.2

$$
K_{1}=-0.792 \text { open configuration }
$$

$=-0.555$ box configuration

$K_{2} \quad=0$ underground and high resistance grounded system

$=-0.113$ grounded systems

$\mathrm{G} \quad=$ Gap between conductors $(\mathrm{mm})$

As we mentioned earlier, we will be studying low voltage systems. In such systems, the protective devices are mostly within panels and switchgears, and our system is grounded for safety purposes. Therefore, $\mathrm{K} 1$ and $\mathrm{K} 2$ are -0.555 and -0.113 , respectively.

Hence the normalized energy becomes:

$$
E_{n}=10^{-0.633+1.081 * \log \left(I_{a}\right)}
$$

\subsubsection{Incident Energy Estimation}

We use the normalized incident energy to find the actual incident energy at any distance with arcing time duration at normal surface by the following equation [16].

$$
E=4.184 C_{f} E_{n}\left(\frac{t}{0.2}\right)\left(\frac{610}{D}\right)^{x}
$$

Where

$\mathrm{E}=$ incident energy $\left(\mathrm{J} / \mathrm{cm}^{2}\right)$

$\mathrm{Cf}=$ calculation factor $\quad=1.0$ for voltage $>1000 \mathrm{~V}$

$=1.5$ for voltage $<1000 \mathrm{~V}$

$\mathrm{t} \quad=$ arcing time (seconds)

$\mathrm{D}$ = working distance from $\operatorname{arc}(\mathrm{mm})$

$\mathrm{x}=$ distance exponent as show in the following table [16] 
Table 3-3 x factor for various equipment

\begin{tabular}{|l|c|c|}
\hline \multicolumn{3}{|c|}{ Distance factor $x$ for various voltages and enclosure types } \\
\hline \multicolumn{1}{|c|}{ Enclosure type } & $\mathbf{0 . 2 0 8}$ to $\mathbf{1 0 0 0 V}$ & $>\mathbf{1 K V}$ to $\mathbf{1 5 K V}$ \\
\hline Open air & 2 & 2 \\
\hline Switchgear & 1.473 & 0.973 \\
\hline MCC and panels & 1.641 & NA \\
\hline Cable & 2 & 2 \\
\hline
\end{tabular}

Our system is low voltage system. Therefore, $\mathrm{C}_{\mathrm{f}}$ is 1.5 and $\mathrm{x}$ is dependent on whether we are on MCC, panel or switchgear. The distance from the arc or the energized electrical conductor to the person working on the electric panel is standardized by the IEEE-1584 as per the following table [16].

Table 3-4 Equipment typical working distance

\begin{tabular}{|l|l|}
\hline \multicolumn{2}{|c|}{ Typical working distance D as per IEEE-1584 } \\
\hline $5 \mathrm{KV}$ and 15 KV switch gear & 36 inch \\
\hline Low voltage switchgear & 24 \\
\hline Low voltage Panel or MCC & 18 \\
\hline Cable & 18 \\
\hline
\end{tabular}

\subsubsection{Arc Flash Protection Boundary}

In his paper, "The other electric hazard: electric arc blast burns", Ralph lee evaluated the incident energy that causes a curable burn which is $1.2 \mathrm{cal} / \mathrm{cm} 2$ [6]. This value is crucial in the arc flash hazard studies. The distance from the energized conductor at which the incident energy is equivalent to1.2cal $/ \mathrm{cm} 2$ is named arc flash boundary. At this distance, the person without personal protective equipment may get a second degree burn which is curable. The boundary distance is given by the following equation: 
$D_{B}=610 *\left[4.18 C_{f} E_{n}\left(\frac{t}{0.2}\right)\left(\frac{1}{E_{B}}\right)\right]^{\frac{1}{x}}$

Where

$D_{B}=$ distance of the boundary from the arcing point $(\mathrm{mm})$

$C_{f}=$ calculation factor $=1.0$ for voltage $>1000 \mathrm{~V}$

$=1.5$ for voltage $<1000 \mathrm{~V}$

$E_{n}=$ incident energy normalized

$E_{B}=$ incident energy at the boundary distance $(1.2 \mathrm{cal} / \mathrm{cm} 2)$

$\mathrm{t} \quad=\operatorname{arcing}$ time $($ seconds)

$\mathrm{x} \quad=$ the distant exponent (from IEEE-1584 distance exponent table)

$I_{b f}=$ bolted faulted current $(\mathrm{KA})$

\subsubsection{NFPA 70E protection boundaries.}

According to NFPA, the flash boundaries are four:

1. Flash protection boundary: explained in the previous section 3.4 .4

2. Limited approach boundary: 42 inch for $480 \mathrm{~V}$

3. Restricted Approach boundary: 12 inch for $480 \mathrm{~V}$

4. Prohibited Approach boundary: 1 inch for 480 inch

\subsubsection{Energy Levels and Arc Flash Hazard Categories}

In order to protect the person who is working at the electrical equipment, he/she need to wear the appropriate clothing and the personal protective equipment (PPE) rated for the expected incident energy. The selected PPE must have rating greater than that of the maximum incident energy possible. Beside the IEEE 1584, NFPA 70E standard published a safety requirement and divides the incident energy levels into five categories (0-4), with each category representing the level of danger, which depends upon the incident energy level [NFPA 70 E 2004]. Category 0 
represents 0 or no risk, whereas category 4 is very dangerous. The tables below shows the level of incident energy associated with each category.

Table 3-5 The level of incident energy associated with each category NFPA70E2000

\begin{tabular}{|c|c|}
\hline \multicolumn{2}{|c|}{ Hazard Classification as per NFPA 70E 2000 } \\
\hline Category & Energy Level \\
\hline 0 & $<1.2 \mathrm{Cal} / \mathrm{cm} 2$ \\
\hline 1 & $5 \mathrm{Cal} / \mathrm{cm} 2$ \\
\hline 2 & $8 \mathrm{Cal} / \mathrm{cm} 2$ \\
\hline 3 & $25 \mathrm{Cal} / \mathrm{cm} 2$ \\
\hline 4 & $40 \mathrm{Cal} / \mathrm{cm} 2$ \\
\hline
\end{tabular}

Table 3-6 The level of incident energy associated with each category NFPA70E2004

\begin{tabular}{|c|c|}
\hline \multicolumn{2}{|c|}{ Hazard Classification as per NFPA 70E 2004 } \\
\hline Category & Energy Level \\
\hline 0 & $<2 \mathrm{Cal} / \mathrm{cm} 2$ \\
\hline 1 & $4 \mathrm{Cal} / \mathrm{cm} 2$ \\
\hline 2 & $8 \mathrm{Cal} / \mathrm{cm} 2$ \\
\hline 3 & $25 \mathrm{Cal} / \mathrm{cm} 2$ \\
\hline 4 & $40 \mathrm{Cal} / \mathrm{cm} 2$ \\
\hline
\end{tabular}


Table 3-7 The level of incident energy associated with each category NFPA70E2009

\begin{tabular}{|c|c|}
\hline \multicolumn{2}{|c|}{ Hazard Classification as per NFPA 70E 2009 } \\
\hline Category & Energy Level \\
\hline 0 & $<1.2 \mathrm{Cal} / \mathrm{cm} 2$ \\
\hline 1 & $4 \mathrm{Cal} / \mathrm{cm} 2$ \\
\hline 2 & $8 \mathrm{Cal} / \mathrm{cm} 2$ \\
\hline 3 & $25 \mathrm{Cal} / \mathrm{cm} 2$ \\
\hline 4 & $40 \mathrm{Cal} / \mathrm{cm} 2$ \\
\hline
\end{tabular}

Table 3-8 The level of incident energy associated with each category NFPA70E2012

\begin{tabular}{|c|c|}
\hline \multicolumn{2}{|c|}{ Hazard Classification as per NFPA 70E 2012 } \\
\hline Category & Energy Level \\
\hline A & $<2 \mathrm{Cal} / \mathrm{cm} 2$ \\
\hline B & $4 \mathrm{Cal} / \mathrm{cm} 2$ \\
\hline C & $8 \mathrm{Cal} / \mathrm{cm} 2$ \\
\hline D & $25 \mathrm{Cal} / \mathrm{cm} 2$ \\
\hline E & $40 \mathrm{Cal} / \mathrm{cm} 2$ \\
\hline F & $100 \mathrm{Cal} / \mathrm{cm} 2$ \\
\hline G & $120 \mathrm{Cal} / \mathrm{cm} 2$ \\
\hline
\end{tabular}

\subsection{Summary}

This Chapter introduces the calculations of arc flashes and reports relevant power system studies in the context of arc flash hazards. The application of short circuit current calculation in power system is highlighted with emphasis on the effect of X/R ratio on protective devices. The coordination of protective devices within a power system is explained. Arc flash calculations are presented in light of the IEEE 1584 Guide underlining the arcing current, normalized energy, incident energy, and protection boundary. Different risk categories with their corresponding values of incident energy are reported based on different industry standards. 


\section{Chapter Four - Changeability of Arcing Parameters and Proposal for Arc Flash Calculation}

This chapter contains a review of comments of IEEE 1584 guide methodology. It is not possible to calculate the exact arc current or the related incident energy due to the randomness nature of arc flash. The equations used in IEEE standard are empirical and based on regression analysis. The IEEE equations is a best fit curve with an R-square of $98.3 \%$, R-square is a measure of the equation fit to the data [16]. These results are based on specific humidity, pressure, ambient temperature and other factors. Various studies indicate these factors affect the value of arc flash even though they are not represented in IEEE equation [39]. Therefore, applying these equations using data from various facilities may not produce the same result analysis.

\subsection{Arcing Current Analysis Based on Clearing Time and Incident Energy}

The arc current will determine the arc clearing time. If the calculated arc current is close enough to the knee of the time current curve TTC, a tiny variation in current will cause a big change in arc time. This may result in huge variation in incident energy. The IEEE proposed solution is to have two arcing currents. The first is the calculated arc current and the second is $85 \%$ of the first calculated arc current. Moreover, the relevant values of the incident energy are calculated and the bigger one will be selected.

This approach is derived from the difference between the test data in the laboratory and the calculated data using empirical equations. Figure 4.1 indicated the error percentage between calculated and lab results. First, the estimated arc current was calculated for different conditions, and compared with the measured data. The difference between these two presented as the percentage of estimated values. The positive error represents bigger calculated data then measured one. The median located at negative value of $-4.2 \%$, which is in the safe side. The red graph in Figure 4.1 represents the same procedure with $85 \%$ of the calculated currents. The median also 
located at $-18.4 \%$ of the measured arc current. The remaining of the points $(8.5 \%)$ are bigger than the measured values. (IEEE Data Appendix A).

Even though we are calculating a definite value, in reality it is a number that may lay between upper and lower limits.

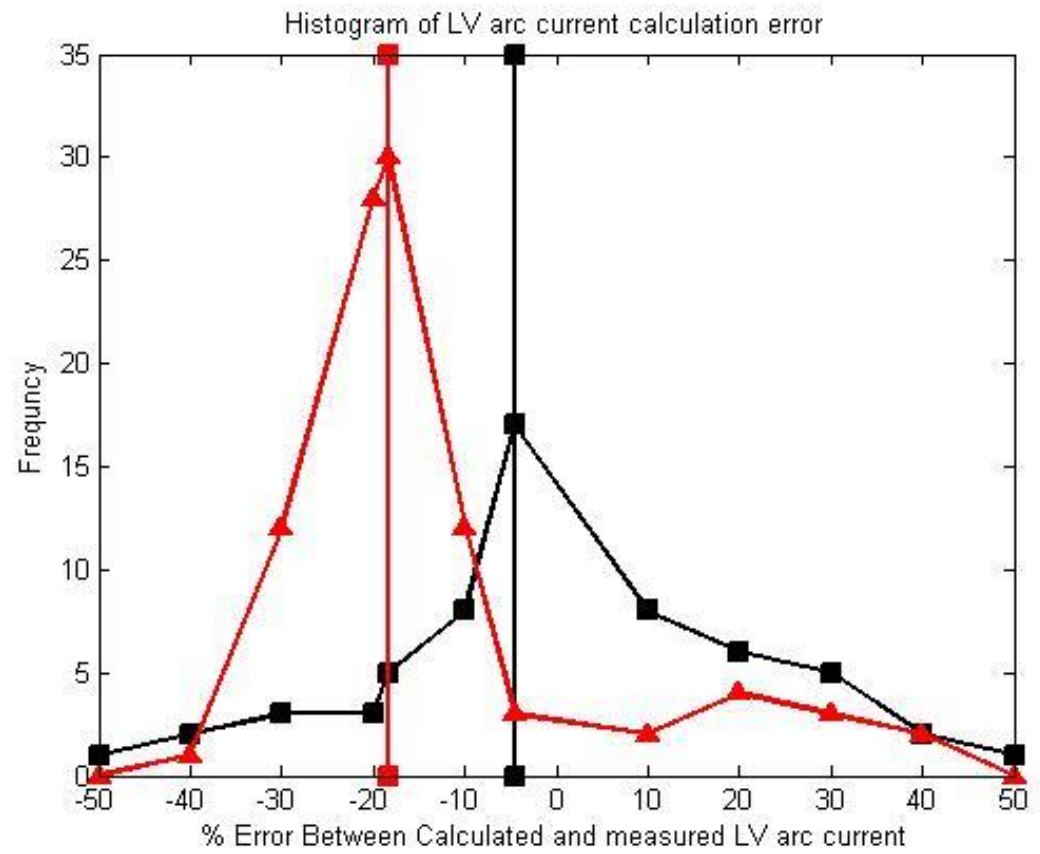

Figure 4-1 Histogram of LV arc current calculation error

Table 4-1 highlights the upper and lower limits of low voltage arcing currents for different probability values.

Table 4-1 Min and Max likely changeability in LV arcing currents [39].

\begin{tabular}{|llccc|}
\hline $\begin{array}{l}\text { Mean } \\
\text { Deviation, \% } \\
\text { Current }\end{array}$ & $\begin{array}{l}\text { Standard } \\
\text { Deviation, \% }\end{array}$ & Probability, $\%$ & $\begin{array}{c}\text { Minimum } \\
\text { arcing Current }\end{array}$ & $\begin{array}{l}\text { Maximum } \\
\text { arcing }\end{array}$ \\
\hline 2.0 & & & & \\
& 15.2 & 95 & -23.0 & 27.1 \\
& 99 & -33.4 & 37.4 \\
& 90 & -17.5 & 21.5 \\
& 68 & -05.1 & 09.1 \\
\hline
\end{tabular}


The changeability in arcing current will affect the clearing time and consequently may cause variation in incident energy level. The incident energy may become bigger for smaller arc currents in case the arc current falls in the inverse time part of the time current characteristics.

\subsection{Changeability of Incident Energy}

The actual incident energy is different from the estimated one. By examining the IEEE data (Appendix A) we can plot the difference between the measured and estimated value of the incident energy verses the frequency of its appearance. Figure 4-2 shows the frequency distribution of the deviation of the actual incident energy from estimated value. This is done by examining the IEEE data found in Appendix A. The estimated incident energy was calculated in different conditions, and compared with the measured values. The difference as a percentage of estimated values. As indicated in Figure 4-2, the arcs in open air have measured incident energy which is smaller than estimated. Therefore, the difference between the measured and estimated energy is negative. However, in box configuration, calculated incident energy may or may not be greater than measurement. This creates a possibility that calculations may be misleading in some cases. Accordingly, the reflection on the changes in hazard mitigation is obvious.

The approximation of deviation is greater or equal than $20 \%$. In other words, the actual incident energy is less or equal to $80 \%$ of the estimated one. However, this is not the case for arcs in enclosure or box. From figure 4-2 we can see clearly that the deviation of measured incident energy in box can be bigger than $70 \%$ of the estimated one. 


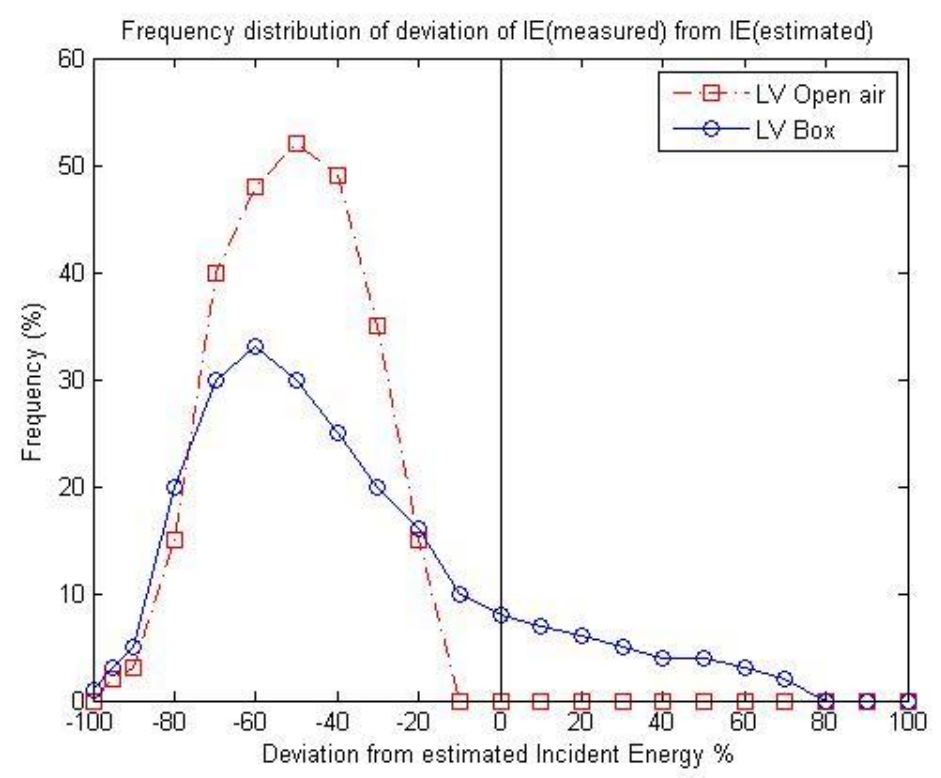

Figure 4-2 Frequency distribution of deviation of measured incident from calculated one

\subsection{Changeability of the Gap between Electrodes and its Effect on Arcing Current}

The arcing current developed in the standard IEEE 1584 is a function of gap between conductors in Equation 3.1 reproduced bellow:

$$
I_{a}=10^{K+0.662 \log \left(I_{b f}\right)+0.0966 V+0.000526 G+0.5588 V * \log \left(I_{b f}\right)-0.00304 G * \log \left(I_{b f}\right)}
$$

It is not possible to assess the hazard at every point in the power installation, nor necessary. Therefore, the assessment will be conducted only at those locations where workers are exposed to arc flash risk.

Switchgears, panels and MCC's are all subject to arc flash hazard assessment (AFH) if, they represent a threat or risk. An engineer will take a look at the single line diagram of the installation or make a site visit and decide about the different locations. Therefore, the assumption is to have fixed voltage and fixed fault current in specific locations. In order to examine the effect of electrode gaps on the arcing current the Equation 3.1 has to be represented as a function of the gap G. 


$$
\begin{aligned}
& I_{a}=F(G)=10^{K+0.662 \log \left(I_{b f}\right)+0.0966 V+0.000526 G+0.5588 V * \log \left(I_{b f}\right)-0.00304 G * \log \left(I_{b f}\right)} \\
& \frac{d F(G)}{d G}=\ln (10) * F(G)\left[0.000526-0.00304 \log \left(I_{b f}\right)\right] \\
& \frac{d F(G)}{d G}=0.00304 * \ln (10) * F(G) *\left[\frac{0.000526}{0.00304}-\log \left(I_{b f}\right)\right] \\
& \frac{d F(G)}{d G}=0.00304 * \ln (10) * F(G) *\left[\frac{0.000526}{0.00304}-\log \left(I_{b f}\right)\right]
\end{aligned}
$$

Therefore,

$$
\begin{aligned}
& \frac{d F(G)}{d G}>0 \text { if } \mathrm{I}_{\mathrm{bf}}<1.489 \\
& \frac{d F(G)}{d G}<0 \text { if } \mathrm{I}_{\mathrm{bf}}>1.489
\end{aligned}
$$

Which is always the case. This yield that $\frac{d F(G)}{d G}<0$ and the arcing current decrease as the gap increases.

Figure 4-3 shows the variation of arc current as a function of gap between phases. The arcing current is an exponential function of the gap G. However, within limited range of gap variation the function has linear behavior. Moreover, by examining the graph in Figure 4-3 it is clear that there is a variation to arc current. If we can approximate the limits of the variation, then we determine the bounds of the arcing current and clearing time which lead us to the possible incident energy. 


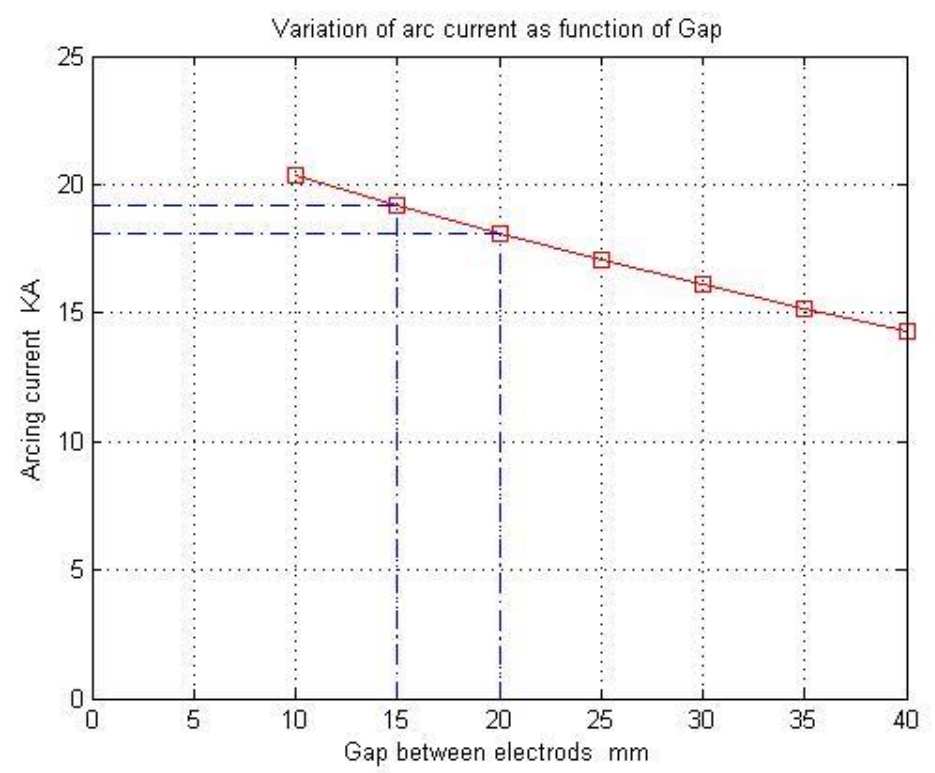

Figure 4-3 Changeability of arc current as a function of gap for $\mathrm{Ib}=36 \mathrm{KA}$ and $\mathrm{V}=208 \mathrm{~V}$

As it can be interpreted from figure 4-4, change of available fault current effects the changeability of the arcing current accordingly considering different rate of change. Change in arcing current may express in terms rate of change and gap variation as it stated in 4.1:

$$
\Delta I a=k_{G} * \Delta G+C_{1}
$$

Such that $k_{G}$ is the slop where $K_{G}<0$ a constant that can be derived from the graph

$$
k_{G}=\frac{I a_{1}-I a_{2}}{G_{1}-G_{2}}
$$

The percentage variation in arcing current can be expressed as follows:

$$
I a(\%)=k_{G} * G(\%)+C_{2}
$$

By including this variation in the calculation of the arcing current $I a$, we are more close to an adequate value of arcing current and the associated incident energy. 


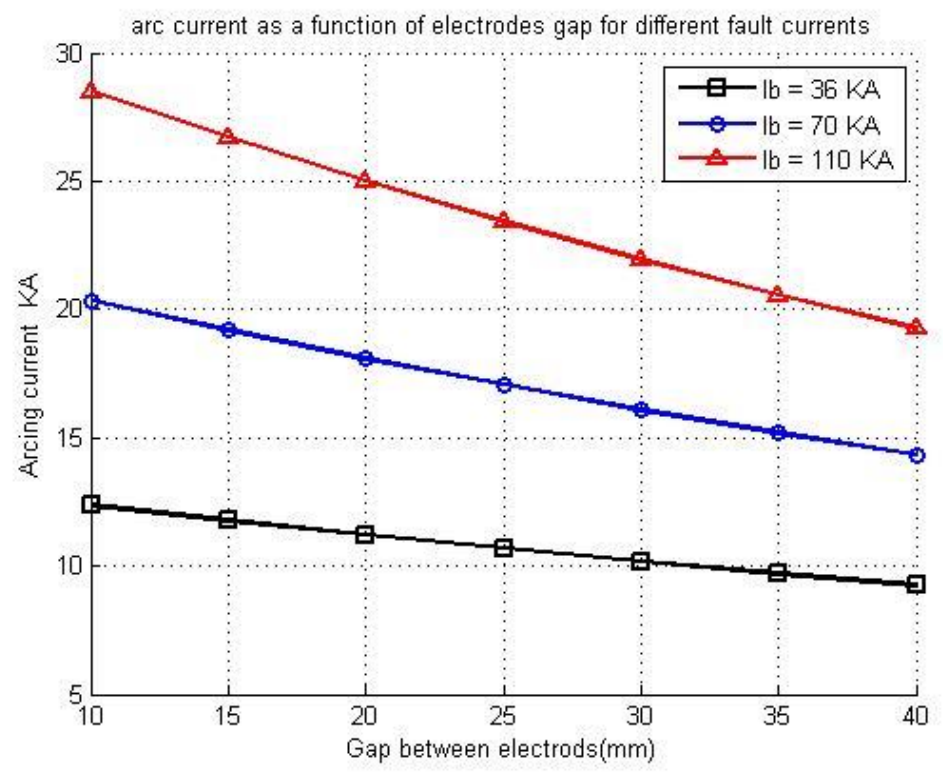

Figure 4-4 Arc current as a function of gap for different fault currents with V=208V

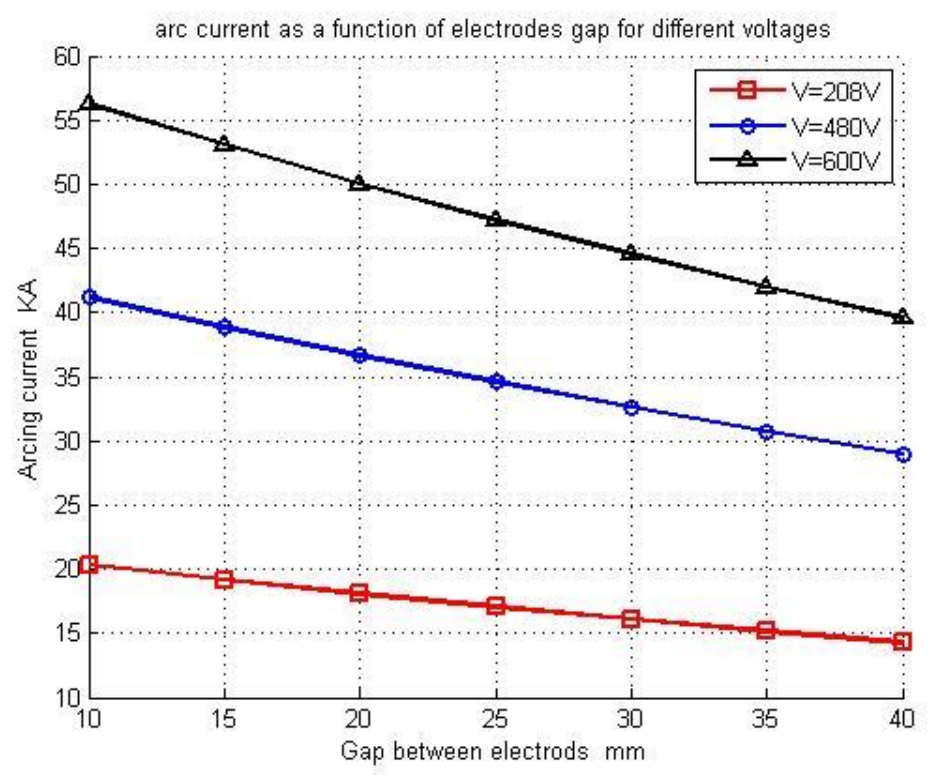

Figure 4-5 Changeability of arc current as a function of electrodes gap and $\mathrm{Ib}=70 \mathrm{KA}$ 


\subsection{Changeability of the voltage between electrodes and its effect on arcing current and time}

The arcing current also is a function of voltage system. Arcing current is responsive to voltage fluctuation. There are several electric code standard for voltage drops. These electric codes restrict the voltage drop of $5 \%$ for low voltage systems. However this voltage drop is $8 \%$ for medium voltage systems. As we know, equipment may operate at $\pm 10 \%$ of their rating voltage. The voltage fluctuates as the loads are connected and disconnected. Equation 3.1 reproduced bellow:

$$
I_{a}=10^{K+0.662 \log \left(I_{b f}\right)+0.0966 V+0.000526 G+0.5588 V * \log \left(I_{b f}\right)-0.00304 G * \log \left(I_{b f}\right)}
$$

Rewriting $I_{a}$ as a function of $\mathrm{V}$ :

$$
\begin{aligned}
& I_{a}=F(V)=10^{K+0.662 \log \left(I_{b f}\right)+0.0966 V+0.000526 G+0.5588 V * \log \left(I_{b f}\right)-0.00304 G * \log \left(I_{b f}\right)} \\
& \frac{d F(V)}{d V}=\ln (10) * F(V) *\left[0.0966-0.05588 \log \left(I_{b f}\right)\right] \\
& \frac{d F(V)}{d V}=0.05588 * \ln (10) * F(V) *\left[\frac{0.0966}{0.05588}+\log \left(I_{b f}\right)\right]
\end{aligned}
$$

Therefore,

$$
\frac{d F(V)}{d V}>0 \text { if } \mathrm{I}_{\mathrm{bf}}>0.0186
$$

Which is always the case. This yield that $\frac{d F(G)}{d G}>0$ and the arcing current increase as the voltage increases.

Figure 4-6 shows the variation of arc current as a function of system voltage. The arcing current is an exponential function of the system voltage V. However, within limited range of voltage variation the function has linear behavior. Moreover, by examining the graph in Figure 4-6 it is clear that there is a variation to arc current. If we can approximate the limits of the variation, then we determine the bounds of the arcing current and clearing time which lead us to the possible incident energy. 


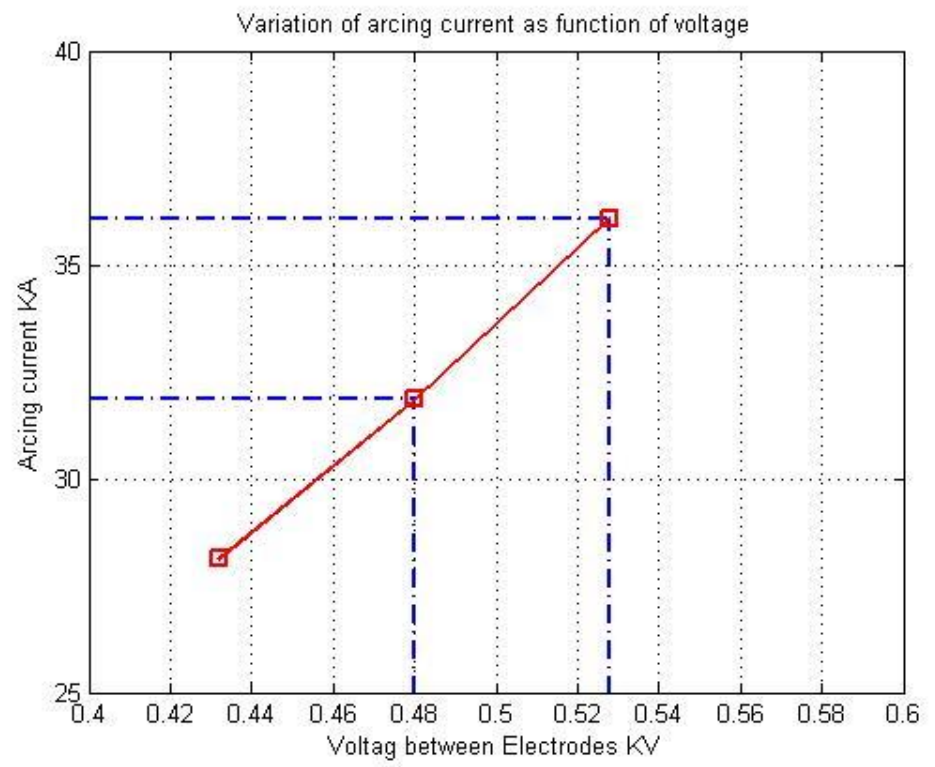

Figure 4-6 Changeability of arc current as a function of voltage for $\mathrm{Ib}=70 \mathrm{KA}$ and $\mathrm{G}=32 \mathrm{~mm}$

As it can be interpreted from figure 4-6, change of available fault current effects the changeability of the arcing current accordingly considering different rate of change. Change in arcing current may express in terms rate of change and gap variation as it stated in 4.3:

$$
\Delta I a=K_{V} * \Delta V+C_{1}
$$

Such that $k_{V}$ is the slop where $K_{V}>0$ a constant that can be derived from the graph

$$
k_{V}=\frac{I a_{1}-I a_{2}}{V_{1}-V_{2}}
$$

The percentage variation in arcing current can be expressed as follows:

$$
\text { Ia } \%=k_{V} * V \%+C_{2}
$$

If we assume $\mathrm{V}=1$ volt, this will result in $I a \%=k_{V} \%$ which means that if the voltage varies by 1 volt this will result in a variation of $k_{V} \%$ in the value of arcing current $(I a)$. By including this 
variation in the calculation of the arcing current $I a$, we are more close to an adequate value of arcing current and the associated incident energy.

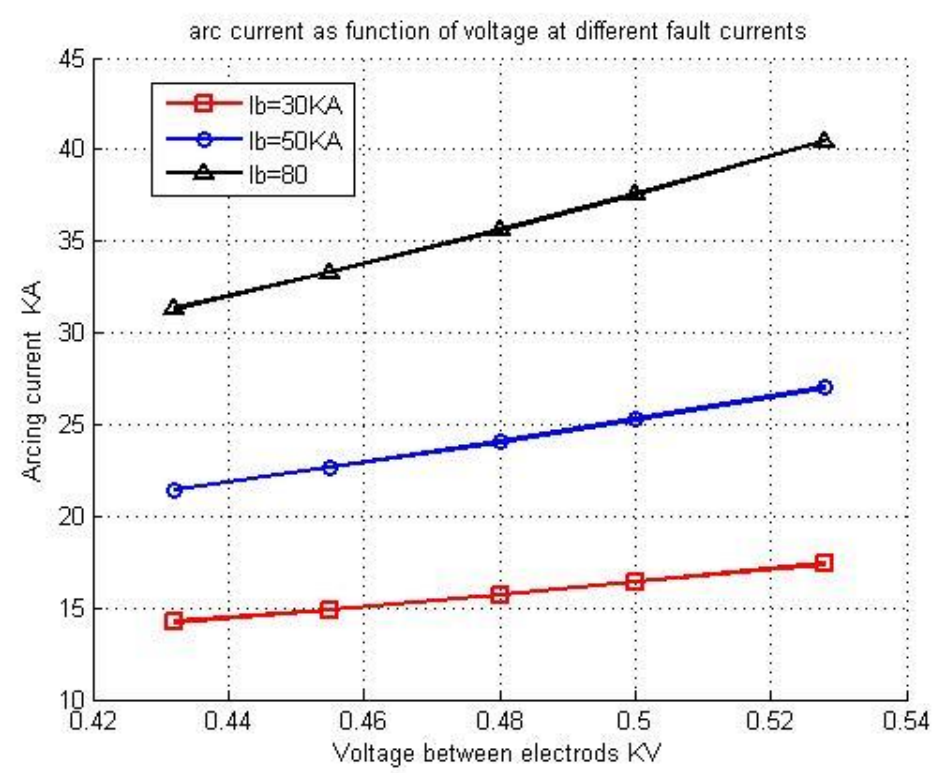

Figure 4-7 Arc current as a function of voltage for different fault currents with $\mathrm{G}=32 \mathrm{~mm}$

\subsection{Time current curve affect on arcing time}

The TCC for protective devices is used to determine the arcing current time that the protective device need to clear the fault. The response characteristics are shown on standard time current curves. There is always a differences between individual breakers or fuses of the same kind, type and rate even though they have the same rate. In the case that the TCC of a fuse represented by a line and all the variations are below the actual line, the curve may be formulated base on the manufacturer data using curve fitting technique. However, if there is any added manufacturer tolerance have to be taken into consideration for more adequate value to the arcing time 


\subsection{A proposed steps and flowchart of calculating arc flash}

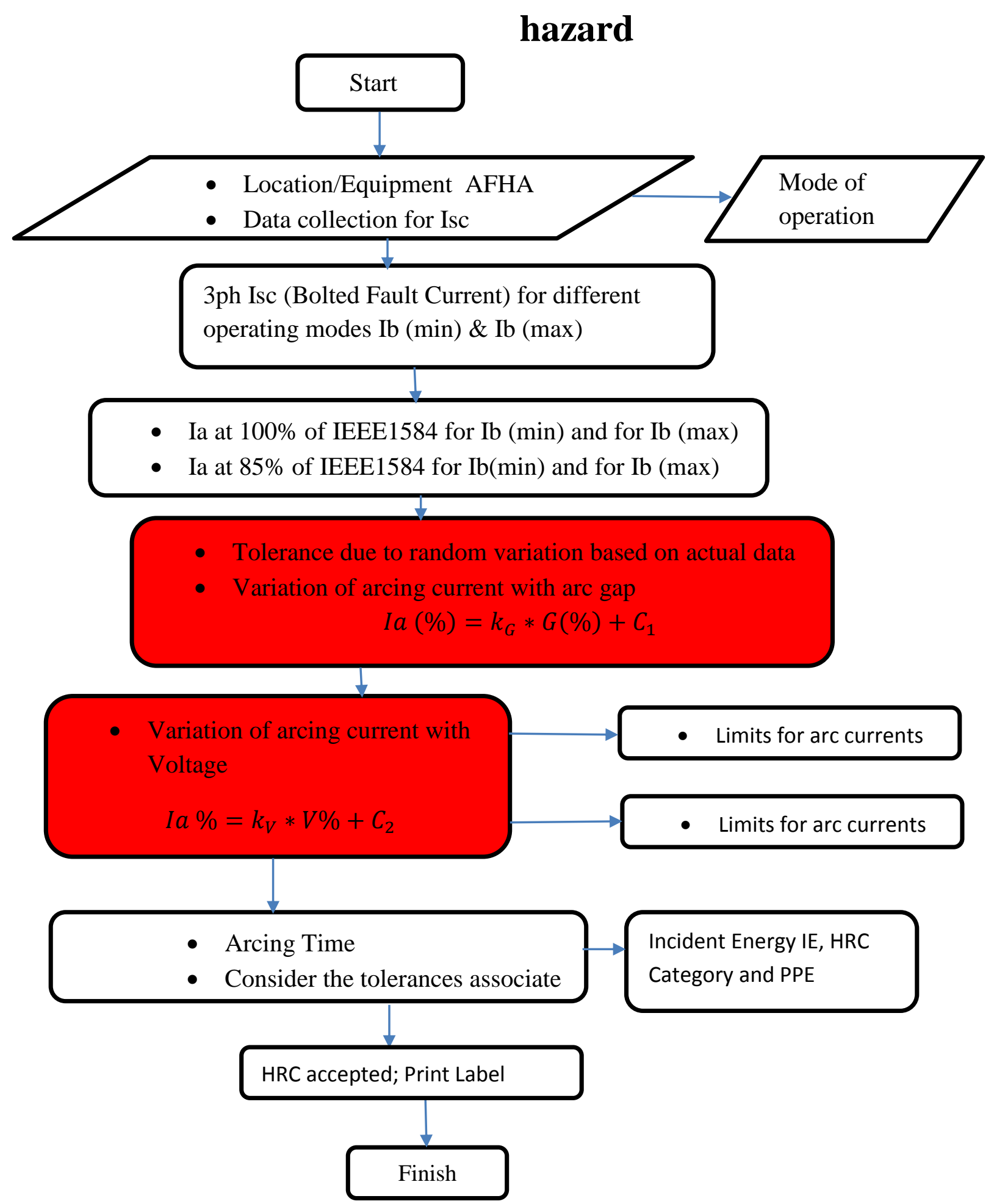




\subsection{Summary}

This Chapter considers the issue of parameter changeability and its effects on arc flash hazard mitigation. First, the technical studies on the empirical formulae given in the IEEE 1584 Guide and their suitability to address accurate values of arc flash variables are highlighted. The impact of uncertainty in the gap length between electrodes on the arc flash hazard is mathematically derived. The same is repeated for the system voltage value. Next, a methodology is proposed to incorporate the variations of gap and voltage in arc flash calculation procedures. 


\section{Chapter Five - Simulation Results and Observations}

In Chapters 1-4, we detailed the arc flash circumstances, calculations and analysis. The work performed in this thesis focuses on the effect of the variation in arcing current and arcing time due to the variation in voltage and gap between electrodes. In this chapter we test our analysis through the approaches recommended by other researchers to reduce the danger of arc flash incident energy. We investigate these approaches and simulate them in ETAP and MATLAB software platforms in order to compare the results after we consider the effect of voltage and gap variations.

Tinsley et. al recommend in their paper, "Beyond the Calculations: Life after Arc Flash Analysis", that the arc flash incident energy can be reduced by changing the work procedure, modifying existing settings and increasing the working distances [40]. In addition, it is also recommend that the best way to mitigate personnel exposure to the arc flash hazard is to accomplish the work in a de-energized state [41]. Further, others recommend certain techniques must be implemented at the time of the initial design in order to mitigate the risk of arc flash [11]. We will now highlight these various approaches and we test and measure the impact of the voltage variation and gap variation on the final results of arc current and incident energy.

\subsection{Increasing the working distance}

Based on equation 3.5, the incident energy is inversely proportional to the distance, meaning that as the distance increases, the incident energy decreases [42]. The increase in the distance can be achieved by performing the switching or racking operation away from the panels by using remote operating equipment [41] and [43].

Figure 5-1, Figure 5-2 and Figure 5-3 show the simulation output and the impact that the increased distance has on the energy level and the risk category. Table 5-1 and table 5-2 highlight the simulation results. It is clear that the increasing the working distance from 24 and 18 inches to 48 and 24 inches in Buses 54 and 61 respectively. This will results in the incident energy decreases from $53.69 \mathrm{Cal} / \mathrm{cm}^{2}$ to $19.342 \mathrm{Cal} / \mathrm{cm}^{2}$ in Bus 54 which affect the risk category decreases from 
category Dangerous (4) to category 3. In Bus 61 the incident energy decreases from $1.25 \mathrm{Cal} / \mathrm{cm}^{2}$ which represent risk category 1 to $0.778 \mathrm{Cal} / \mathrm{cm}^{2}$ which represent category 0 (no risk).

Now if we consider voltage variation as $\pm 10 \%$, the voltage may decrease from $480 \mathrm{~V}$ to $432 \mathrm{~V}$. This will reflect on the arcing current as per equation (4-4)

The simulation gives an incident energy of $26.34 \mathrm{Cal} / \mathrm{cm}^{2}$ AFH category 03, instead of 19.34 $\mathrm{Cal} / \mathrm{cm} 2$. Even though the risk category is the same but the IE has increased.

Now if we consider variation of the gap as $\pm 8 \mathrm{~mm}$, so the gap may increase from $32 \mathrm{~mm}$ to 40 $\mathrm{mm}$. This will reflect on the arcing current as per equation (4-2)

The simulation gives an incident energy of $24.83 \mathrm{Cal} / \mathrm{cm}^{2}$ AFH category 03, instead of 19.34 $\mathrm{Cal} / \mathrm{cm}^{2}$. Even though the risk category is the same but the incident energy IE has increased. 


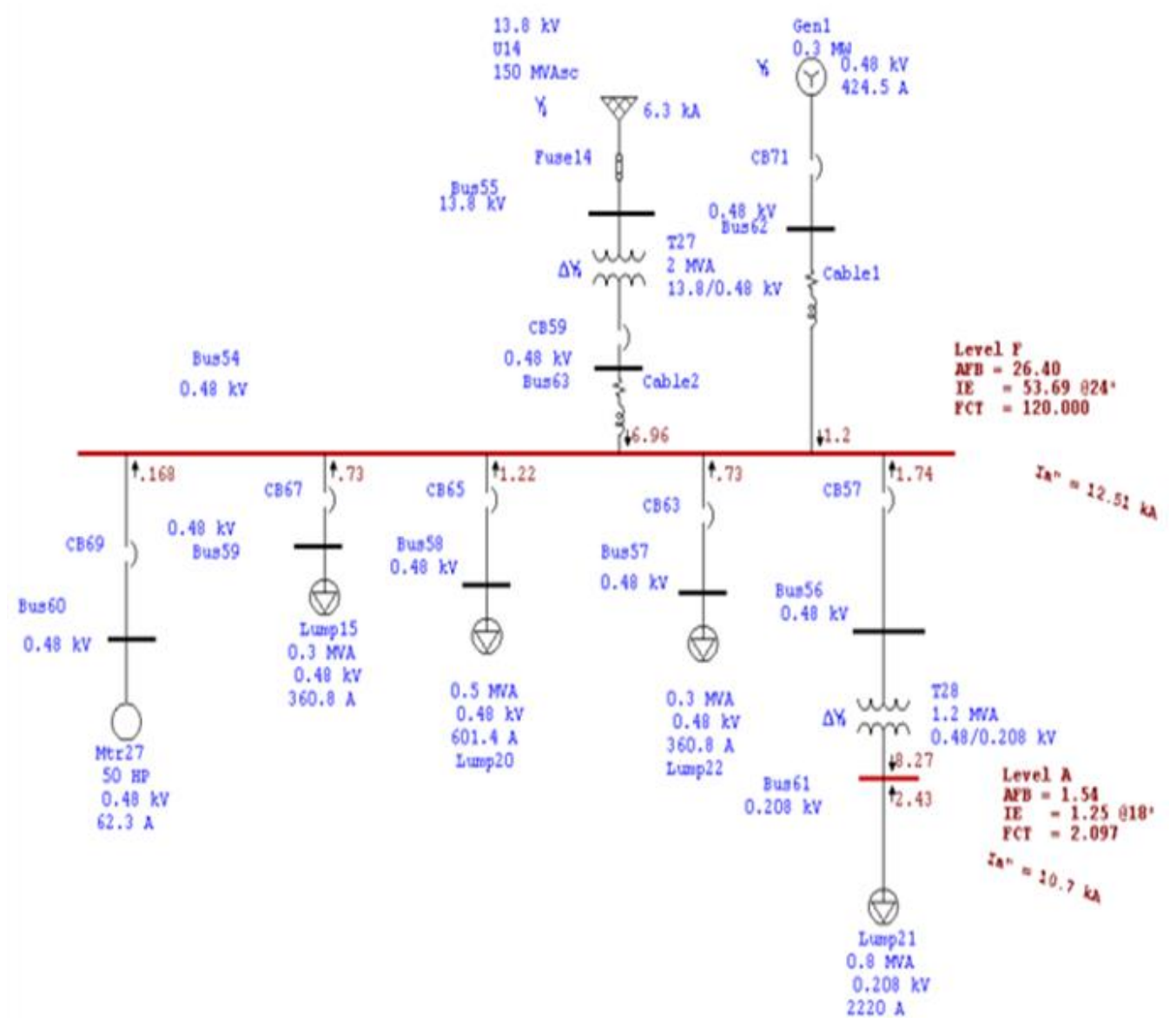

Figure 5-1 Arc flash simulation at Bus 54 and Bus 61. 


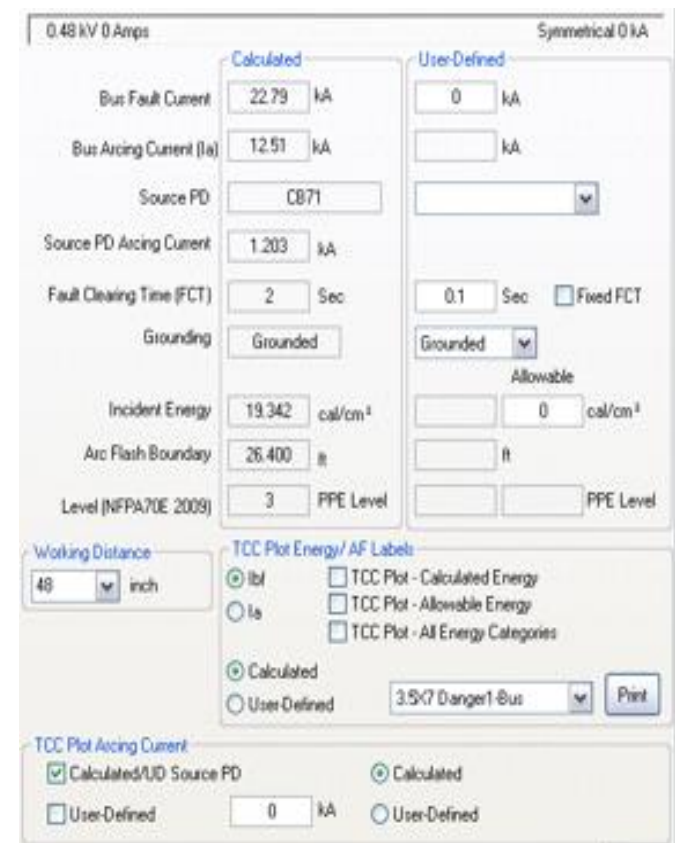

Figure 5-2 Arc flash simulation at Bus 54 at working distance of 48 inches.

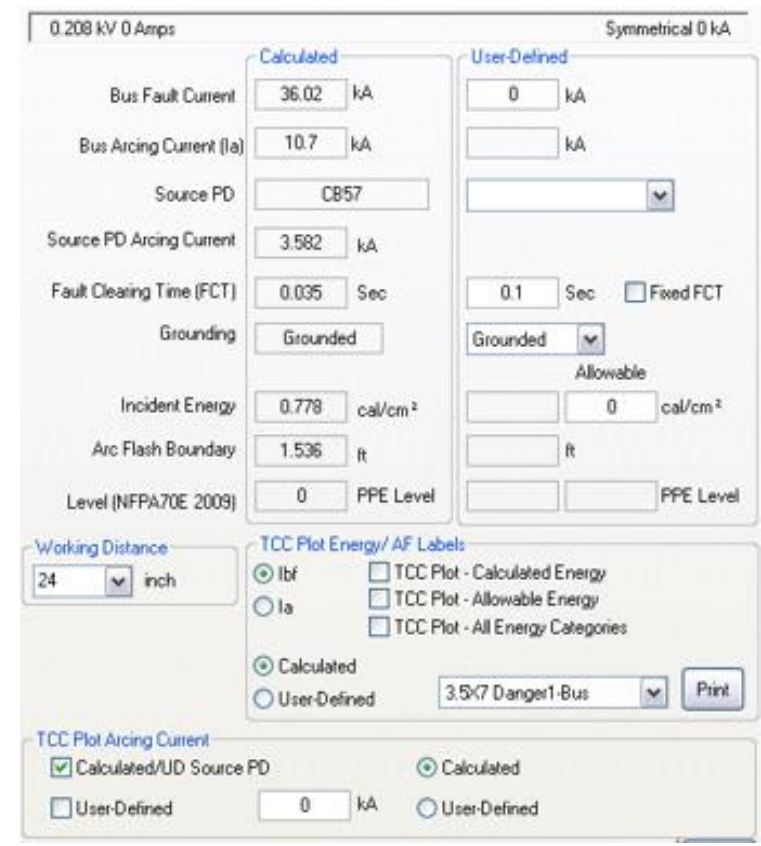

Figure 5-3 Arc flash simulation at Bus 61 at working distance of 24 inches 
Table 5-1 Simulation results for Bus 54

\begin{tabular}{|l|c|c|c|}
\hline & Working Distance 24” & Working Distance 48” & Notes \\
\hline Arcing Current (Iac) & $12.51 \mathrm{KA}$ & $12.51 \mathrm{KA}$ & No Change \\
\hline Fault Clearing Time (FCT) & $2 \mathrm{Sec}$ & $2 \mathrm{sec}$ & No Change \\
\hline Arc Flash Boundary (AFB) & $26.40 \mathrm{ft}$ & $26.40 \mathrm{ft}$ & No Change \\
\hline PPE Level & 4 & 3 & Changed \\
\hline Incident Energy (IE) & $53.69 \mathrm{Cal} / \mathrm{cm}^{2}$ & $19.34 \mathrm{Cal} / \mathrm{cm}^{2}$ & Changed \\
\hline
\end{tabular}

Table 5-2 Simulation results for Bus

\begin{tabular}{|l|c|c|c|}
\hline & Working Distance 18” & Working Distance 24” & Notes \\
\hline Arcing Current (Iac) & $10.7 \mathrm{KA}$ & $12.51 \mathrm{KA}$ & No Change \\
\hline Fault Clearing Time (FCT) & $0.035 \mathrm{Sec}$ & $0.035 \mathrm{sec}$ & No Change \\
\hline Arc Flash Boundary (AFB) & $1.54 \mathrm{ft}$ & $1.54 \mathrm{ft}$ & No Change \\
\hline PPE Level & 1 & 0 & Changed \\
\hline Incident Energy (IE) & $1.25 \mathrm{Cal} / \mathrm{cm}^{2}$ & $0.778 \mathrm{Cal} / \mathrm{cm}^{2}$ & Changed \\
\hline
\end{tabular}

\subsection{Modifying the protective device settings}

$$
E=4.184 C_{f} E_{n}\left(\frac{t}{0.2}\right)\left(\frac{610}{D}\right)^{x}
$$

Based on equation 3.5, the incident energy is proportional with the fault clearing time $(\mathrm{t})$, and this time is obtained from the protective device time current characteristics (TTC). This means that by modifying the settings of the circuit breaker, we can decrease the time, resulting in a decrease in the incident energy (IE) and consequently, the hazard risk.

Figure 5-4, Figure 5-5, Figure 5-6 and Figure 5-7 shows the simulation output and the impact of setting modification on the energy level and the risk category. 


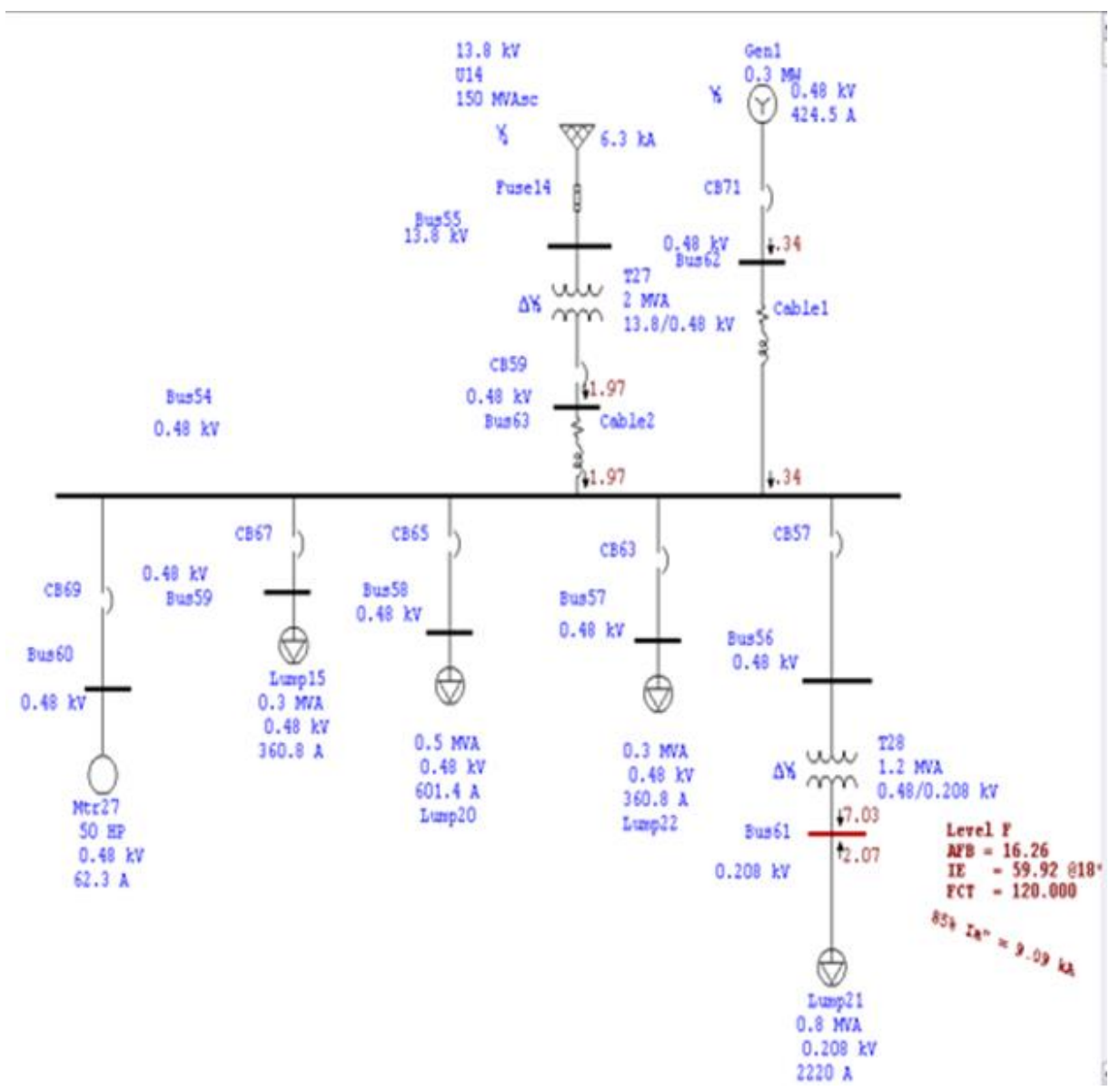

Figure 5-4 Simulation of the power system with the High Instantaneous setting of CB57 


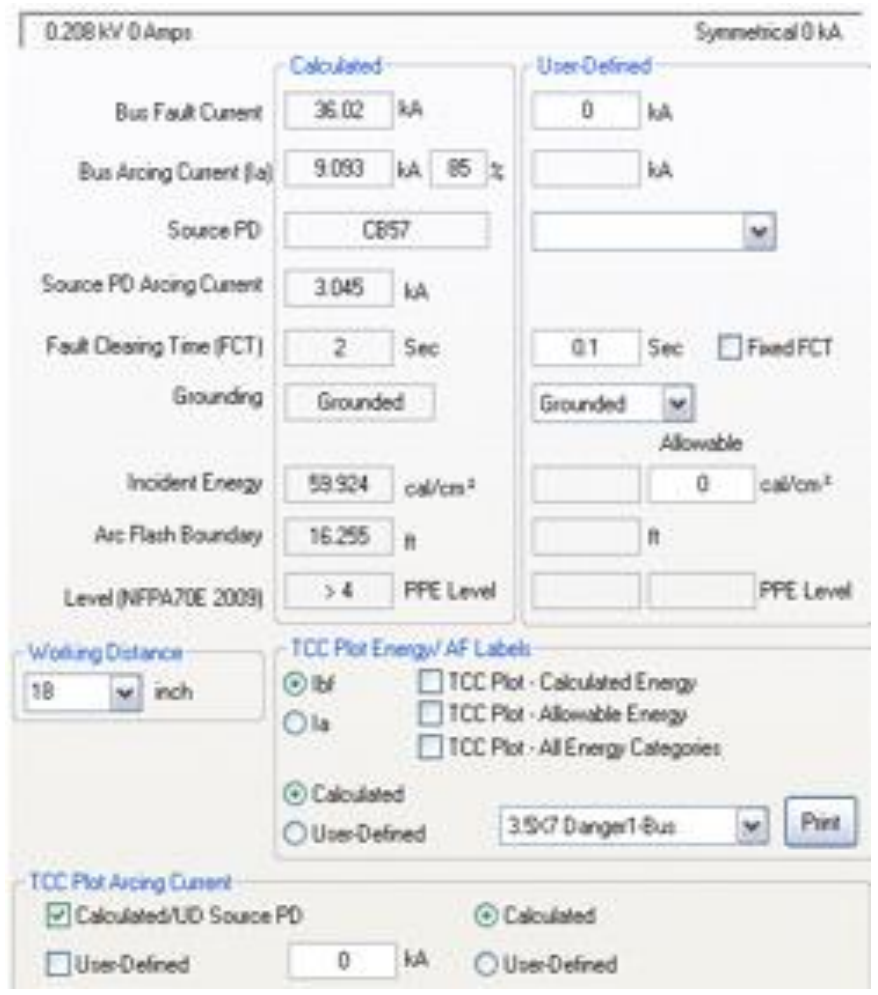

Figure 5-5 Arc flash factors affected from the High Instantaneous setting of CB57 


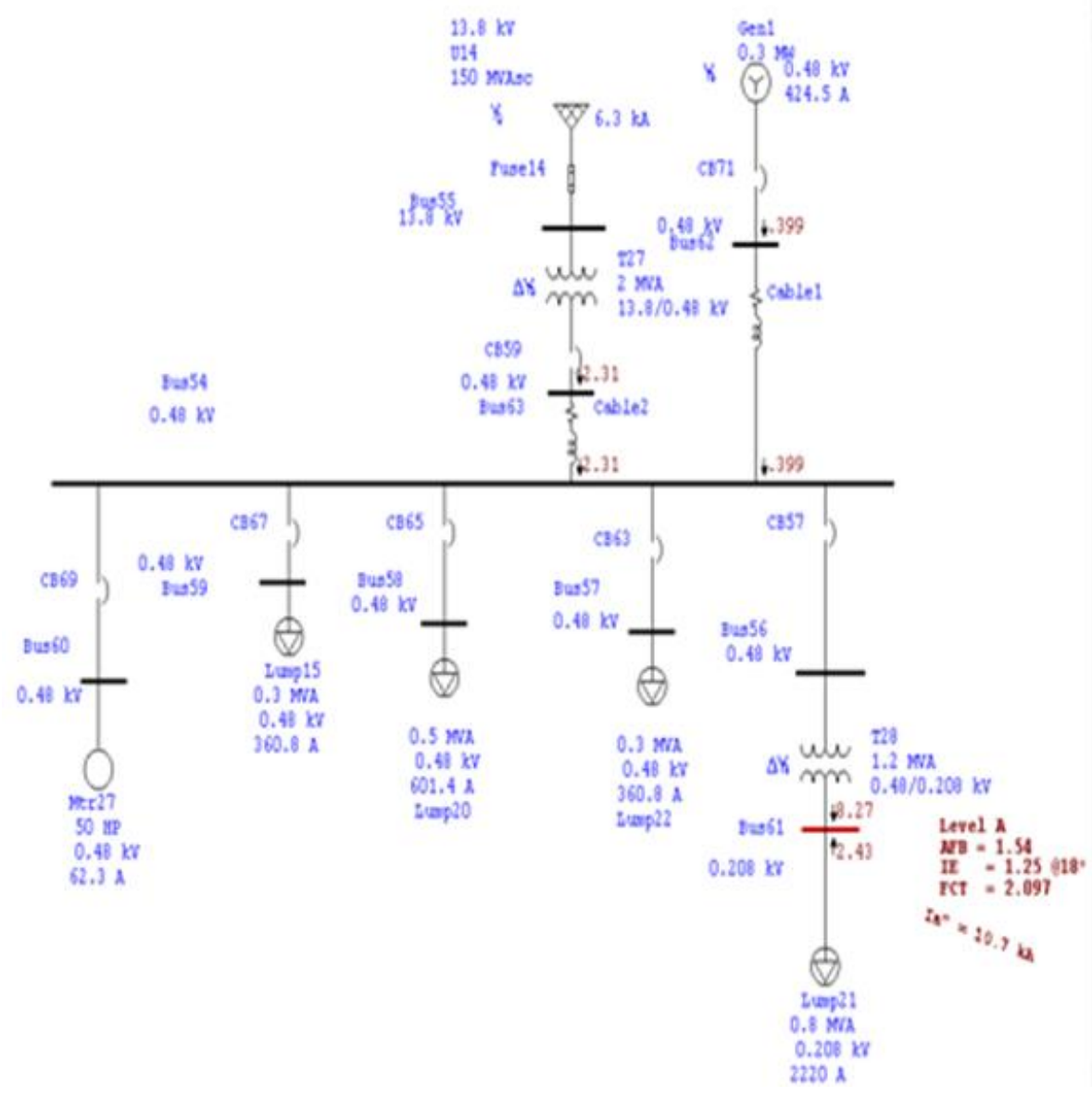

Figure 5-6 Simulation of the power system with the Low Instantaneous setting of CB57 


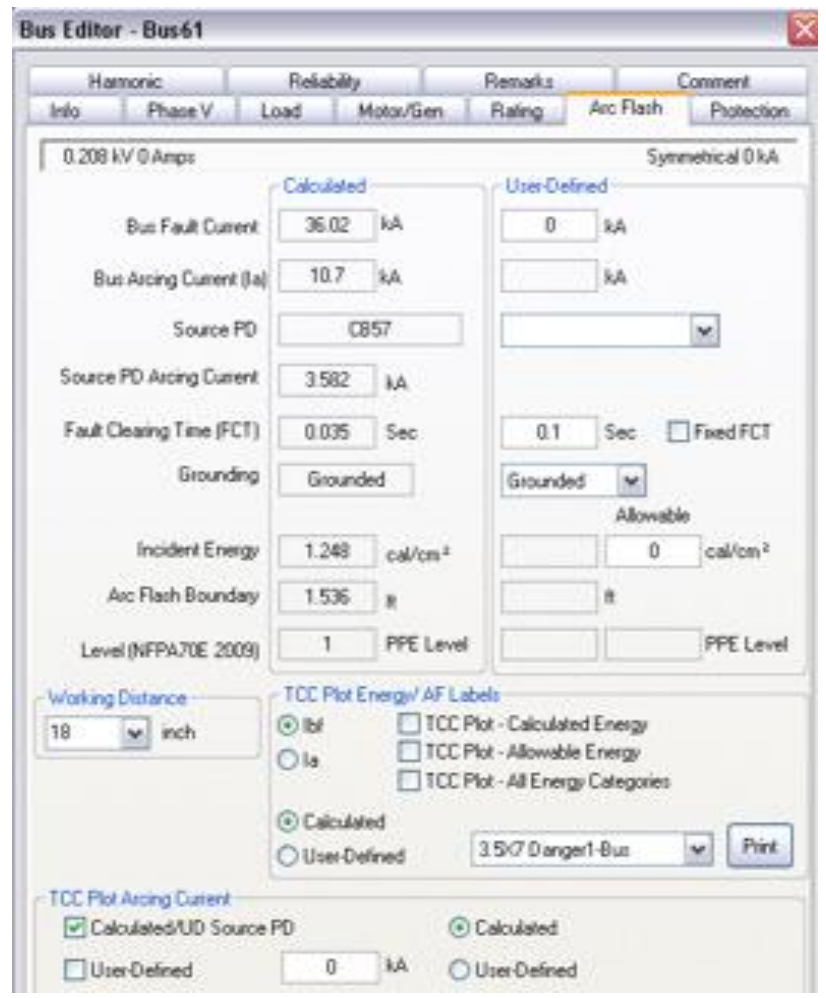

Figure 5-5-7 Arc flash factors affected from the Low Instantaneous setting of CB57

The Instantaneous Setting of CB57 is high as demonstrated in figure 5-4 and Figure 5-5. If we modify the Instantaneous setting to low state, the incident energy is dramatically reduced as shown in figure 5-6 and Figure 5-7.

Table 5-3 highlights the simulation results. It is clear that changing the setting from Hight Setting 2 (2665 A) to Low Setting (1500 A) will result in the incident energy decreasing from $59.92 \mathrm{Cal} / \mathrm{cm} 2$ to $1.25 \mathrm{Cal} / \mathrm{cm}^{2}$ and the risk category decreasing from category 4 (Dangerous) to category 0 (No Risk). 
Table 5-3 Simulation results for Bus 61

\begin{tabular}{|l|c|c|c|}
\hline & $\begin{array}{c}\text { CB57 Setting High } \\
(2665 \mathrm{~A})\end{array}$ & $\begin{array}{c}\text { CB57 Setting Low } \\
(1500 \mathrm{~A})\end{array}$ & Notes \\
\hline Working Distance & $18 \mathrm{inch}$ & $18 \mathrm{inch}$ & No change \\
\hline Arcing current & $9.09 \mathrm{KA}$ & $10.7 \mathrm{KA}$ & \pm No change \\
\hline Arc Flash Boundary AFB & $16.26 \mathrm{ft}$ & 1.541 .54 & Changed \\
\hline Incident Energy IE & $59.92 \mathrm{Cal} / \mathrm{cm} 2$ & $1.25 \mathrm{Cal} / \mathrm{cm} 2$ & Changed \\
\hline Fault Clearing Time FCT & $120 \mathrm{cycle}$ & $2.097 \mathrm{cycles}$ & Changed \\
\hline PPE Level & Dangerous & Level 0 No risk & Changed \\
\hline
\end{tabular}




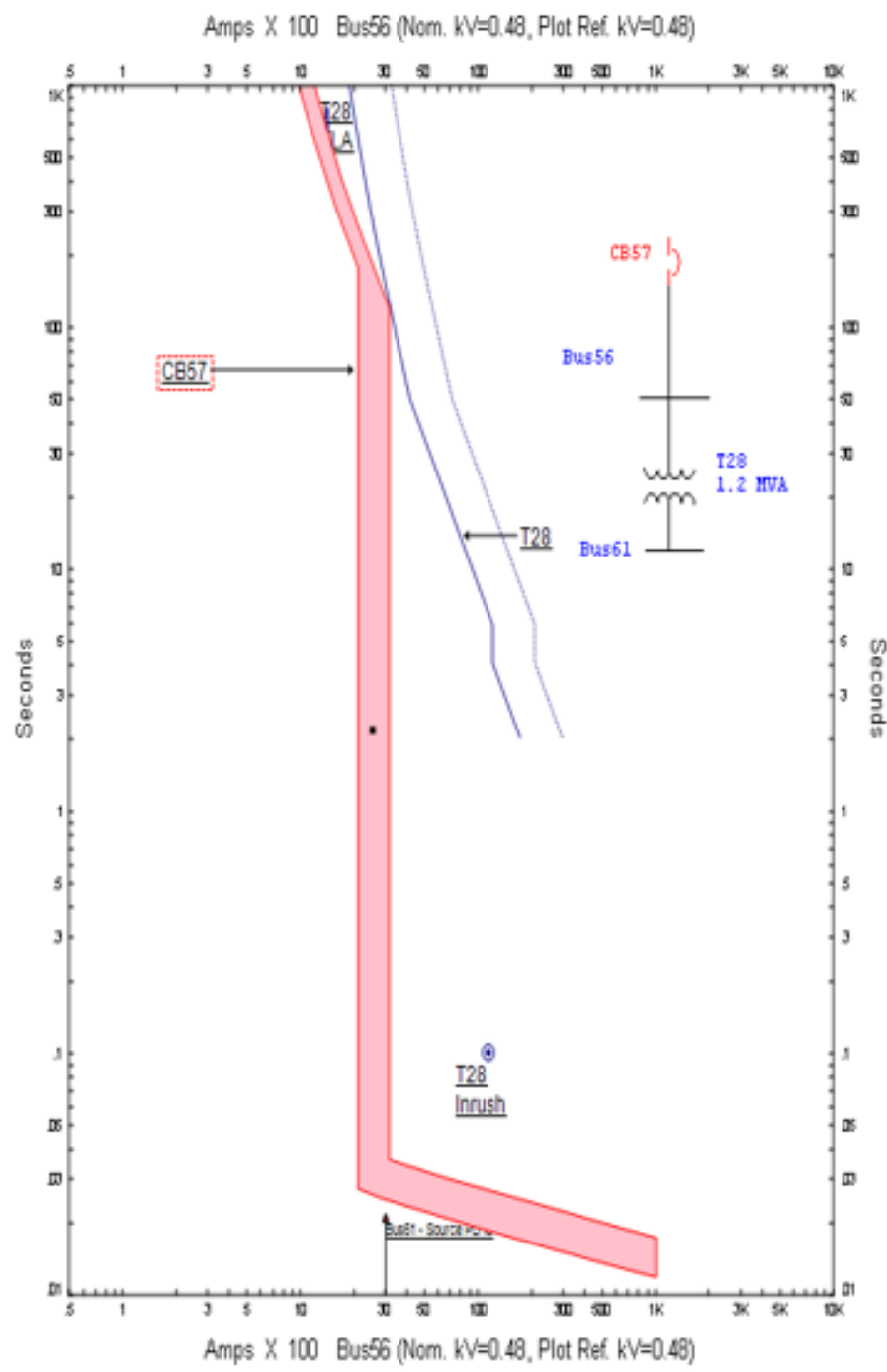

Figure 5-8 The response of CB57 at High Instantanious setting 


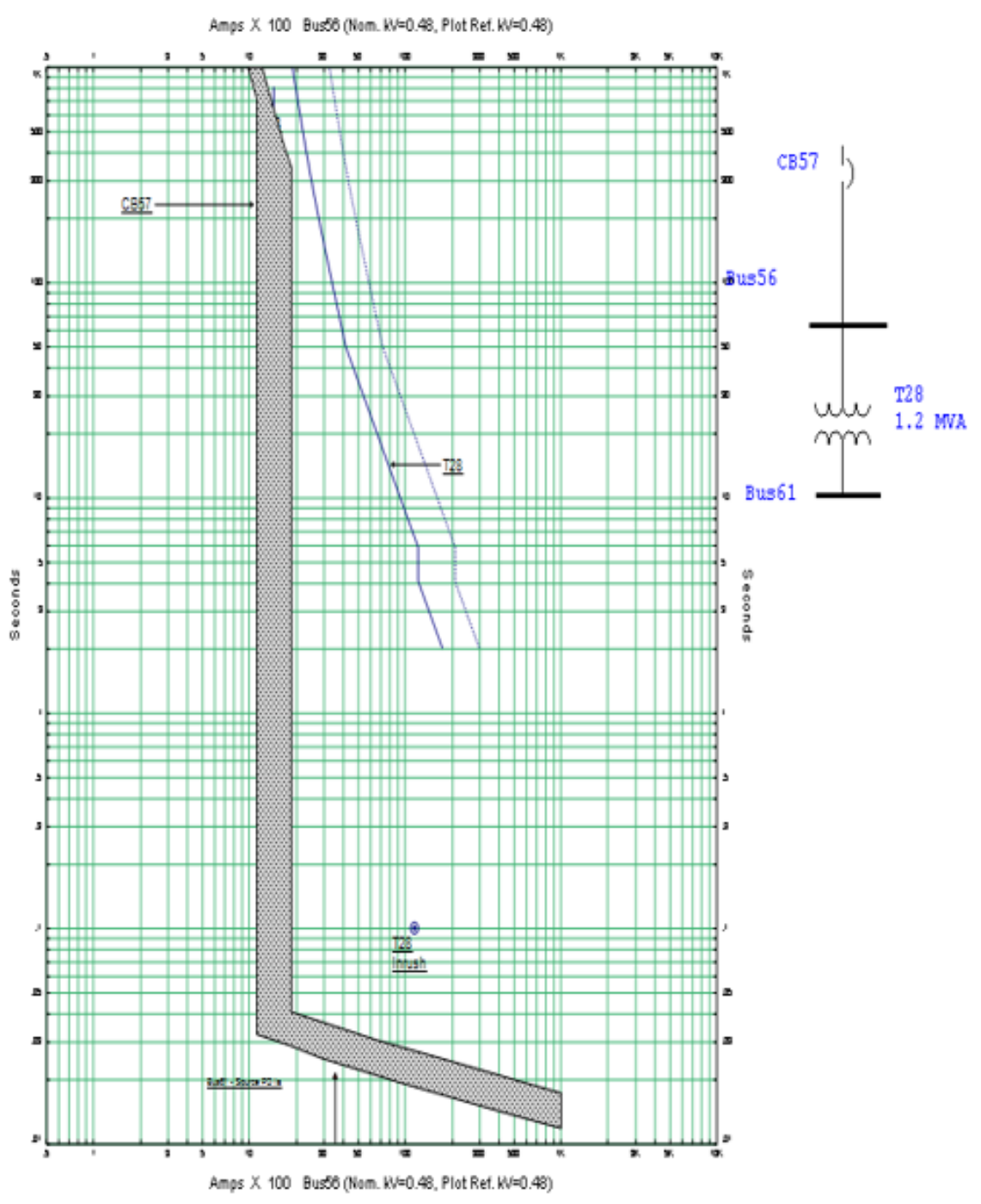

Figure 5-9 The response of CB57 at High Instantanious setting

This technique can only be applied on a temporary basis as long as the worker is working on the energized equipment. Once the worker leaves the area, the setting must be restored to the original setting. It must be noted that the protective device coordination will be affected as we decrease the clearing time [40]. However, we can continue to operate the system regardless of the selective coordination, and decreasing the clearing time will reduce the arcing current, consequently reducing the incident energy. Therefore, we will avoid any damage to electrical equipment and working personnel. Even though the code suggests that the selective coordination only for critical operating power systems (COPS), most of the industrial organizations prefer to use the selective coordination. The drawback from this technique is that any fault that occurs will interrupt all the 
nearby feeders. The manufacturers do not like to disturb the production process and increase the down time, as it is very costly.

Now if we consider variation of the voltage as $\pm 10 \%$, so the voltage may decrease from $208 \mathrm{~V}$ to $188 \mathrm{~V}$. This will reflect on the arcing current as per equation (4-4)

The simulation gives an incident energy of $7.35 \mathrm{Cal} / \mathrm{cm} 2 \mathrm{AFH}$ category 2 , instead of $1.25 \mathrm{Cal} / \mathrm{cm} 2$ Hazard risk category 1.

Now if we consider variation of the gap as $+10 \mathrm{~mm}$, so the gap may increase from $25 \mathrm{~mm}$ to 35 $\mathrm{mm}$. This will reflect on the arcing current as per equation (4-2)

This results in an incident energy of $3.28 \mathrm{Cal} / \mathrm{cm} 2 \mathrm{AFH}$ category 1 , instead of $1.25 \mathrm{Cal} / \mathrm{cm} 2 \mathrm{Hazard}$ risk category 1.

\subsection{Utilize a single main CB for building shut down}

There are different power systems which are already installed in buildings. Some of these power systems have a main panel without a main circuit breaker, and the power is supplied to the building through several feeders, which are protected by circuit breakers. The number of feeders cannot exceed six as per the code regulation. The simulation of a power system that does not have a main circuit breaker results in Figure 5-10 and Figure 5-11. These figures show a main distribution panel (MDP) that has no main breaker and is connected to five feeders, which supply all the loads in the

building. The five feeders are protected by five $\mathrm{CB}$, which represent the disconnecting means of the building. The protective device of the main panel is the fuse located at the primary side of the service transformer. 


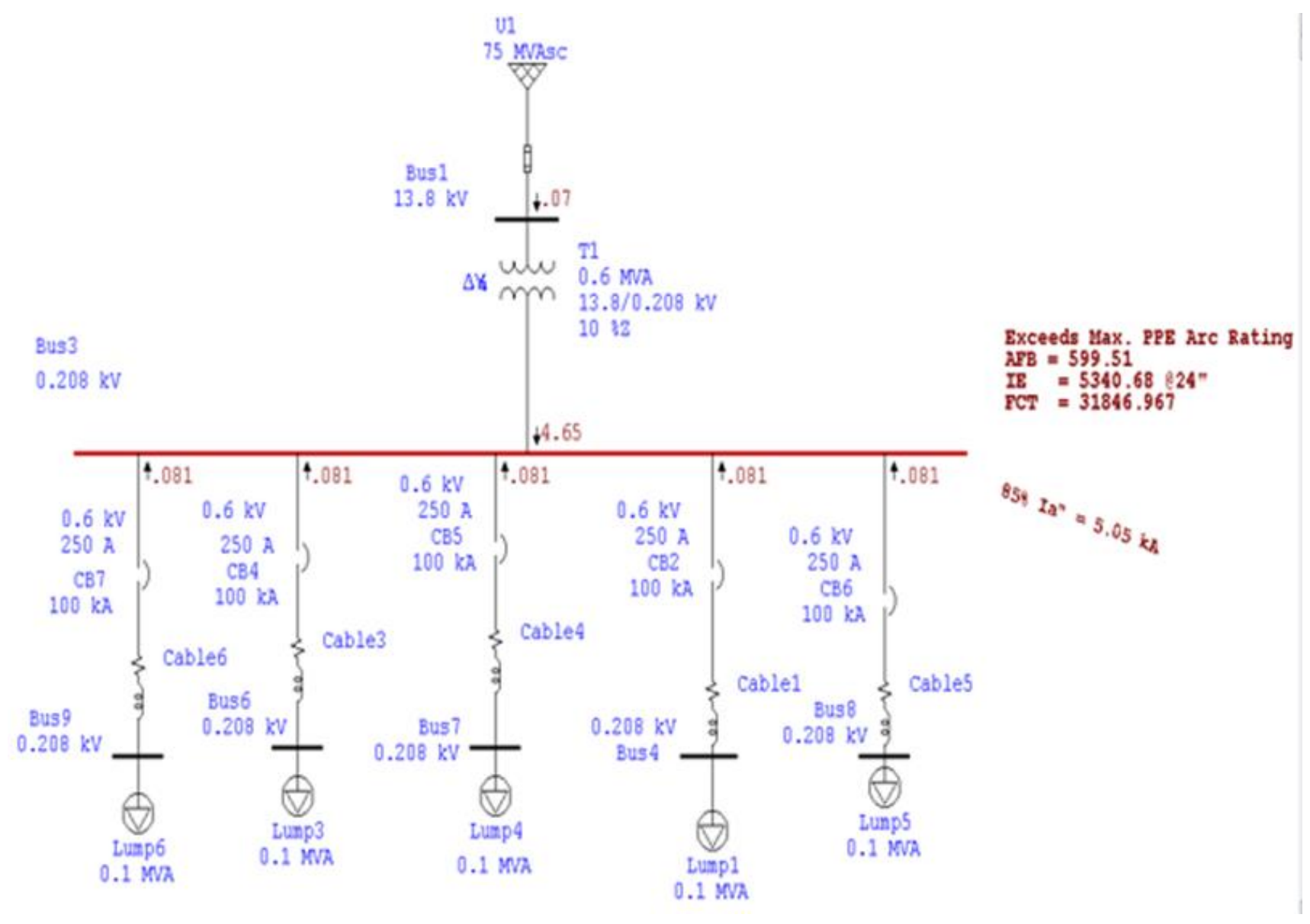

Figure 5-10 Power system without single main CB before the MDP 


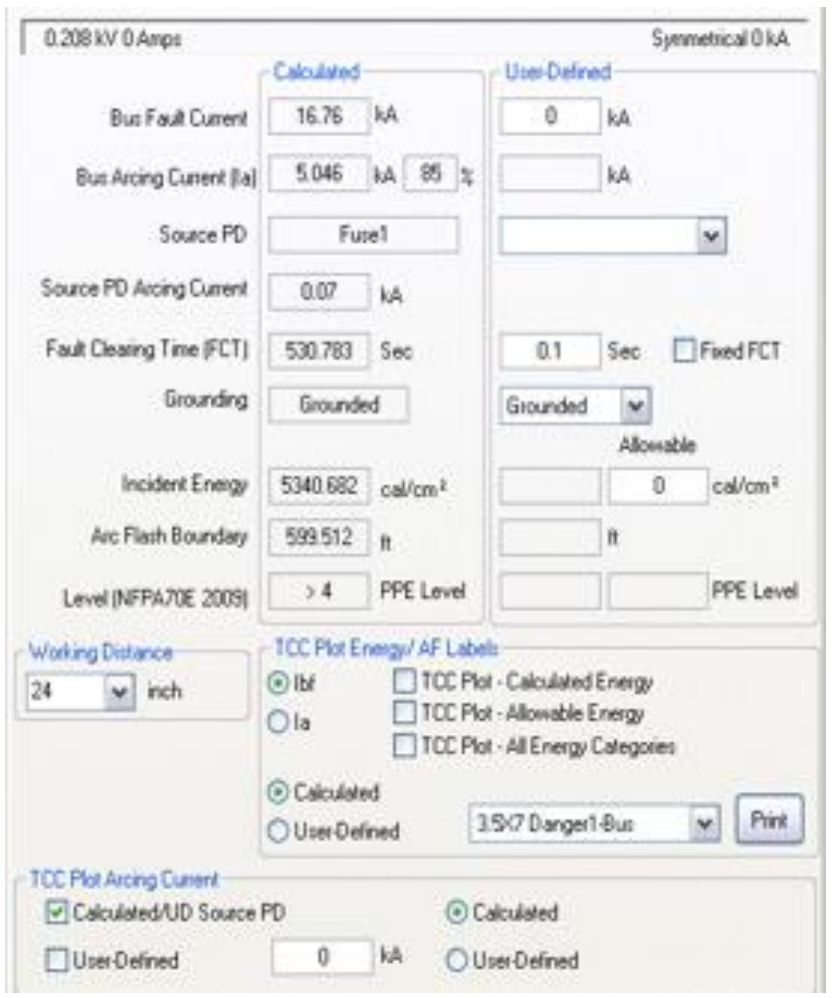

Figure 5-5-11 Arc flash factors affected from the delay response of the Fuse at Bus 1

The TCC in Figure 5-12 shows the fuse interrupting the arcing current in 500 seconds (few minutes). This is a very long time, resulting in an increase in the incident energy to an extremely dangerous level. 


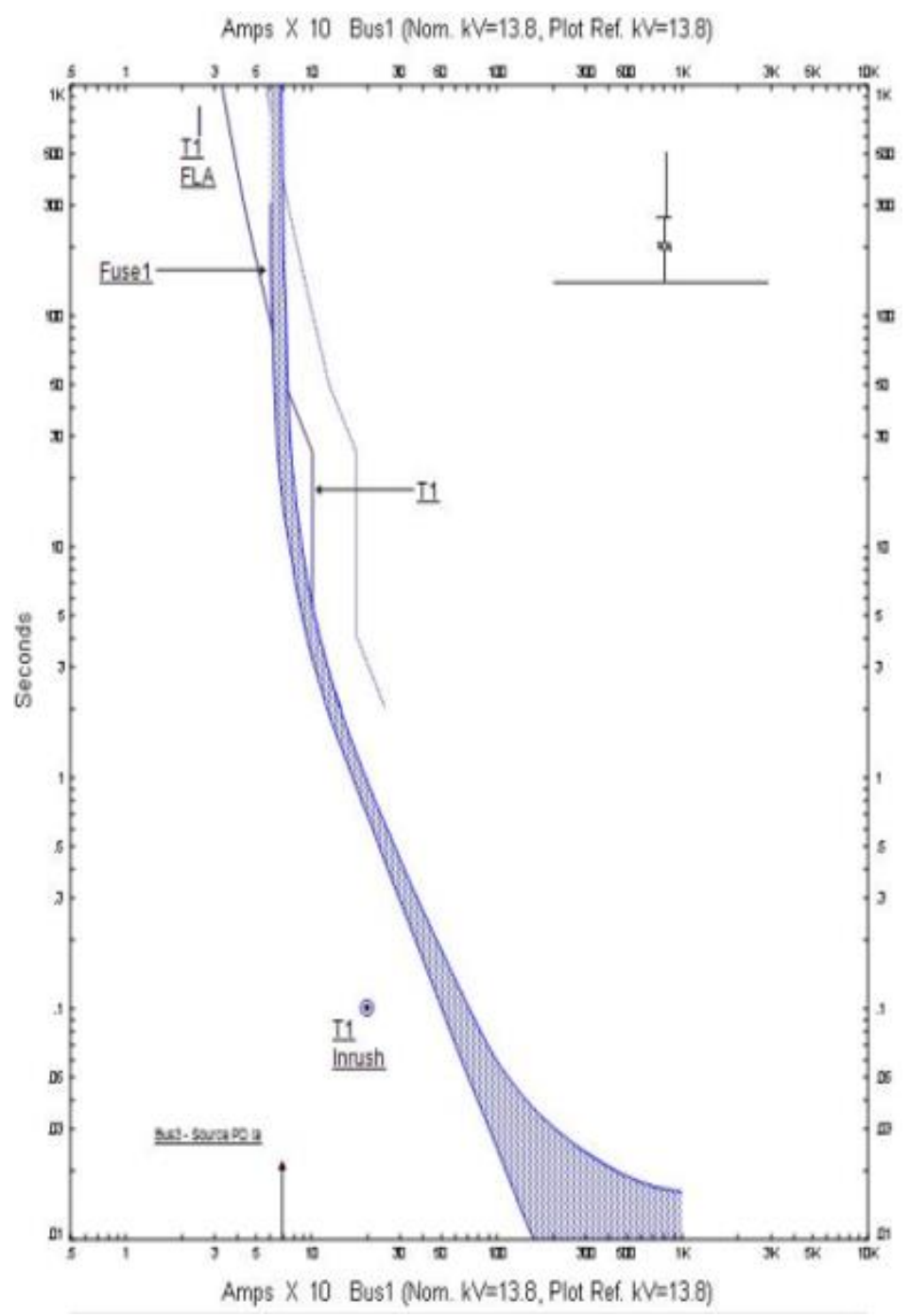

Figure 5-12 The response of the fuse to the arcing current

A single main $\mathrm{CB}$ that is located outside the main distribution board (MDB) can serve as a disconnect mean for the building. The CB should be an LSI type. Therefore, we can adjust the setting in the long time, short time, and instantaneous time domains to achieve the desired incident energy and consequently, reduce the danger level. Figure 5-13 shows the simulation of the same system with main circuit breaker installed before/outside the MDP. The results are summarized in Figure 5-14. 


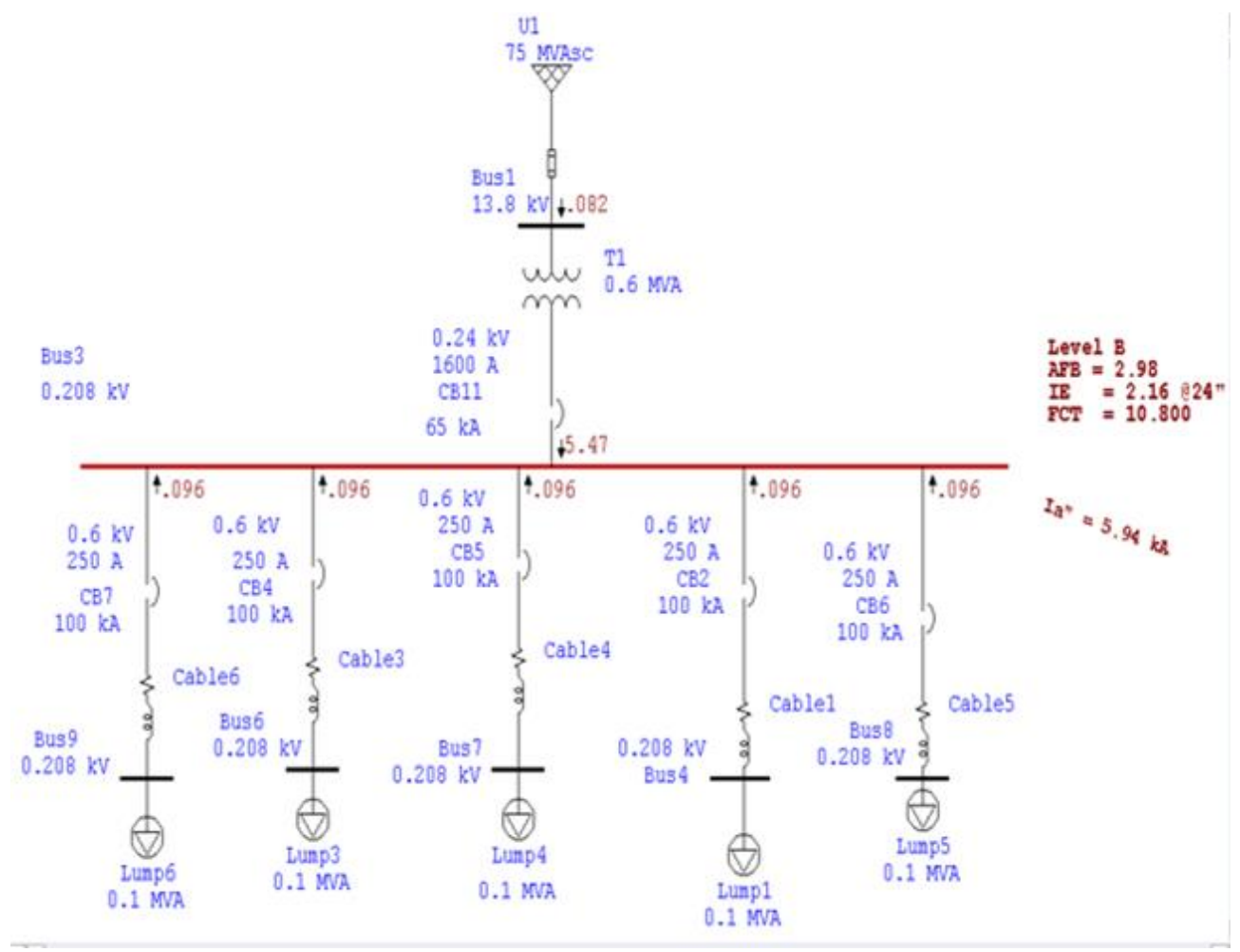

Figure 5-13 The previous Power system with single main CB before the MDP 


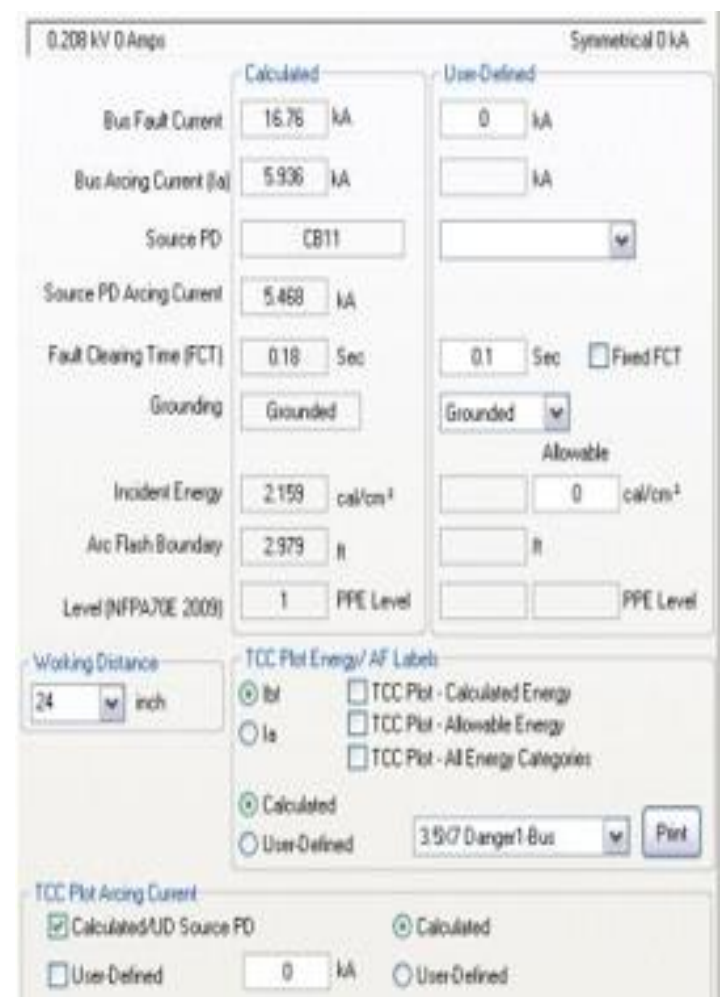

Figure 5-5-14 Arc flash factors affected by the fast response of the CB ahead MDP

Figure 5-4 shows the TCC of the system after we utilize the main breaker. The arcing current is now interrupted in 0.18 seconds. This is a very short time, which will impact the value of the incident energy and reduce the danger level. 
Amps X 10 Bus 1 (Nom. $k V=13.8$, Plot Ret. $k V=13.8$ )

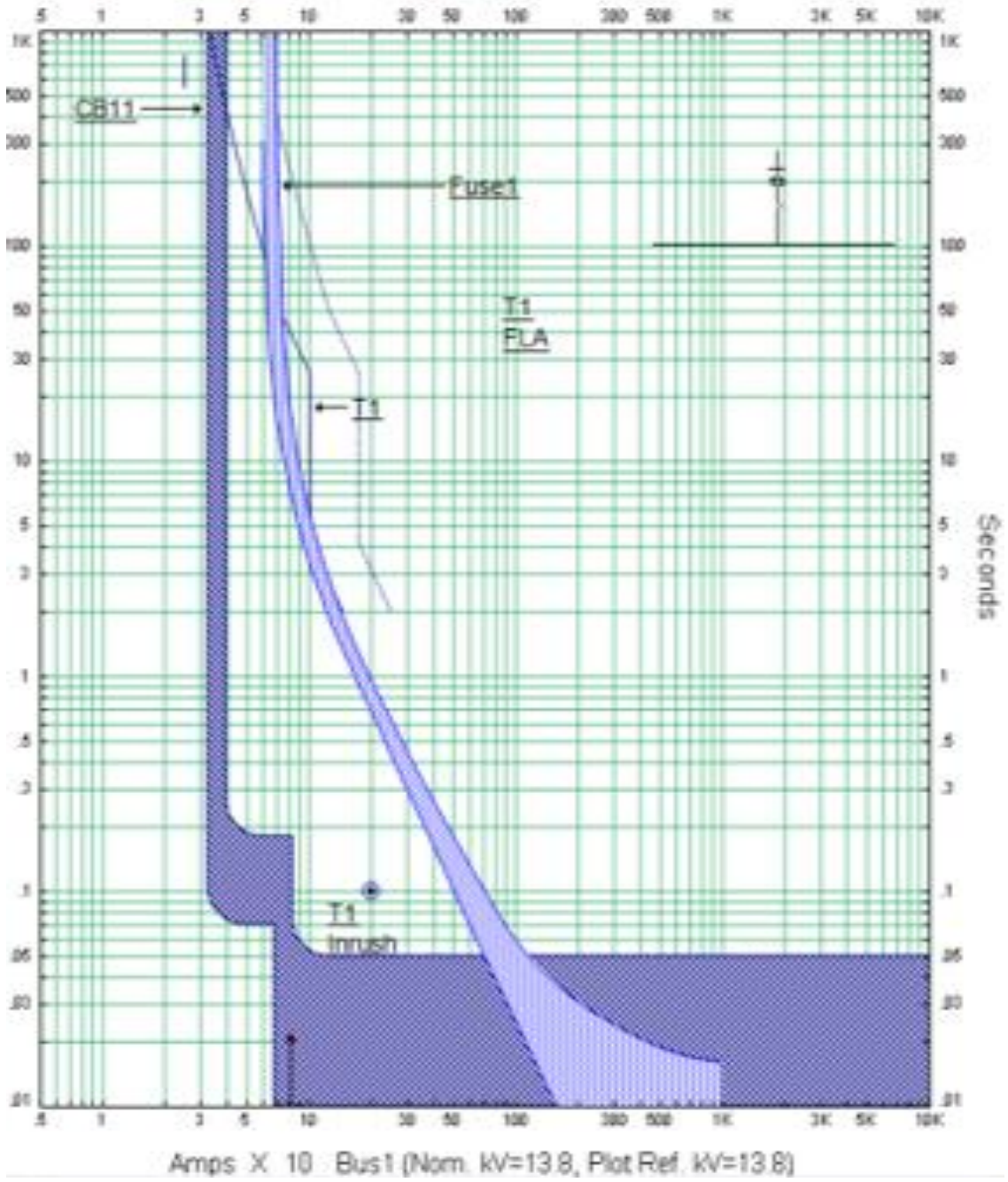

Figure 5-15 The response of the CB to the arcing current

Table 5-4 highlights the simulation results. 
Table 5-4 Simulation results for Bus 3

\begin{tabular}{|l|c|c|c|}
\hline & With CB & Without CB & Notes \\
\hline Available Fault Current & $16.76 \mathrm{KA}$ & $16.76 \mathrm{KA}$ & No change \\
\hline Working Distance & $24 \mathrm{inch}$ & $24 \mathrm{inch}$ & No change \\
\hline Arcing current & $5.94 \mathrm{KA}$ & $5.05 \mathrm{KA}$ & \pm No change \\
\hline Arc Flash Boundary AFB & $2.98 \mathrm{ft}$ & $599 \mathrm{ft}$ & Changed \\
\hline Incident Energy IE & $2.16 \mathrm{Cal} / \mathrm{cm} 2$ & $5340 \mathrm{Cal} / \mathrm{cm} 2$ & Changed \\
\hline Fault Clearing Time FCT & $0.18 \mathrm{sec}$ & $530 \mathrm{sec}$ & Changed \\
\hline PPE Level & 1 & 4 Dangerous & Changed \\
\hline
\end{tabular}

Note that the AFC and the arcing current at the MDP remain the same and the incident energy is reduced from 5340 to $2.16 \mathrm{Cal} / \mathrm{cm} 2$. Overall, this results in going from category 4 extremely dangerous to category 1.

Now if we consider variation of the voltage as $\pm 10 \%$, so the voltage may decrease from $208 \mathrm{~V}$ to $188 \mathrm{~V}$. This will reflect on the arcing current as per equation (4-4)

The simulation gives an incident energy of $7.3 \mathrm{Cal} / \mathrm{cm} 2 \mathrm{AFH}$ category 2 , instead of $2.15 \mathrm{Cal} / \mathrm{cm} 2$.

Now if we consider variation of the gap as $+8 \mathrm{~mm}$, so the gap may increase from $32 \mathrm{~mm}$ to $40 \mathrm{~mm}$. This will reflect on the arcing current as per equation (4-2)

This results in an incident energy of $7.29 \mathrm{Cal} / \mathrm{cm} 2 \mathrm{AFH}$ category 2, instead of $2.15 \mathrm{Cal} / \mathrm{cm} 2 \mathrm{Hazard}$ risk category 1.

\subsection{Install LVPCB instead of the fused disconnect mean before the MDP}

The other type of power system installation that exists in buildings is one which has the main panel with a main fused disconnecting switch at the service entrance. This is acceptable based on the installation standards and electric codes. However, the disconnecting mean must be accessible, 
[NEC 230]. Figure 5-16 shows a single line diagram (SLD) of a main distribution panel (MDP) protected and preceded by main fused disconnect switch.

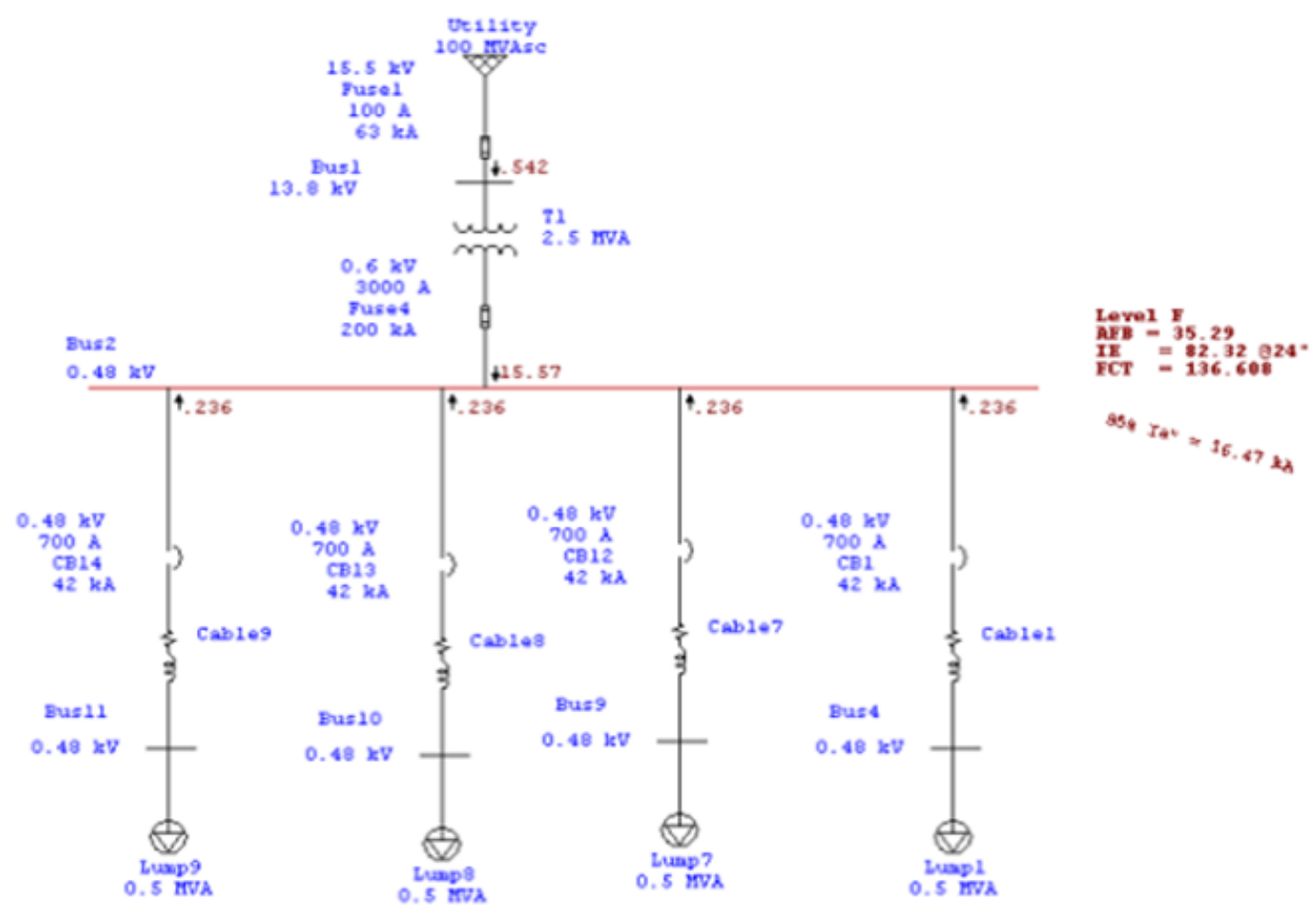

Figure 5-16 Power system with fused disconnect switch before the MDP

The incident energy is $82.32 \mathrm{Cal} / \mathrm{cm} 2$, which is very high and represents a dangerous arc flash hazard category. NFPA regulation does not allow the work to be performed under these conditions.

Figure 5-17 and Figure 5-18 show the TCC graph and the arc flash factors which helps analyze this situation in the time versus current domain. It is clear that the fuse curve interrupts the arcing current at more than 2 seconds, resulting in a dangerous arch flash hazard category. 


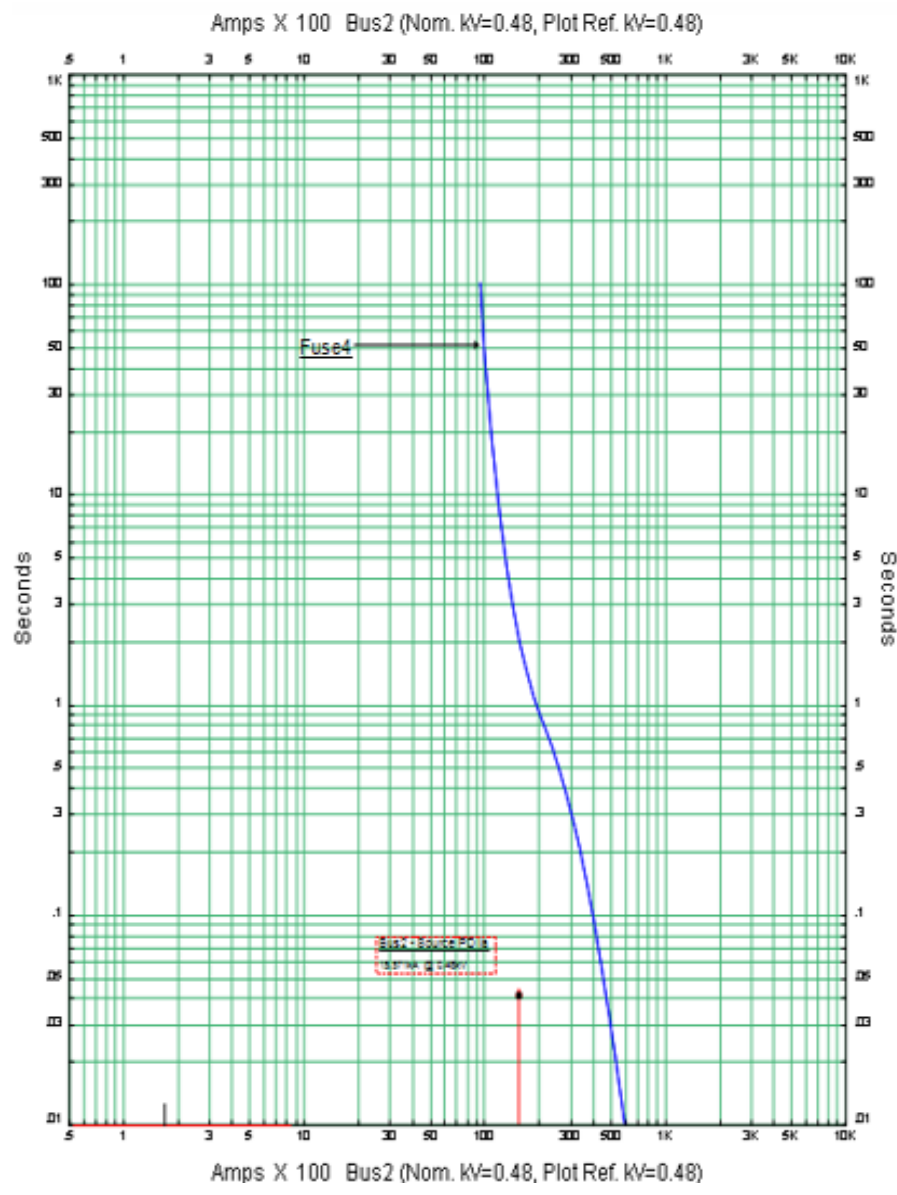

Figure 5-5-17 The response of the fuse to the arcing current 


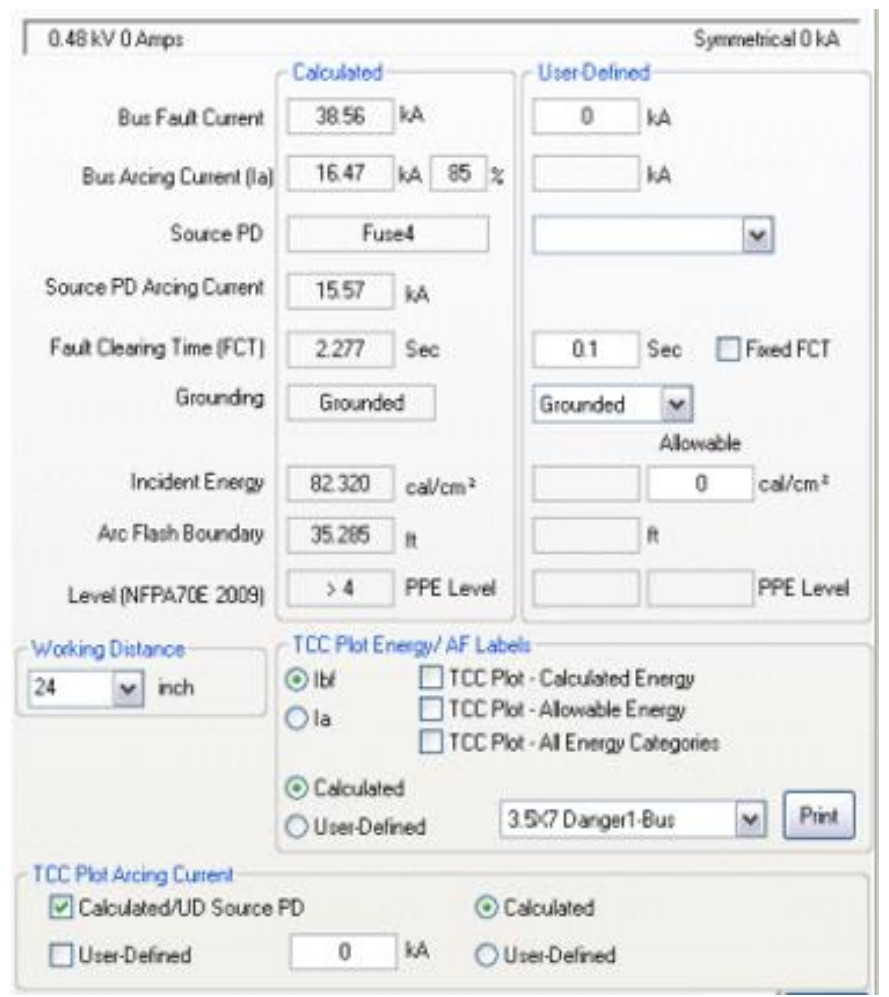

Figure 5-5-18 Arc flash factors affected by the response of the fuse ahead MDP

Figure 5-19 shows the same power system under one different condition. This time, we applied a low voltage power circuit breaker LVPCB in the place of the fused disconnect switch. 


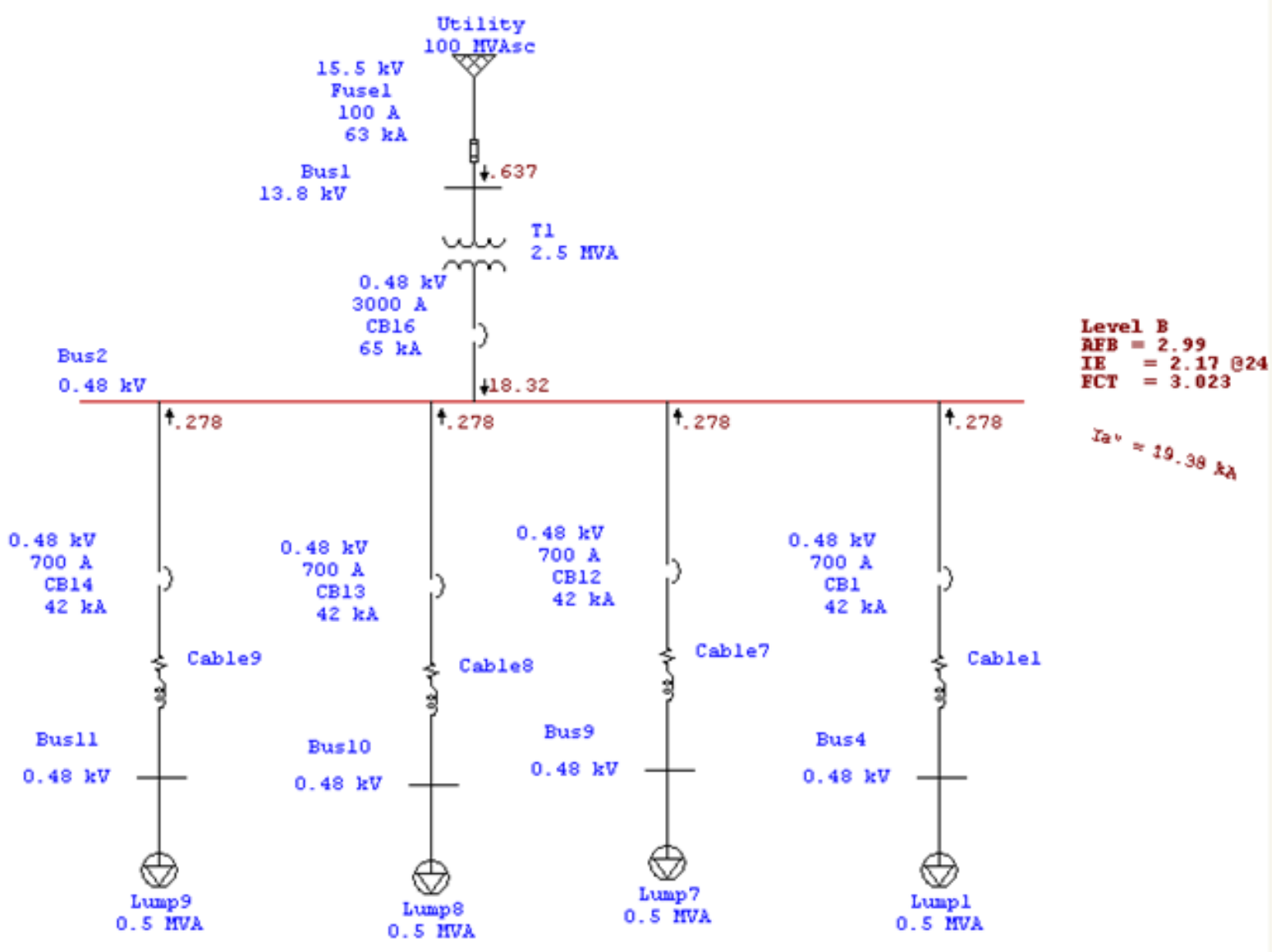

Figure 5-19 Power system with LVCB instead of fused disconnect switch before the MDP

Under this scenario, the incident energy decreases to $2.17 \mathrm{cal} / \mathrm{cm}^{2}$, representing low hazard risk category (category 0). Figure 5-20 and figure 5-21 show the TCC curve of the CB curve, and the arc flash factors demonstrating that the instantaneous setting interrupts the arcing current in a very short time (0.05 seconds) resulting in a hazard category 1. 


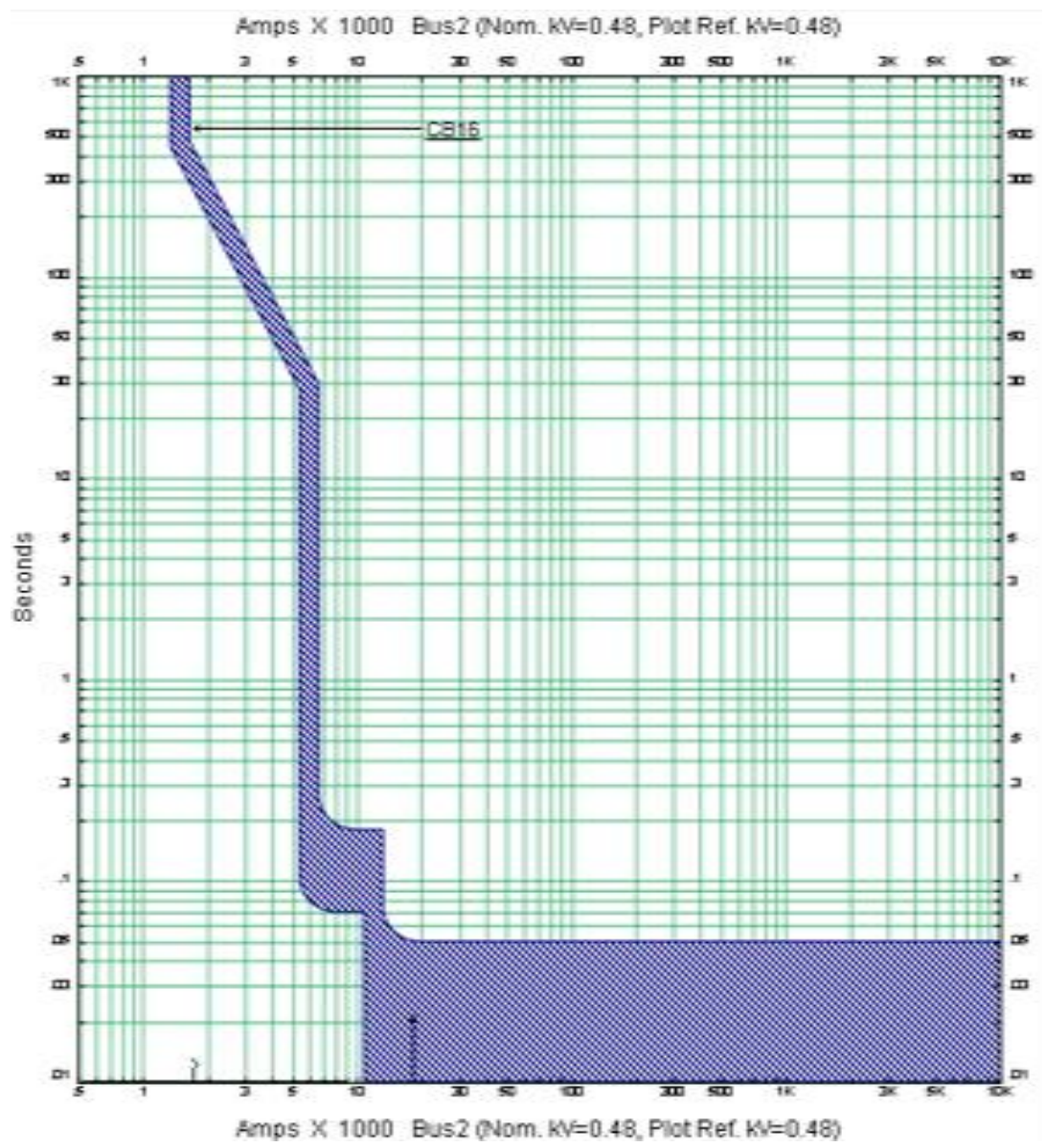

Figure 5-5-20 The response of the LVPCB to the arcing current 


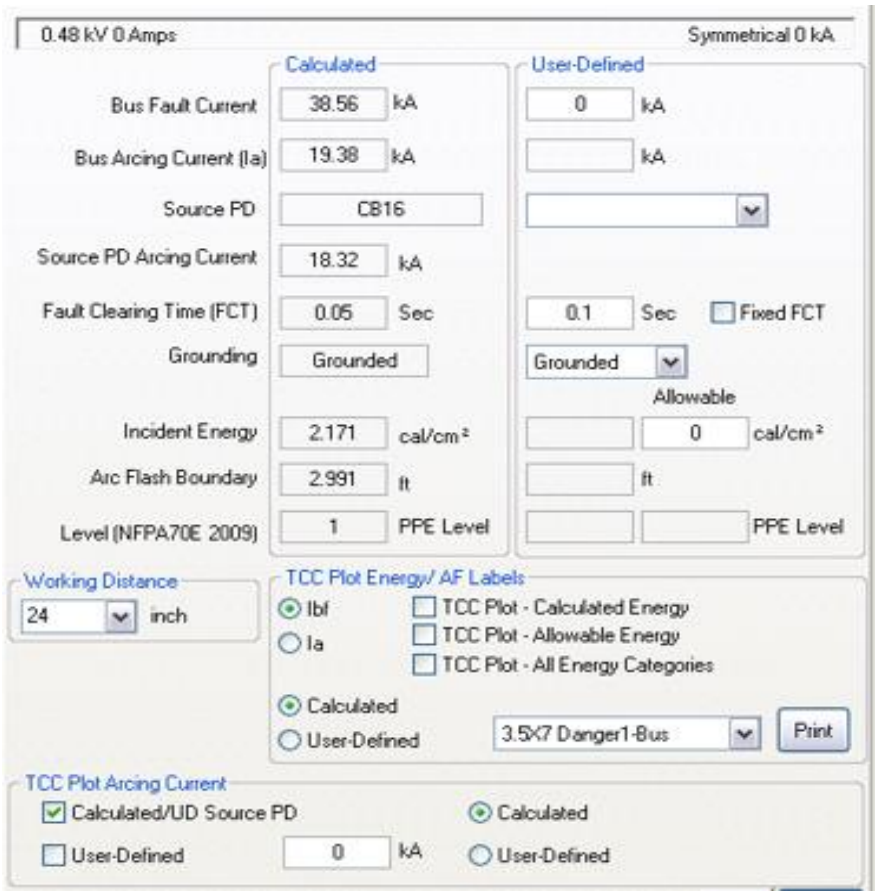

Figure 5-5-21 Arc flash factors affected by the response of the LVPCB ahead MDP

The results of the simulation for this system are displayed in Table 5-5

Table 5-5 Simulation results for Bus 2

\begin{tabular}{|l|c|c|c|}
\hline & CB & Fused disconnecting SW & Notes \\
\hline Available Fault Current & $38.56 \mathrm{KA}$ & $38.56 \mathrm{KA}$ & No change \\
\hline Working Distance & $24 \mathrm{inch}$ & $24 \mathrm{inch}$ & No change \\
\hline Arc Flash Boundary AFB & $3 \mathrm{ft}$ & $35.3 \mathrm{ft}$ & Changed \\
\hline Incident Energy IE & $2.16 \mathrm{Cal} / \mathrm{cm} 2$ & $82.3 \mathrm{Cal} / \mathrm{cm} 2$ & Changed \\
\hline Fault Clearing Time FCT & $0.05 \mathrm{sec}$ & $2.3 \mathrm{sec} \mathrm{sec}$ & Changed \\
\hline PPE Level & 1 & $>4$ Dangerous & Changed \\
\hline
\end{tabular}

Now if we consider variation of the voltage as $\pm 10 \%$, so the voltage may decrease from $480 \mathrm{~V}$ to $432 \mathrm{~V}$. This will reflect on the arcing current as per equation (4-4). The simulation gives an incident energy of $9.17 \mathrm{Cal} / \mathrm{cm} 2 \mathrm{AFH}$ category 3 .

Now if we consider variation of the gap as $+8 \mathrm{~mm}$, so the gap may increase from $32 \mathrm{~mm}$ to $40 \mathrm{~mm}$. This will reflect on the arcing current as per equation (4-2) 
This results in an incident energy of $9.16 \mathrm{Cal} / \mathrm{cm} 2 \mathrm{AFH}$ category 3 , instead of $2.17 \mathrm{Cal} / \mathrm{cm} 2 \mathrm{Hazard}$ risk category 1.

\subsection{Install (LVPCB) in front of the step down transformers rated above 125KVA}

Equipment/loads such as receptacles, lighting, services, heating, ventilating and air conditioning require $120 / 208 \mathrm{~V}$ in their operation. Due to this, we require transformers that are large enough to handle these loads. The arc flash hazard at low voltage transformers is critical since these transformers, along with the panels that are fed from them, are subjected to regular maintenance checkups. These transformers are generally fed from the main distribution panel (MDP) and they are protected by thermal magnetic circuit breakers in most of the power systems. Figure 5-22 shows a typical power system with step down transformer T2, which protected with a

thermal magnetic circuit breaker CB1. Due to the impedance of the transformer, we expect a lower fault current and arcing current at the secondary side of the transformer. 


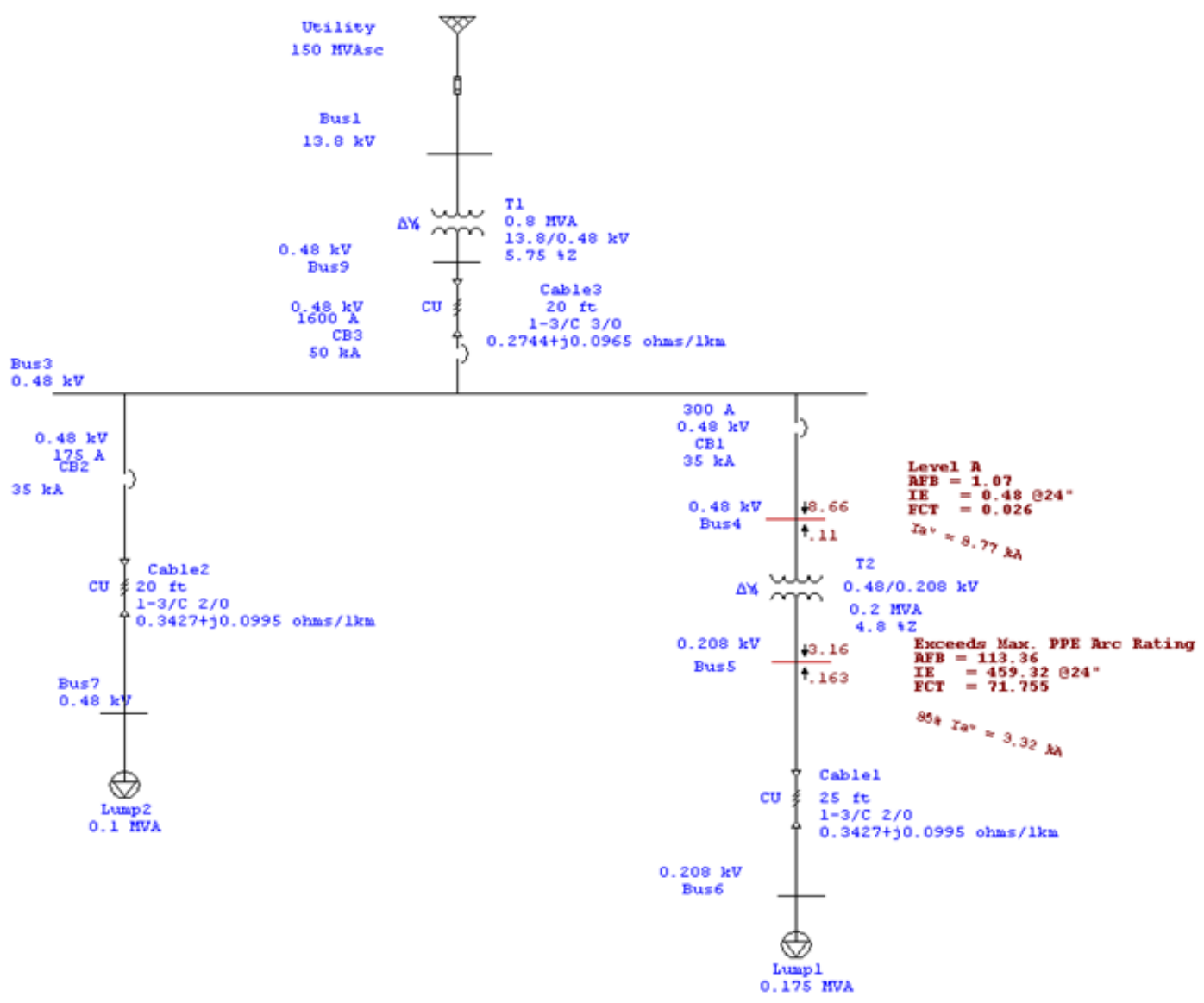

Figure 5-22 Power system with thermal magnetic CB before transformer

The arc flash simulation reveals the following results:

The AFC at both the primary and secondary sides of the transformer are $14.88 \mathrm{KA}$ and $9.06 \mathrm{KA}$ respectively. And from equation 3.1, the arcing current and the fault current are proportional with each other. Therefore, the arcing current at the secondary side of the transformer will be lower in value compared to the arcing current at the primary side. This will result in more time required for the circuit breaker to interrupt the arcing fault that occurs in the secondary side of the transformer. This will result in higher incident energy and a more dangerous hazard category.

This has been supported by the results from the arc flash simulation. See Figure 5-23 and Figure 5-24 for the results on Bus 4 and Bus 5 of the primary and secondary sides of the transformer respectively. 


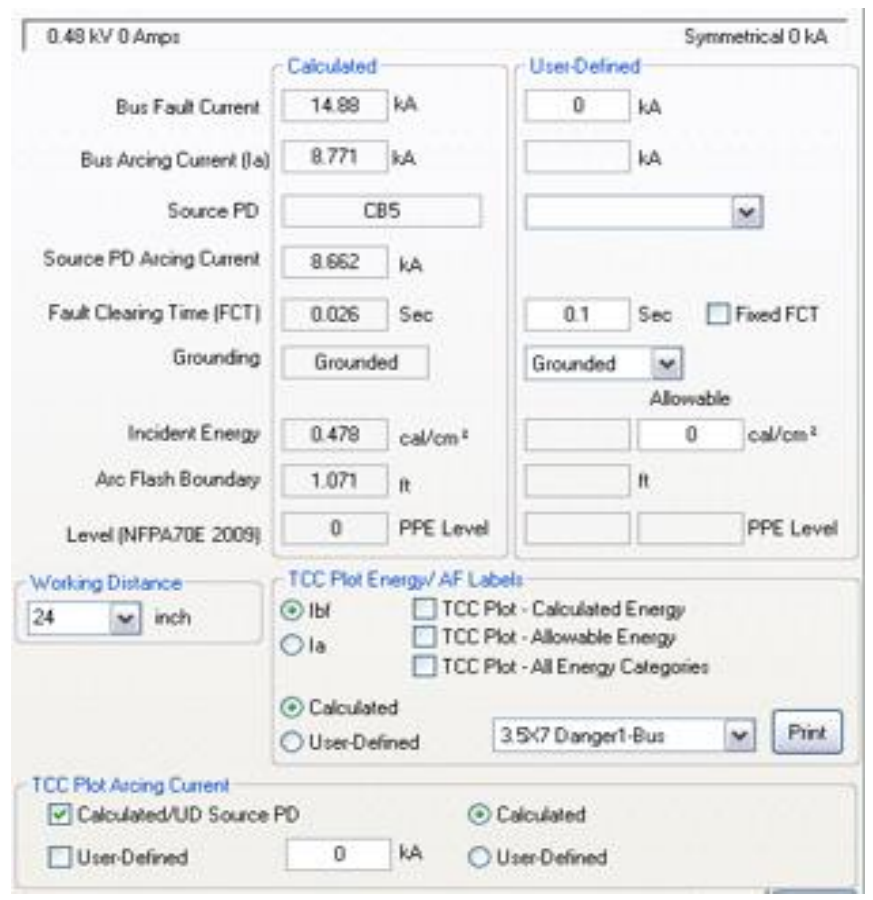

Figure 5-23 Arc flash factors at Bus 4 (Primary of Transformer T2)

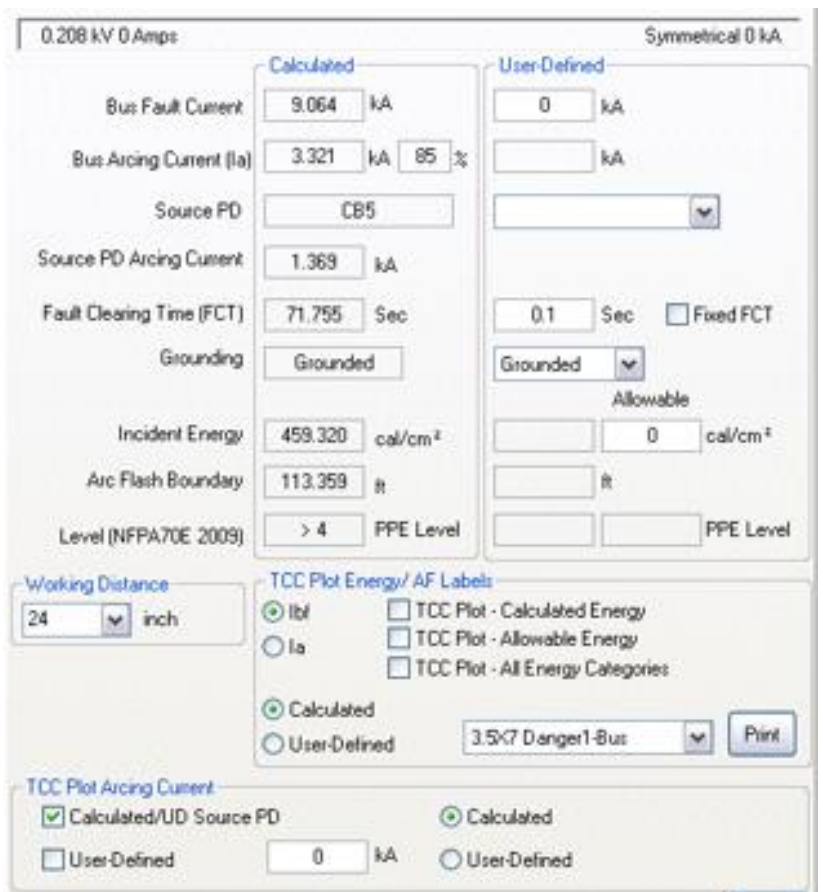

Figure 5-24 Arc flash factors at Bus 5 (Secondary of Transformer T2) 
The incident energy at the primary side is $0.478 \mathrm{Cal} / \mathrm{cm} 2$ while at the secondary side, it is 459 $\mathrm{Cal} / \mathrm{cm} 2$. Figure 5-25 highlights the time versus current domain results. The circuit breaker interrupts the arc current at the primary side of the transformer in 0.026 seconds, which is a relatively short time. Consequently, this results in lower incident energy, representing AFH category 0. Figure 5-25 shows also the delay in the interruption of the arcing current at the secondary side, resulting in a higher incident energy and AFH category 4.

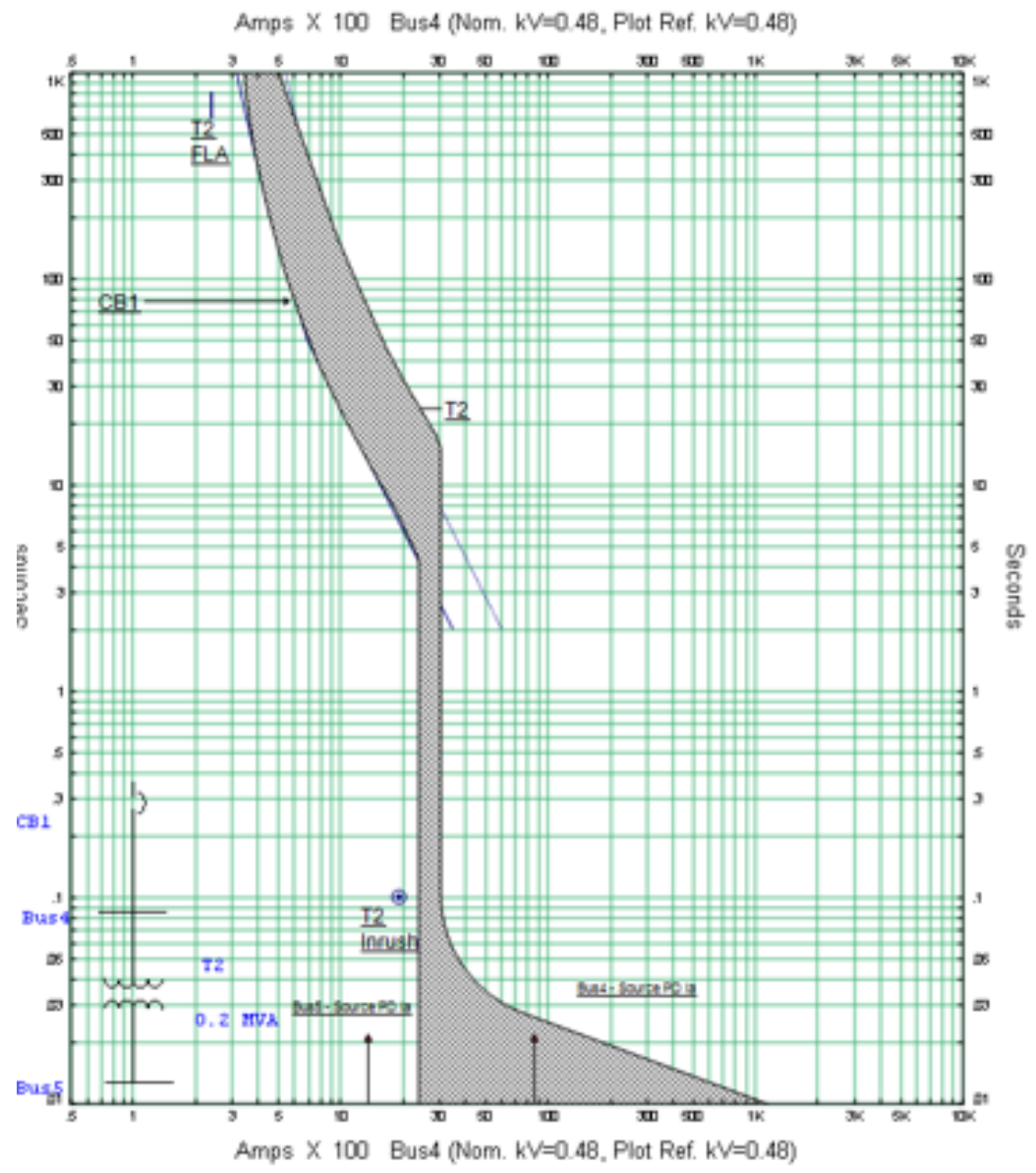

Figure 5-25 The response of the thermal CB1 to the arcing currents.

Now, let's apply a low voltage circuit breaker with adjustable LSI instead of the thermal circuit breaker. Figure 5-26 shows the simulation of the same power system with LSI CB. The results show that the AFC on both sides of the transformer, primary and secondary, are still the same, 
meaning that the arcing currents on both sides of the transformer have not been changed. However, the incident energy is reduced dramatically from $459 \mathrm{Cal} / \mathrm{cm} 2$ to $1.37 \mathrm{Cal} / \mathrm{cm} 2$ on the secondary side. This result reflects AFH category 1 on the secondary side of the transformer instead of 4, as was observed previously see figure 5-27.

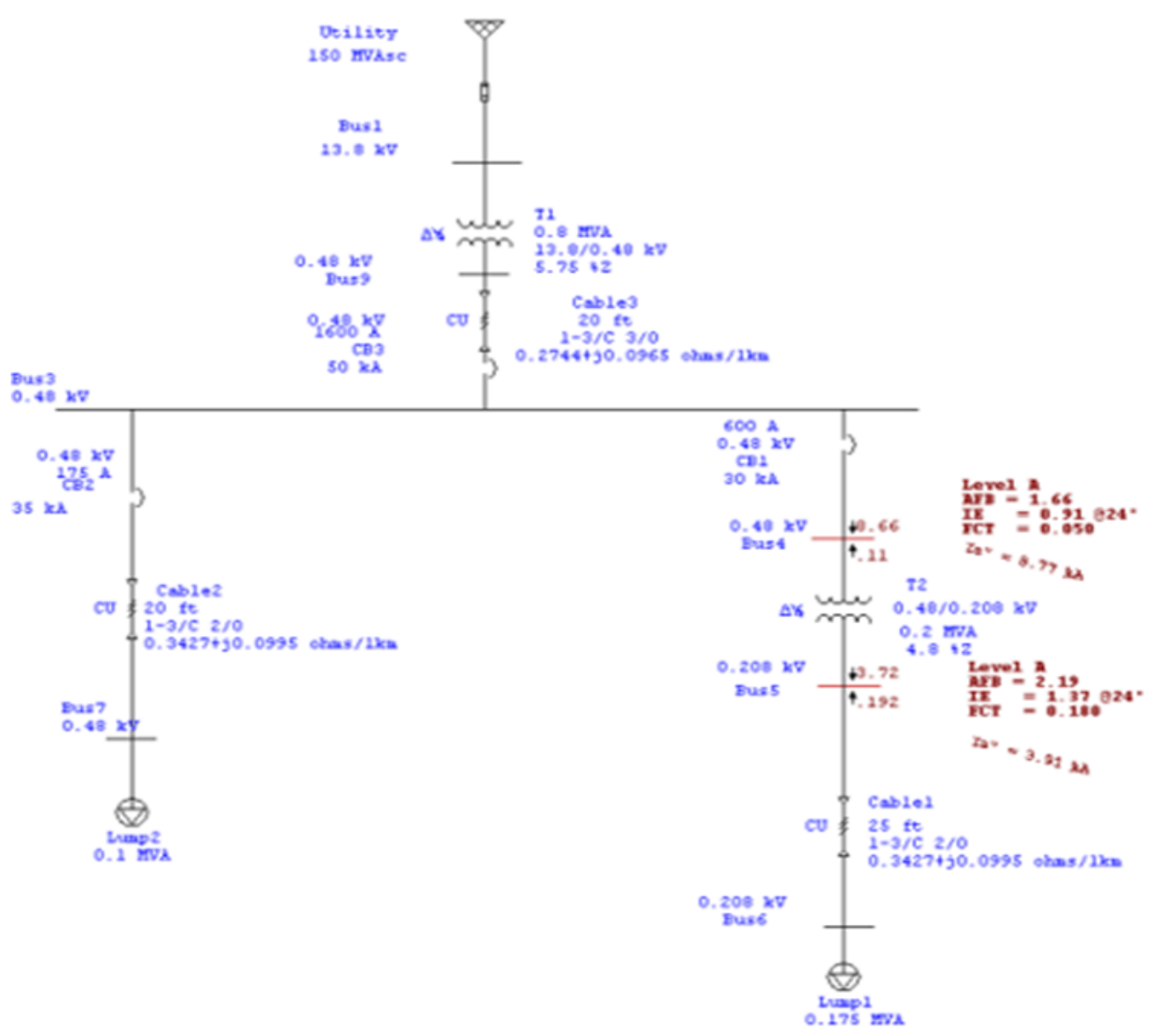

Figure 5-26 Power system with LSI CB before the transformer 


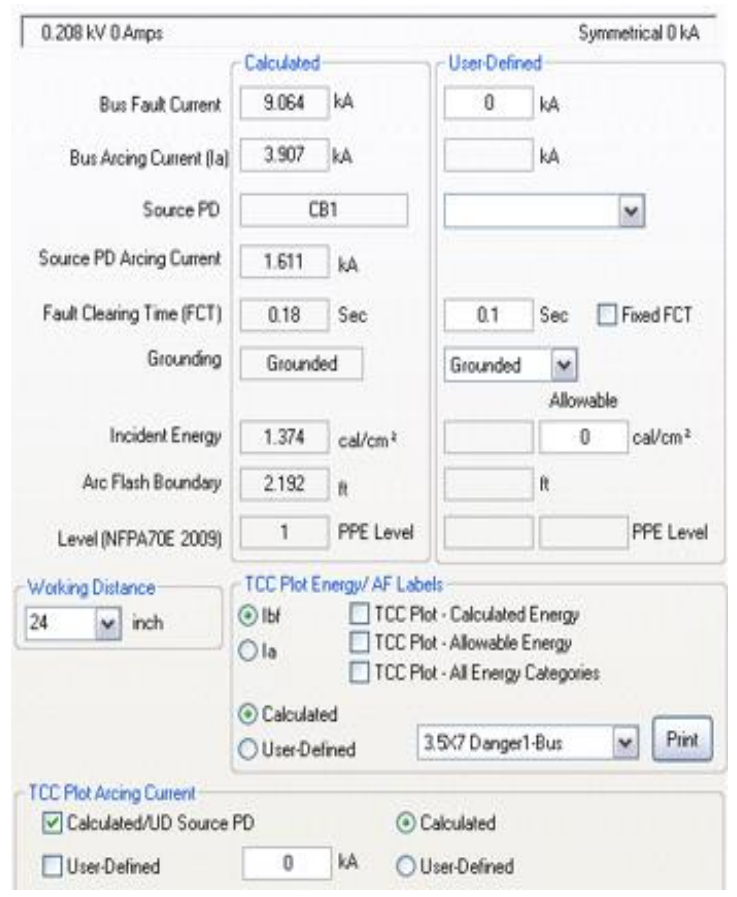

Figure 5-27 Arc flash factors at Bus 5 (Secondary of Transformer T2) using LSI CB

In Figure 5-28, the TCC shows the LSI circuit breaker and arcing current at the primary and secondary sides of the transformer. The lowering of the arcing current at the secondary side of the transformer brings it to the adjustable short time range of the LSI breaker. This results in a reduction of the arcing time, which will reduce the incident energy and the AFH risk category. 


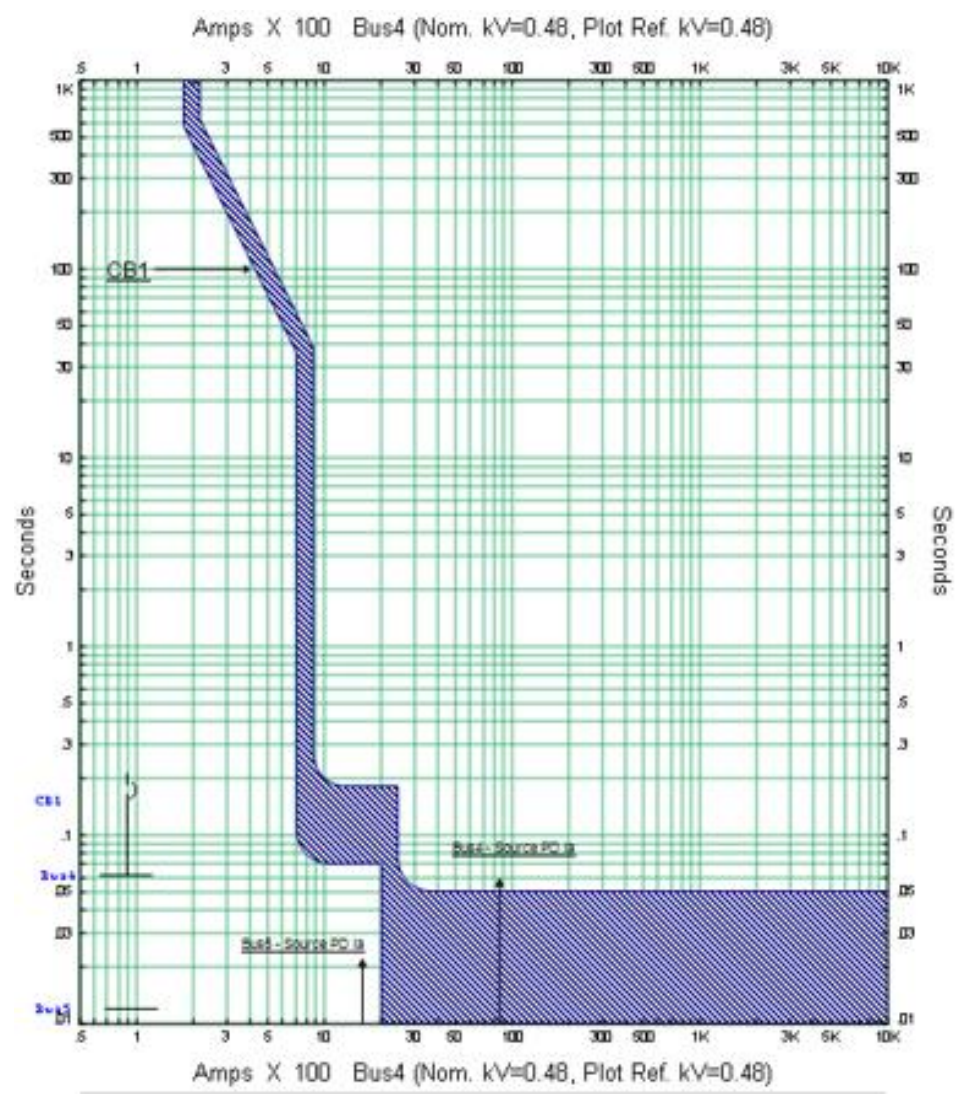

Figure 5-28 The response of the LSI CB to the arcing currents at primery and secondary of T2

Table 5-6 highlights the above results:

Table 5-6 Simulation results for Bus 4 and Bus 5.

\begin{tabular}{|c|l|c|c|}
\hline & & Mag - Thermal CB & LSI CB \\
\hline \multirow{4}{*}{ Bus 4 } & Arcing current & $8.77 \mathrm{KA}$ & $8.77 \mathrm{KA}$ \\
\cline { 2 - 4 } & Incident Energy & $0.478 \mathrm{Cal} / \mathrm{cm} 2$ & $0.915 \mathrm{Cal} / \mathrm{cm} 2$ \\
\cline { 2 - 4 } & Fault Clearing T & $0.026 \mathrm{sec}$ & $0.05 \mathrm{sec}$ \\
\cline { 2 - 4 } & PPE Level & 0 & 0 \\
\hline \multirow{4}{*}{ Bus 5 } & Arcing current & $3.32 \mathrm{KA}$ & 3.9 \\
\cline { 2 - 4 } & Incident Energy & $459 \mathrm{Cal} / \mathrm{cm} 2$ & 1.37 \\
\cline { 2 - 4 } & Fault Clearing & $72 \mathrm{sec}$ & 0.18 \\
\cline { 2 - 4 } & PPE Level & $>4$ & 1 \\
\hline
\end{tabular}


Now if we consider variation of the voltage as $\pm 10 \%$, so the voltage may decrease from $208 \mathrm{~V}$ to $188 \mathrm{~V}$. This will reflect on the arcing current as per equation (4-4)

The simulation gives an incident energy of $18.7 \mathrm{Cal} / \mathrm{cm} 2 \mathrm{AFH}$ category 3.

Now if we consider variation of the gap as $+8 \mathrm{~mm}$, so the gap may increase from $32 \mathrm{~mm}$ to $40 \mathrm{~mm}$. This will reflect on the arcing current as per equation (4-2)

This results in an incident energy of $18.7 \mathrm{Cal} / \mathrm{cm} 2 \mathrm{AFH}$ category 3 .

\subsection{Transformers large than 125 KVA should be replaced with smaller size transformers}

Since the 120/208V loads represent a substantial amount of electric power, we require large transformers to feed these loads. Typical power systems are shown in Figure 5-29.

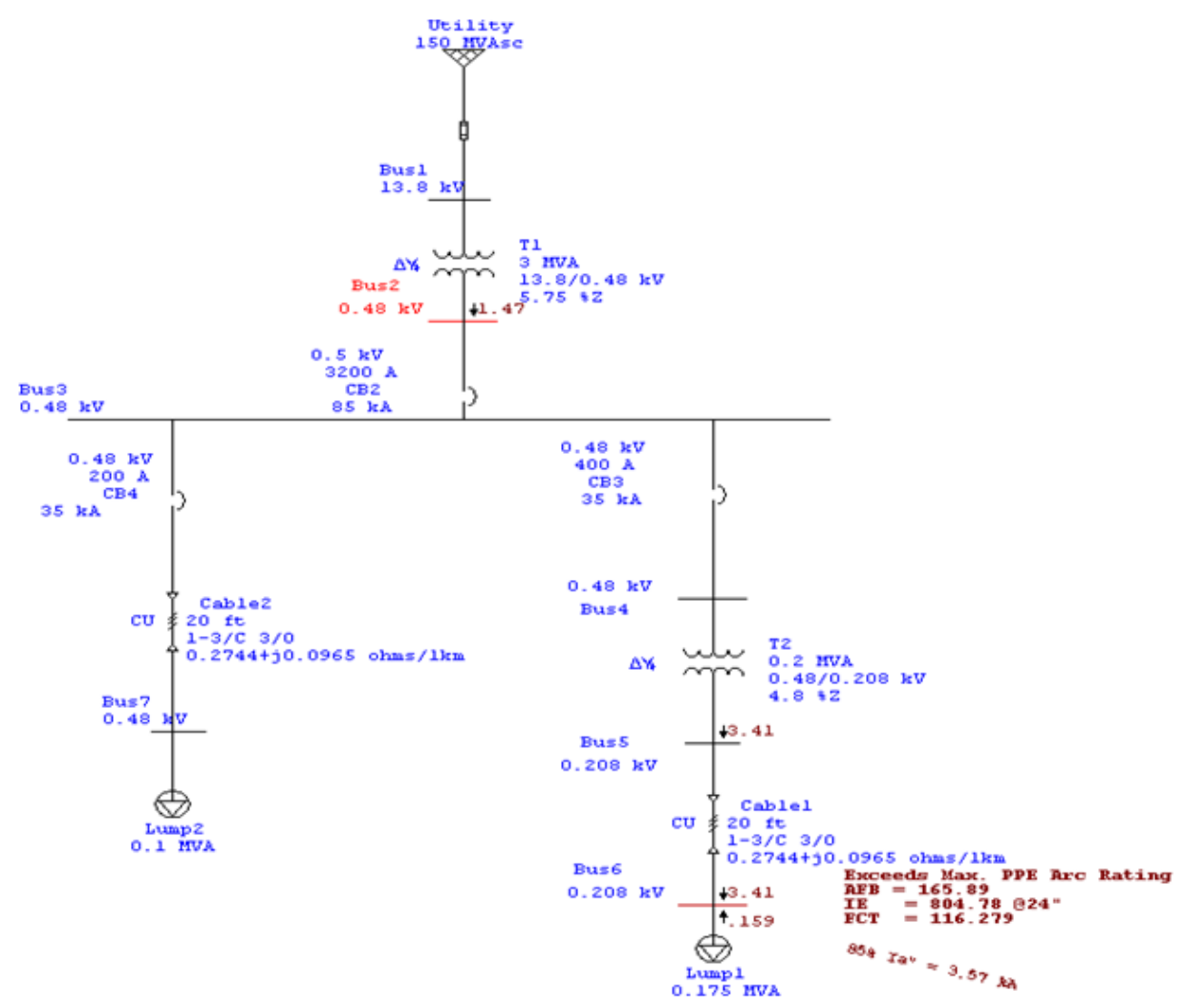

Figure 5-29 Power system with large Transformer T2 feeding 120/208 loads. 
The simulation of this power system is summarized in figure 5-30.

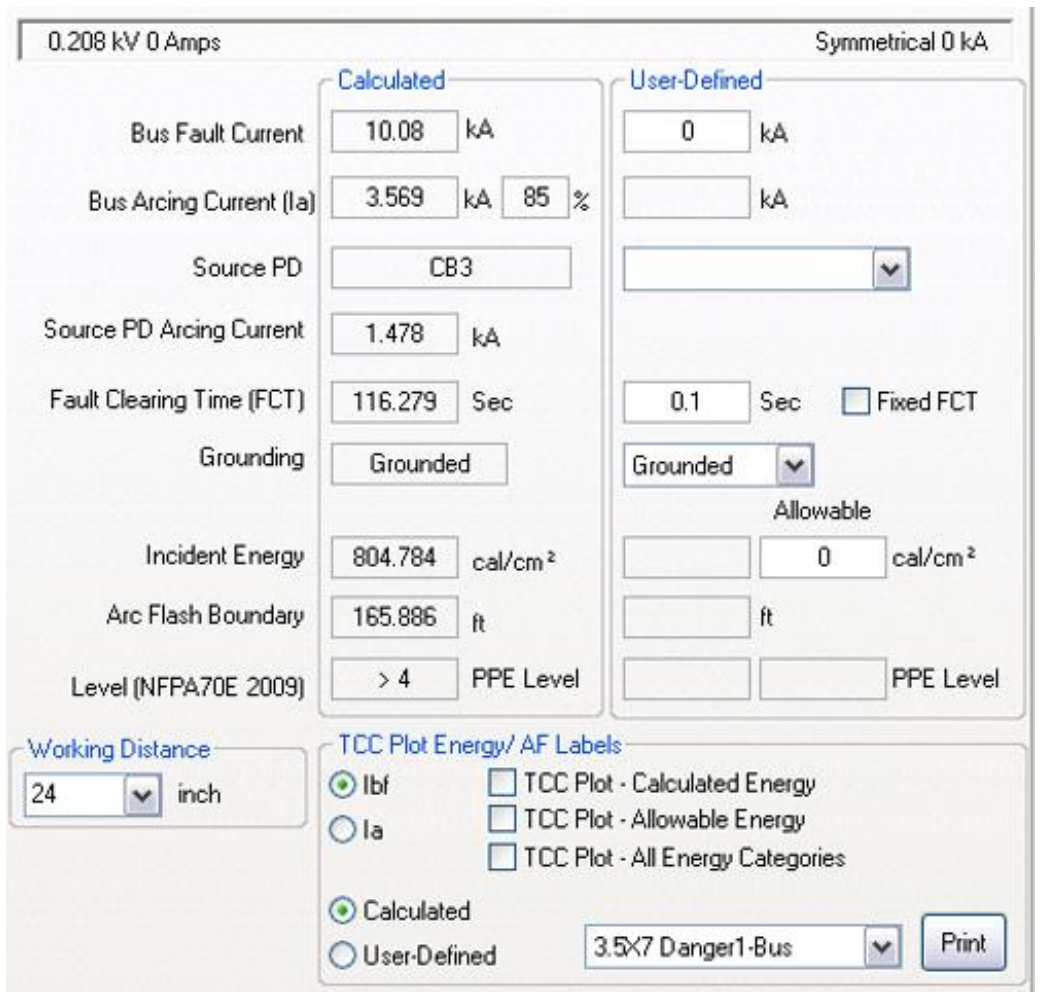

Figure 5-30 Arc flash factors at Bus 6

The incident energy at bus 6 is $804 \mathrm{Cal} / \mathrm{cm} 2$ which represents AFH category 4 (Dangerous). The TCC in Figure 5-31 shows the CB takes longer time to interrupt the arcing current, resulting in higher incident energy. 


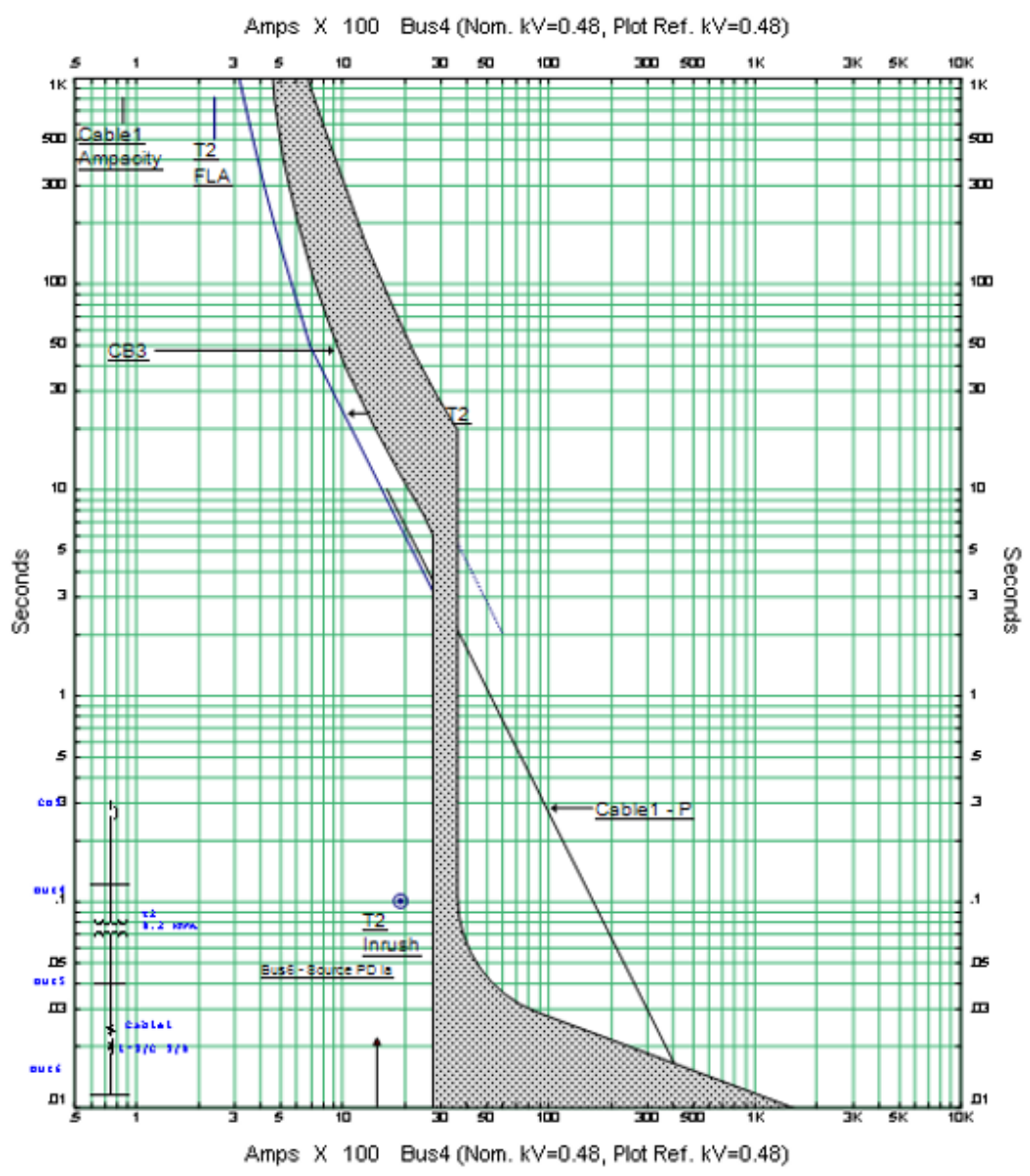

Figure 5-31 The response of CB3 to the arcing currents at Bus 6 .

We simulate a scenario that utilizes three small transformers that are 75KVA each, instead of one large transformer that is 0.2MVA (200KVA). The results are shown in Figure 5-32 below. 


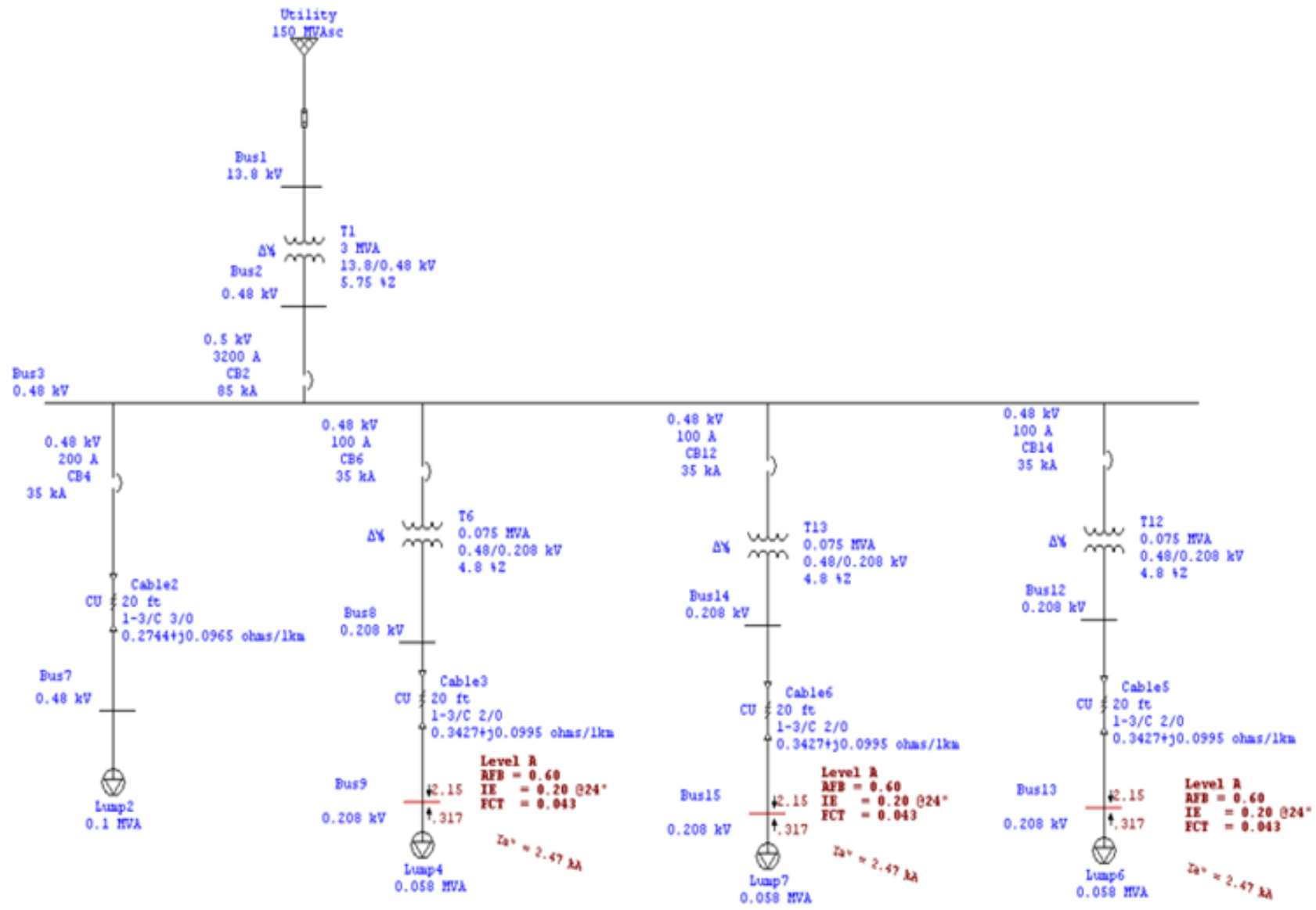

Figure 5-32 Power system with small size Transformers (T6, T13, and T12) instead of T2 in 5-29

The simulation of this power system is summarized in Figure 5-33 


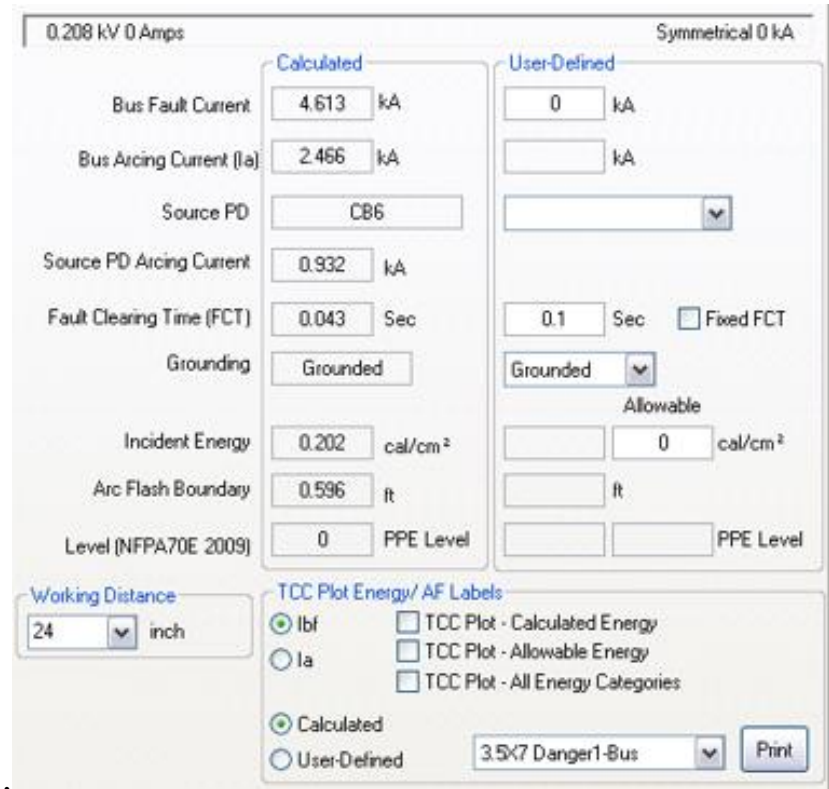

Figure 5-33 Arc flash factors at Bus 9, Bus 15 and Bus 13.

It is clear that the arcing current is reduced because of the increased impedance of the small size of transformers and cables. Therefore, applying small circuit breakers will be sufficient to interrupt the arcing current at small values. Figure 5-34 shows the TCC for such circuit breakers and the time required for interrupting the arc current. It is clear that the interrupting time is less than 0.05 sec, which results in incident energy less than $2 \mathrm{Cal} / \mathrm{cm} 2$ and AFH category 0. 


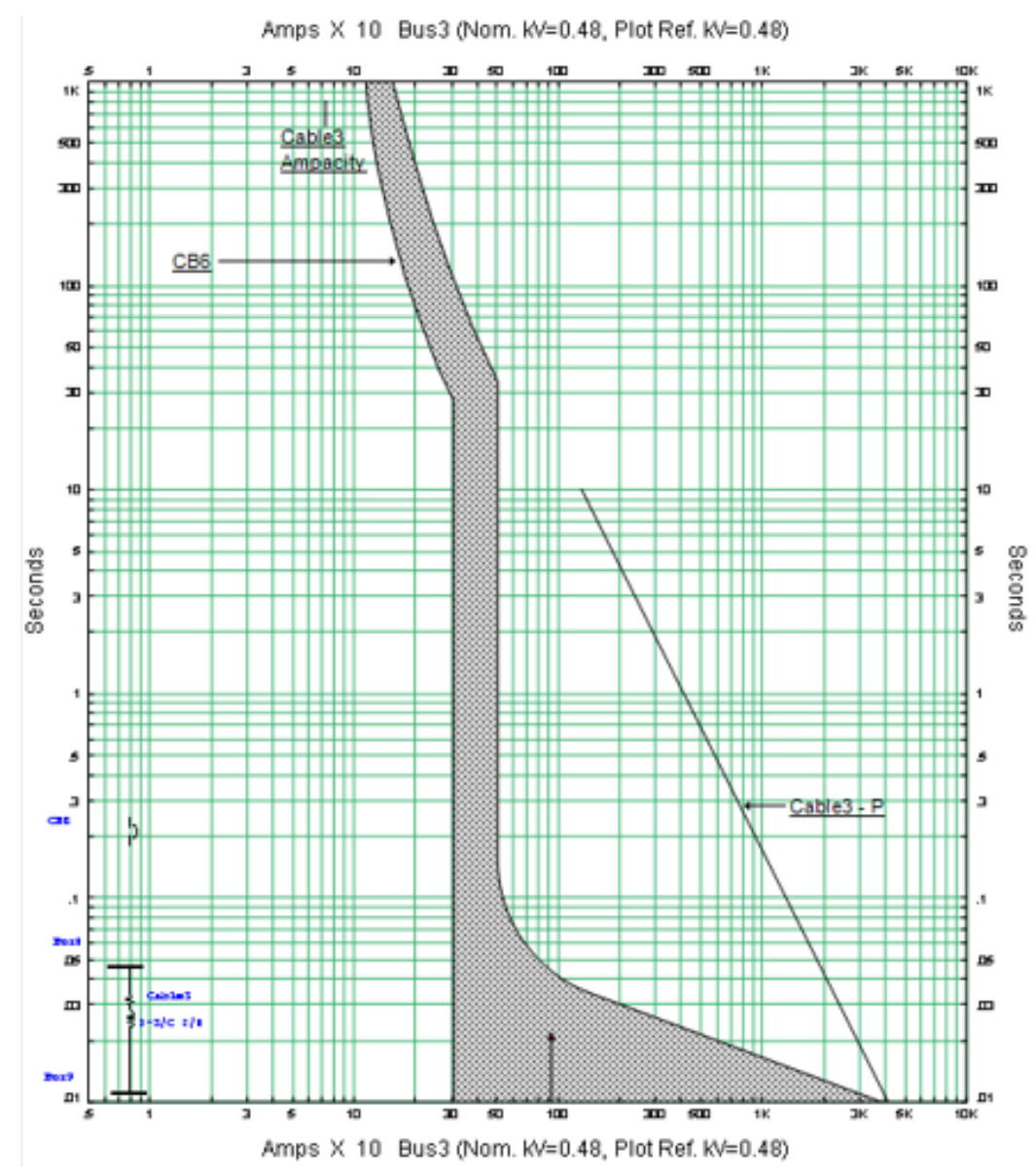

Figure 5-34 The response of CB's 6,12 and 14 to the arcing currents at Bus's 9, 15 and 13.

Table 5-7 summarize the simulation results in both case when we use large transformer and when we use small one.

Table 5-7 Simulation results for Bus 6 and Bus 9

\begin{tabular}{|l|c|c|}
\hline & Using 75KVA TR & Using 200KVA TR \\
\hline Working Distance & $24 \mathrm{inch}$ & $24 \mathrm{inch}$ \\
\hline Incident Energy IE & $0.202 \mathrm{Cal} / \mathrm{cm} 2$ & $804.7 \mathrm{Cal} / \mathrm{cm} 2$ \\
\hline Fault Clearing Time FCT & $0.043 \mathrm{sec}$ & $>2 \mathrm{sec} \mathrm{sec}$ \\
\hline PPE Level & 0 & $>4$ Dangerous \\
\hline
\end{tabular}


Now if we consider variation of the voltage as $\pm 10 \%$, so the voltage may decrease from $208 \mathrm{~V}$ to $188 \mathrm{~V}$. This will reflect on the arcing current as per equation (4-4)

The simulation gives the same result of the incident energy of $0.202 \mathrm{Cal} / \mathrm{cm} 2 \mathrm{AFH}$ category 1 .

Now if we consider variation of the gap as $+8 \mathrm{~mm}$, so the gap may increase from $32 \mathrm{~mm}$ to $40 \mathrm{~mm}$. This will reflect on the arcing current as per equation (4-2)

This results in an incident energy of $0.2 \mathrm{Cal} / \mathrm{cm} 2 \mathrm{AFH}$ category 1.

\subsection{Summary}

In this Chapter, the simulation, results, and observation of the thesis work are reported. Six benchmark cases are selected from literature in order to show the impact of parameter uncertainty on arc flash hazard mitigation. The six cases symbolize different techniques to reduce the hazard of arc flashes without considering parameter variations. Simulations, which clarify the effects of parameter variations on such previously proposed techniques, are carried out. Different system layouts are selected from standard topologies to experiment the simulations. Results show that parameter uncertainty may affect incident energy values as well as the risk category of a given arc flash case. Consequently, care must be taken when arc flash calculations are performed as to the possible changes in results caused by parameter variability, in particular gap length and system voltage, as shown by the results of this Chapter. 


\section{Chapter Six - Conclusions and Future Work}

\subsection{Thesis Summary}

In this work, a thorough study of arc flash and short circuit was initially performed. Different components of power system protection were investigated, and different design implementations of such components and methods were researched with an examination of their benefits. Moreover, different factors and phenomena affecting the arc flash energy estimation, such voltage, gap between electrodes, clearing time, etc. were investigated.

Additionally, in Chapter 4 a new method of arc flash calculation was proposed which takes into consideration the variation in some parameters such as voltage. This is useful for evaluating more adequate arcing current and the arc flash incident energy. Furthermore, in Chapter 5 different power system topology situations and know techniques were built using Electric Transient and Analysis Program (ETAP), the simulation is carried out with and without the proposed variations. The results of which showed the more accurate calculation of such considerations.

\subsection{Summary of Contributions}

- Proposed voltage variation to be used and to be taken into consideration when we calculate the arc current and the incident energy associated.

- Variation in voltage and gap between electrodes may lead to higher incident energy bigger than the estimated one. The bigger value of incident energy should be used to get the maximum risk safety.

- Variation in voltage and gap between electrodes should be taken into consideration in the evaluation process of arc flash mitigation. 


\subsection{Future Work}

Although the consideration of the variation in voltage and gaps between electrodes showed the difference in incident energy calculation, there are other factors that need to be addressed and considered such as humidity degree, ambient temperature and pressure. Therefore, improved models will produce better results of estimated incident energy which provide better protection to personal dealing with power distribution systems. 


\section{References}

[1] R. B. Campbell and D. A. Dini, "Occupational injuries from electrical shock and arc flash events," Technical Report, The Fire Protection Research Foundation, Quincy, MA, USA, 2015.

[2] M. Cooper and T. Price, "Electrical and lightning injuries," Emergency Medicine Clinic of North America, vol. 12, no. 2, 2002, pp. 489-501.

[3] J. Noble, M. Gomez and J. Fish, "Quality of life and return to work following electrical burns," Burns, vol. 32, no. 2, 2006, pp. 259-164.

[4] C. T. Latzo, "Approach to arc flash hazard mitigation in 600 volt power systems," $P h D$ Dissertation, University of south Florida, Los Angles, 2011.

[5] H. L. Floyd, D. R. Doan, C. T. Wu, and S. L. Lovasic, "Arc flash hazards and electrical safety program implementation," Proc. Industry Applications Conference, vol. 3, 2005, pp. 1919-1923.

[6] K. Heid, T. E. Neal, D. Roberts, and S. Wilson, "Why are NFPA 70E and CSA Z462 different?," Proc. IEEE-IAS Electrical Safety Workshop, 2012, pp. 1-7.

[7] Teamsters Canada Rail Conference, "What is Bill C45?" available online at http://www.teamstersrail.ca/TCRC_BillC45_Westray.htm

[8] G. D. Gregory, I. Lyttle, and C. M. Wellman, "Arc flash calculations in systems protected by low-voltage circuit breakers," IEEE Trans. Industry Applications, vol. 39, no. 4, 2003, pp. 1193-1199.

[9] A. Koumbourlis, "Electric Injuries," Critical Care Medicine, vol. 30, no. 11, 2002, pp. 424430.

[10] R. C. Lee, "Biophysical injury mechanism in electrical shock victims," Annual Review Of Biomedical Engineering," Proc. Annual International Conference of the IEEE Engineering Medicine and Biology Society, 1990, pp. 1502-1504.

[11] R. H. Lee, "The other electrical hazard: Electric arc blast burns," IEEE Trans. Industry Applications, vol. 18, no. 3, 1982, pp. 246-251.

[12] R. H. Lee, "Presures developed by arcs," IEEE Trans. Industry Applications, vol. 23, no. 4, 1987, pp. 760-763. 
[13] R. L. Doughty, E. N. Thomas, and H. L. Floyd, "Predicting incident energy to better manage the electric arc hazard on $600 \mathrm{~V}$ power distribution systems," Proc. IEEE Industry Application Society Annual Petroleum and Chemical Industry Conference, 1998, pp. 329346.

[14] R. Jones, D. Liggett, M. Capelli-Schellpfeffer, T. Macalady, L. Saunders, R. Downey, L. Mc-Clung, A. Smith, S. Jamil, and V. Saporita, "Staged tests to increase awareness of arcflash hazards in electrical equipment," IEEE Trans. Industry Applications, vol. 36, no. 2, 2000, pp. 659-667.

[15] T. Gammon and ,. J. Matthews, "IEEE 1584-2002, incident energy factors and simple $480 \mathrm{~V}$ incident energy equations," IEEE Industry Application Magazine, vol. 11, no. 1, 2005, pp. 23-31.

[16] National Electric Code, National Fire Protection Association (NFPA), 2008.

[17] J. J. Burke, Power Distribution Engineering: Fundamentals and Applications, CRC Press, 1994.

[18] C. D. Richard, The Electrical Engineering HandBook, CRC Press, 1993.

[19] IEEE Recommended Practice for Electrical Power Distribution for Industrial Plants, IEEE Std. 141 (Red Book), 2001.

[20] IEEE Guide for arc flash hazard calculation, IEEE Std. 1584, 2002.

[21] H. S. David, Electrical Systems in Buildings, New York: Dalmar Publishers Inc, 1988.

[22] G. J. Duncan, M. S. Sarma and T. J. Overbye, Power System Analysis and Design, Cengage Learning, 2012.

[23] C. Christopoulos and A. wright, Electrical Power System Protection, Springer, 1999.

[24] IEEE Recommended practice for applying low voltage circuit breakers used in industrial and commercial power systems (IEEE Blue Book), IEEE Std. 1015, 2005.

[25] D. D. Roybal, "Circuit breaker interrupting capacity and short time current rating," Proc. Pulp and Paper Industry Technical Conference, 2004, pp. 130-134.

[26] IEEE standard for low voltage AC power circuit breakers used in enclosures, IEEE Std. C37, 2015. 
[27] C. W. Kimblin and R. W. Long, "Low voltage power circuit breakers and molded case circuit breakers - a comparision of test requirements," Proc. IEEE Industrial and Commercial Power Systems Technical Conference, 1999, pp. 1-7.

[28] C. H. Flurscheim, Power Circuit Breaker Theory and Design, IEE Power Engineering Series 1, 1982.

[29] IEEE Recommended Practice for Grounding of Industrial and Commercial Power Systems (Green Book), IEEE Std. 142, 2001.

[30] P. G. Newberry, "Fuse technology progress to date," Electronic and Power Magazine, Vol. 22, No. 2, 1976, pp. 91-93.

[31] K. Lane, "Beware of simplistic fault current calculations," Electrical Construction and Maintenance, 2004. Available online at: http://ecmweb.com/content/beware-simplisticfault-current-calculations

[32] IEEE Recommended Practice for Protection and Coordination of Industrial and Commercial Power Systems (Buff Book), IEEE Std. 242, 2001.

[33] G. Parise, L. Martirano, U. Grasselli, and L. Benetti, "The arc-fault circuit protection,” Proc. IEEE Industry Applications Conference, Vol. 3, 2001, pp. 1817-1822.

[34] E. Ralph, Industrial Power Distribution, $1^{\text {st }}$ Edition, New Jersey: Printice hall, 2002.

[35] N. Tleis, Power System Modelling and Fault Analysis: Theory and Practice, Newnes, 2007.

[36] UL Standard for Low-Voltage AC and DC Power Circuit Breakers Used in Enclosures, UL 1066, 2012.

[37] IEEE Standard for Trip Systems for Low-Voltage AC and General Purpose DC Power Circuit Breakers, IEEE Std. C37.20.4, 2013.

[38] D. D. Roybal, "Standards and ratings for the application of molded case, insulated case, and power circuit breakers," Proc. IEEE Pulp and Paper Industry Technical Conference, 19-23 June, 2000, pp. 195-204. 
[39] C. S. Pierre, D. Castor, C. Davis, R. Luo, and S. Shrestha, "Practical solution guide to arc flash hazards," EasyPower, 2013. Available online at: https://www.nttinc.com/wpcontent/uploads/2015/01/PracSolGuideArcHaz-LR1.pdf

[40] T. H. Wallace, A. M. Graham, and H. Michael, "Beyond the calculations: Life after arc flash analysis," Proc. IEEE Pulp and Paper Industry Technical Conference, 24-28 June 2007, pp. 250-256.

[41] I. Catherine, U. Kerssebaum, H. Eichinger, and D. Daniel, " Mitigating personnel exposure to the arc flash hazard," Proc. Conference of the European Petroleum and Chemical Industry Committee (PCIC Europe), 26-28 May 2009, pp. 146-152.

[42] C. Inshaw and R. A. Wilson, "Arc flash hazard analysis and mitigation," Proc. IEEE Annual Conference for Protective Relay Engineers, 5-7 April 2005, pp. 145-157.

[43] D. R. Doan, J. Slivka, and C. Bohrer, "A summary of arc flash hazard assessments and safety improvements," Proc. IEEE Petrolum and Chemical Industry Technical Conference, 2007, pp. 1-7. 


\section{APPENDIX A: IEEE Data}

\begin{tabular}{|c|c|c|c|c|c|c|c|c|c|c|c|c|c|c|c|c|c|}
\hline $\begin{array}{c}\text { Open } \\
\text { Circuit } \\
\text { Voltage ph- } \\
\text { ph (KV) }\end{array}$ & $\begin{array}{c}\text { System } \\
\text { Grounded- } \\
-Y, N \\
\text { HRG }\end{array}$ & $\begin{array}{l}\text { Bolted } \\
\text { fault } \\
\text { current } \\
\text { (KA) }\end{array}$ & XRR Ratio & $\begin{array}{c}\text { Electrode } \\
\text { material } \\
S S, A L, \\
C H, C S\end{array}$ & $\begin{array}{c}\text { Gap } \\
\text { between } \\
\text { electrodes } \\
\text { (mm) }\end{array}$ & $\begin{array}{c}\text { Gap } \\
\text { electrodes } \\
\text { to box (mm) }\end{array}$ & $\begin{array}{c}\text { Distance } \\
\text { from arc to } \\
\text { calorimeters } \\
(\mathrm{mm})\end{array}$ & $\begin{array}{l}\text { S Arc Duration } \\
\text { (msec) }\end{array}$ & $\begin{array}{c}\text { Box } \\
\text { wioth + } \\
\text { height2 } \\
(\mathrm{mm})\end{array}$ & $\begin{array}{c}\text { Box } \\
\text { depth } \\
(\mathrm{mm})\end{array}$ & $\begin{array}{c}\text { No. of } \\
\text { phases }\end{array}$ & $\begin{array}{c}\text { Electrode } \\
\text { configuration } \\
\text { (Parallel or } \\
\text { Inline) }\end{array}$ & $\begin{array}{l}\text { Arc } \\
\text { Current } \\
\text { (KA) }\end{array}$ & $\begin{array}{c}\text { Arc } \\
\text { Voltage } \\
L-L(K V)\end{array}$ & $\begin{array}{l}\text { Arc energy } \\
(\mathrm{k})\end{array}$ & $\begin{array}{l}\text { Incident } \\
\text { energy, the } \\
\text { mean of } 7 \\
\text { calorimeters } \\
(\text { callcm²) }\end{array}$ & $\begin{array}{l}\text { Incident } \\
\text { energy, the } \\
\text { max off } \\
\text { calorimeters } \\
\text { (call/cm²) }\end{array}$ \\
\hline 0.610 & $N$ & 36.250 & & $\mathrm{CH}$ & 31.800 & 10000 & 600 & 100 & 10000 & 10000 & 3 & $D$ & 19.930 & 0.323 & 1296.300 & & 1.20 \\
\hline 0.610 & $N$ & 36.250 & & $\mathrm{CH}$ & 50.800 & 10000 & 600 & 100 & 10000 & 10000 & 3 & Della & 14.120 & 0.338 & 879.100 & & 1.16 \\
\hline 0.610 & $\mathrm{~N}$ & 36.250 & & $\mathrm{CH}$ & 19.100 & 10000 & 600 & 100 & 10000 & 10000 & 3 & Parallel & 25.520 & 0.248 & 1303.600 & & 2.03 \\
\hline 0.610 & $\mathrm{~N}$ & 36.250 & & $\mathrm{CH}$ & 25.400 & 10000 & 600 & 100 & 10000 & 10000 & 3 & Parallel & 24.230 & 0.268 & 1367.600 & & 1.90 \\
\hline 0.610 & $\mathrm{~N}$ & 36.250 & & $\mathrm{CH}$ & 31.800 & 10000 & 600 & 100 & 10000 & 10000 & 3 & Parallel & 22.120 & 0.284 & 1342.600 & & 2.20 \\
\hline 0.610 & N & 36.250 & & $\mathrm{CH}$ & 50.800 & 10000 & 600 & 100 & 10000 & 10000 & 3 & Parallel & 17.790 & 0.328 & 1234.600 & & 1.92 \\
\hline 0.610 & N & 36.250 & & $\mathrm{CH}$ & 76.200 & 10000 & 600 & 100 & 10000 & 10000 & 3 & Parallel & 11.760 & 0.365 & 849.200 & & 1.23 \\
\hline 0.610 & $\mathrm{~N}$ & 36.250 & & $\mathrm{CH}$ & 19.100 & 102 & 600 & 100 & 10000 & 10000 & 3 & Parallel & 24.900 & 0.268 & 1413.900 & & 1.80 \\
\hline 0.610 & N & 36.250 & & $\mathrm{CH}$ & 25.400 & 102 & 600 & 100 & 10000 & 10000 & 3 & Parallel & 24.670 & 0.266 & 1403.500 & & 2.27 \\
\hline 0.610 & $\mathrm{~N}$ & 36.250 & & $\mathrm{CH}$ & 31.800 & 102 & 600 & 100 & 10000 & 10000 & 3 & Parallel & 22.820 & 0.302 & 1444.000 & & 2.32 \\
\hline 0.610 & N & 36.250 & & $\mathrm{CH}$ & 31.800 & 102 & 600 & 100 & 533 & 533 & 3 & Parallel & 28.670 & 0.213 & 1174.100 & & 6.97 \\
\hline 0.768 & $\mathrm{~N}$ & 50.390 & & $\mathrm{CH}$ & 32.000 & 10000 & 610 & 100 & 10000 & 10000 & 3 & Parallel & 34.880 & 0.529 & 2306.100 & 3.71 & 4.63 \\
\hline 0.687 & N & 45.360 & & $\mathrm{CH}$ & 32.000 & 10000 & 610 & 100 & 10000 & 10000 & 3 & Parallel & 30.150 & 0.466 & 1638.600 & 2.98 & 3.87 \\
\hline 0.614 & $\mathrm{~N}$ & 40.920 & & $\mathrm{CH}$ & 32.000 & 10000 & 610 & 100 & 10000 & 10000 & 3 & Parallel & 24.080 & 0.472 & 1358.300 & 2.46 & 2.96 \\
\hline 0.616 & N & 35.290 & & $\mathrm{CH}$ & 32.000 & 10000 & 610 & 100 & 10000 & 10000 & 3 & Parallel & 22.300 & 0.461 & 1217.900 & 2.31 & 2.52 \\
\hline 0.623 & N & 31.160 & & $\mathrm{CH}$ & 32.000 & 10000 & 610 & 100 & 10000 & 10000 & 3 & Parallel & 20.990 & 0.433 & 1090.200 & 2.05 & 2.30 \\
\hline 0.617 & N & 27.660 & & $\mathrm{CH}$ & 32.000 & 10000 & 610 & 100 & 10000 & 10000 & 3 & arallel & 18.740 & 0.439 & 1004.600 & 1.80 & 97 \\
\hline 0.614 & N & 23.410 & & $\mathrm{CH}$ & 32.000 & 10000 & 610 & 100 & 10000 & 10000 & 3 & Parallel & 16.440 & 0.443 & 920.400 & 1.49 & .78 \\
\hline 0.615 & N & 19.080 & & $\mathrm{CH}$ & 32.000 & 10000 & 610 & 100 & 10000 & 10000 & 3 & Parallel & 13.270 & 0.443 & 701.800 & 1.10 & 1.25 \\
\hline 0.616 & $\mathrm{~N}$ & 16.300 & & $\mathrm{CH}$ & 32.000 & 10000 & 610 & 100 & 10000 & 10000 & 3 & Parallel & 11.580 & 0.454 & 619.300 & 0.94 & 1.10 \\
\hline 0.614 & N & 40.920 & & $\mathrm{CH}$ & 32.000 & 10000 & 457 & 100 & 10000 & 10000 & 3 & Parallel & 25.470 & 0.450 & 1350.900 & 4.63 & 5.52 \\
\hline 0.614 & $\mathrm{~N}$ & 40.920 & & $\mathrm{CH}$ & 32.000 & 10000 & 762 & 100 & 10000 & 10000 & 3 & Parallel & 25.440 & 0.445 & 1373.500 & 1.86 & 2.04 \\
\hline 0.759 & $\mathrm{~N}$ & 51.190 & & $\mathrm{CH}$ & 32.000 & 102 & 610 & 100 & 508 & 508 & 3 & Parallel & 41.150 & 0.375 & 1757.800 & 9.40 & 12.46 \\
\hline 0.680 & N & 46.050 & & $\mathrm{CH}$ & 32.000 & 102 & 610 & 100 & 508 & 508 & 3 & Parallel & 36.330 & 0.343 & 1437.500 & 7.41 & 9.85 \\
\hline 0.612 & N & 41.990 & & $\mathrm{CH}$ & 32.00 & 102 & 610 & 100 & 508 & 508 & 3 & arallel & 31.590 & 0.340 & 1266.400 & 5.16 & 8.01 \\
\hline 0.618 & N & 36.250 & & $\mathrm{CH}$ & 32.000 & 102 & 610 & 100 & 508 & 508 & 3 & Parallel & 27.310 & 0.351 & 1122.200 & 3.76 & 5.40 \\
\hline 0.613 & $\mathrm{~N}$ & 31.200 & & $\mathrm{CH}$ & 32.000 & 102 & 610 & 100 & 508 & 508 & 3 & Parallel & 24.920 & 0.330 & 970.900 & 2.97 & 4.01 \\
\hline 0.617 & N & 27.660 & & $\mathrm{CH}$ & 32.000 & 102 & 610 & 100 & 508 & 508 & 3 & Parallel & 21.900 & 0.328 & 844.200 & 2.87 & 3.63 \\
\hline 0.611 & $\mathrm{~N}$ & 23.650 & & $\mathrm{CH}$ & 32.000 & 102 & 610 & 100 & 508 & 508 & 3 & Parallel & 19.010 & 0.324 & 743.900 & 2.32 & 2.96 \\
\hline 0.615 & $\mathrm{~N}$ & 19.080 & & $\mathrm{CH}$ & 32.000 & 102 & 610 & 100 & 508 & 508 & 3 & Parallel & 15.570 & 0.245 & 602.300 & 1.91 & 3.10 \\
\hline 0.616 & $\mathrm{~N}$ & 16.300 & & $\mathrm{CH}$ & 32.000 & 102 & 610 & 100 & 508 & 508 & 3 & Parallel & 13.240 & 0.318 & 505.000 & 1.67 & 2.55 \\
\hline 0.612 & N & 41.990 & & $\mathrm{CH}$ & 32.000 & 102 & 457 & 100 & 508 & 508 & 3 & Parallel & 31.360 & 0.347 & 1257.100 & 9.35 & 12.06 \\
\hline 0.612 & N & 41.990 & & $\mathrm{CH}$ & 32.000 & 102 & 762 & 100 & 508 & 508 & 3 & Parallel & 32.120 & 0.327 & 1227.500 & 4.13 & 5.03 \\
\hline 0.612 & N & 41.990 & & $\mathrm{CH}$ & 32.000 & 102 & 914 & 100 & 508 & 508 & 3 & Parallel & 32.150 & 0.325 & 1187.100 & 3.15 & 4.24 \\
\hline 0.612 & $\mathrm{~N}$ & 41.990 & & $\mathrm{CH}$ & 32.000 & 102 & 1219 & 100 & 508 & 508 & 3 & Parallel & 31.790 & 0.332 & 1243.000 & 1.81 & 2.73 \\
\hline 0.612 & N & 41.990 & & $\mathrm{CH}$ & 32.000 & 102 & 1524 & 100 & 508 & 508 & 3 & Parallel & 32.160 & 0.328 & 1224.500 & 1.05 & 2.08 \\
\hline 0.600 & N & 106.000 & 7.900 & $\mathrm{CH}$ & 32.000 & 102 & 448 & 100 & 508 & 508 & 3 & Parallel & 45.980 & & 4205.000 & 22.42 & 35.71 \\
\hline 0.600 & N & 65.900 & 9.950 & $\mathrm{CH}$ & 32.000 & 102 & 448 & 100 & 508 & 508 & 3 & Parallel & 36.770 & & 2918.000 & 16.21 & 21.29 \\
\hline 0.600 & $\mathrm{~N}$ & 44.100 & 11.000 & $\mathrm{CH}$ & 32.000 & 102 & 448 & 100 & 508 & 508 & 3 & Parallel & 25.970 & & 1433.000 & 12.23 & 15.68 \\
\hline 0.600 & N & 22.600 & 4.900 & $\mathrm{CH}$ & 32.000 & 102 & 448 & 100 & 508 & 508 & 3 & Parallel & 15.800 & & 875.000 & 5.93 & 7.79 \\
\hline 0.600 & N & 0.671 & 40.000 & $\mathrm{CH}$ & 32.000 & 102 & 610 & 2060 & 508 & 508 & 3 & Parallel & 0.603 & & & & 1.30 \\
\hline 0.600 & $\mathrm{~N}$ & 0.671 & 40.000 & $\mathrm{CH}$ & 32.000 & 102 & 610 & 2060 & 508 & 508 & 3 & Parallel & 0.615 & 0.282 & 568.000 & & 1.20 \\
\hline
\end{tabular}




\begin{tabular}{|c|c|c|c|c|c|c|c|c|c|c|c|c|c|c|c|c|c|}
\hline $\begin{array}{l}\text { Open } \\
\text { Circuit } \\
\text { Voltage ph- } \\
\text { ph (KV) }\end{array}$ & $\begin{array}{c}\text { System } \\
\text { Grounded- } \\
-Y, N, \\
\text { HRG }\end{array}$ & $\begin{array}{l}\text { Bolted } \\
\text { fault } \\
\text { current } \\
\text { (kA) }\end{array}$ & XRRatio & $\begin{array}{l}\text { Electrode } \\
\text { material } \\
S S, \mathrm{AL}_{\text {, }} \\
\mathrm{CH}, \mathrm{CS}\end{array}$ & $\begin{array}{c}\text { Gap } \\
\text { between } \\
\text { electrodes } \\
\text { (mm) }\end{array}$ & $\begin{array}{c}\text { Gap } \\
\text { electrodes } \\
\text { to box (mm) }\end{array}$ & $\begin{array}{c}\text { Distance } \\
\text { from arcto } \\
\text { calorimeters } \\
(\mathrm{mm})\end{array}$ & $\begin{array}{l}\text { Arc Duration } \\
\text { (msec) }\end{array}$ & $\begin{array}{c}\text { Box } \\
\text { width + } \\
\text { height2 } \\
(\mathrm{mm})\end{array}$ & $\begin{array}{l}\text { Box } \\
\text { depth } \\
(\mathrm{mm})\end{array}$ & $\begin{array}{l}\text { No. of } \\
\text { phases }\end{array}$ & $\begin{array}{c}\text { Electrode } \\
\text { configuration } \\
\text { (Parallel or } \\
\text { Inline) }\end{array}$ & $\begin{array}{l}\text { ArC } \\
\text { Current } \\
\text { (KA) }\end{array}$ & $\begin{array}{l}\text { Arc } \\
\text { Voltage } \\
\text { L-L (KV) }\end{array}$ & $\begin{array}{c}\text { Arc energy } \\
(\mathrm{k})\end{array}$ & $\begin{array}{l}\text { Incident } \\
\text { energy, the } \\
\text { mean of7 } \\
\text { calorimeters } \\
\text { (callcm²) }\end{array}$ & $\begin{array}{l}\text { Incident } \\
\text { energy, the } \\
\text { max of } 7 \\
\text { calorimeters } \\
\text { (calcms') }\end{array}$ \\
\hline 0.600 & $N$ & 0.671 & 40.000 & $\mathrm{CH}$ & 32.000 & 102 & 610 & 2060 & 508 & 508 & 3 & Parallel & 0.613 & 0.308 & 589.000 & & 1.20 \\
\hline 0.600 & N & 0.671 & 40.000 & $\mathrm{CH}$ & 32.000 & 102 & 610 & 2060 & 508 & 508 & 3 & Parallel & 0.624 & 0.279 & 571.000 & & 1.20 \\
\hline 0.600 & N & 3.478 & 25.000 & $\mathrm{CH}$ & 32.000 & 102 & 610 & 2037 & 508 & 508 & 3 & Parallel & 2.992 & 0.331 & 3123.000 & & 23.50 \\
\hline 0.600 & $\mathrm{~N}$ & 3.478 & 25.000 & $\mathrm{CH}$ & 32.000 & 102 & 610 & 2037 & 508 & 508 & 3 & Parallel & 3.053 & 0.326 & 3150.000 & & 18.50 \\
\hline 0.600 & $N$ & 3.478 & 25.000 & $\mathrm{CH}$ & 32.000 & 102 & 610 & 2037 & 508 & 508 & 3 & Parallel & 3.022 & 0.331 & 3097.000 & & 17.00 \\
\hline 0.590 & Y & 3.350 & 25.000 & $\mathrm{CH}$ & 10.000 & 10 & 610 & 805 & 508 & 508 & 3 & Parallel & 3.133 & 0.241 & 963.000 & & 7.00 \\
\hline 0.590 & $Y$ & 3.350 & 25.000 & $\mathrm{CH}$ & 10.000 & 10 & 610 & 805 & 508 & 508 & 3 & Parallel & 3.156 & 0.249 & 947.000 & & 7.00 \\
\hline 0.590 & Y & 3.350 & 25.000 & $\mathrm{CH}$ & 10.000 & 10 & 610 & 805 & 508 & 508 & 3 & Parallel & 3.145 & 0.237 & 928.000 & & 6.90 \\
\hline 0.590 & $\mathrm{~N}$ & 3.350 & 25.000 & $\mathrm{CH}$ & 40.000 & 10 & 610 & 203 & 508 & 508 & 3 & Parallel & 2.833 & 0.312 & 287.000 & & 1.70 \\
\hline 0.590 & N & 3.350 & 25.000 & $\mathrm{CH}$ & 40.000 & 10 & 610 & 203 & 508 & 508 & 3 & Parallel & 2.828 & 0.307 & 279.000 & & 1.70 \\
\hline 0.590 & $\mathrm{~N}$ & 3.350 & 25.000 & $\mathrm{CH}$ & 40.000 & 10 & 610 & 210 & 508 & 508 & 3 & Parallel & 2.818 & 0.298 & 280.000 & & 1.40 \\
\hline 0.590 & Y & 3.350 & 25.000 & $\mathrm{CH}$ & 40.000 & 102 & 610 & 210 & 508 & 508 & 3 & Parallel & 2.582 & 0.430 & 344.000 & & 1.70 \\
\hline 0.590 & Y & 3.350 & 25.000 & $\mathrm{CH}$ & 40.000 & 102 & 610 & 203 & 508 & 508 & 3 & Parallel & 2.584 & 0.407 & 335.000 & & 1.40 \\
\hline 0.590 & Y & 3.350 & 25.000 & $\mathrm{CH}$ & 40.000 & 102 & 610 & 209 & 508 & 508 & 3 & Parallel & 2.546 & 0.442 & 344.000 & & 1.40 \\
\hline 0.590 & $N$ & 3.350 & 25.000 & $\mathrm{CH}$ & 10.000 & 102 & 610 & 808 & 508 & 508 & 3 & Parallel & 3.162 & 0.241 & 941.000 & & 4.30 \\
\hline 0.590 & N & 3.350 & 25.000 & $\mathrm{CH}$ & 10.000 & 102 & 610 & 808 & 508 & 508 & 3 & Parallel & 3.150 & 0.246 & 932.000 & & 4.60 \\
\hline 0.590 & N & 3.350 & 25.000 & $\mathrm{CH}$ & 10.000 & 102 & 610 & 808 & 508 & 508 & 3 & Parallel & 3.175 & 0.241 & 957.000 & & 5.00 \\
\hline 0.590 & N & 30.000 & 6.500 & $\mathrm{CH}$ & 10.000 & 102 & 610 & 597 & 508 & 508 & 3 & Parallel & 24.194 & & & & 19.30 \\
\hline 0.590 & $\mathrm{~N}$ & 30.000 & 6.500 & $\mathrm{CH}$ & 10.000 & 102 & 610 & 597 & 508 & 508 & 3 & Parallel & 24.080 & & & & 22.00 \\
\hline 0.590 & $N$ & 30.000 & 6.500 & $\mathrm{CH}$ & 10.000 & 102 & 610 & 597 & 508 & 508 & 3 & Parallel & 24712 & & & & 18.10 \\
\hline 0.590 & $\mathrm{~N}$ & 30.000 & 6.500 & $\mathrm{CH}$ & 40.000 & 102 & 610 & 96 & 508 & 508 & 3 & Parallel & 21.068 & 0.352 & 1104.000 & & 3.40 \\
\hline 0.590 & $N$ & 30.000 & 6.500 & $\mathrm{CH}$ & 40.000 & 102 & 610 & 96 & 508 & 508 & 3 & Parallel & 21.204 & 0.341 & 1068.000 & & 3.20 \\
\hline 0.590 & $\mathrm{~N}$ & 30.000 & 6.500 & $\mathrm{CH}$ & 40.000 & 102 & 610 & 96 & 508 & 508 & 3 & Parallel & 21.649 & 0.334 & 1065.000 & & 3.10 \\
\hline 0.590 & N & 30.000 & 6.500 & $\mathrm{CH}$ & 10.000 & 102 & 610 & 495 & 508 & 508 & 3 & Parallel & 24.694 & 0.237 & 4857.000 & & 15.10 \\
\hline 0.590 & $N$ & 30.000 & 6.500 & $\mathrm{CH}$ & 10.000 & 102 & 610 & 166 & 508 & 508 & 3 & Parallel & 24.531 & 0.229 & 1590.000 & & 4.30 \\
\hline 0.590 & Y & 30.000 & 6.500 & $\mathrm{CH}$ & 10.000 & 102 & 610 & 172 & 508 & 508 & 3 & Parallel & 24.503 & 0.244 & 1714.000 & & 5.00 \\
\hline 0.590 & Y & 30.000 & 6.500 & $\mathrm{CH}$ & 10.000 & 102 & 610 & 166 & 508 & 508 & 3 & Parallel & 24.544 & 0.234 & 1618.000 & & 5.00 \\
\hline 0.590 & N & 30.000 & 6.500 & $\mathrm{CH}$ & 10.000 & 10 & 610 & 164 & 508 & 508 & 3 & Parallel & 24.746 & 0.615 & 16966.000 & & 7.80 \\
\hline 0.590 & N & 30.000 & 6.500 & $\mathrm{CH}$ & 10.000 & 10 & 610 & 169 & 508 & 508 & 3 & Parallel & 24.679 & 0.244 & 1680.000 & & 7.70 \\
\hline 0.590 & N & 30.000 & 6.500 & $\mathrm{CH}$ & 10.000 & 10 & 610 & 169 & 508 & 508 & 3 & Parallel & 24.213 & 0.256 & 1729.000 & & 9.10 \\
\hline 0.590 & Y & 30.000 & 6.500 & $\mathrm{CH}$ & 40.000 & 10 & 610 & 169 & 508 & 508 & 3 & Parallel & 21.776 & 0.331 & 1911.000 & & 8.80 \\
\hline 0.590 & Y & 30.000 & 6.500 & $\mathrm{CH}$ & 40.000 & 10 & 610 & 160 & 508 & 508 & 3 & Parallel & 22.180 & 0.322 & 1857.000 & & 8.20 \\
\hline 0.590 & Y & 30.000 & 6.500 & $\mathrm{CH}$ & 40.000 & 10 & 610 & 160 & 508 & 508 & 3 & Parallel & 22.326 & 0.319 & 1840.000 & & 8.40 \\
\hline 0.250 & $Y$ & 20.000 & 7.000 & $\mathrm{CH}$ & 10.000 & 10 & 610 & 230 & 508 & 508 & 3 & Parallel & 13.564 & 0.203 & 884.000 & & 370 \\
\hline 0.250 & Y & 20.000 & 7.000 & $\mathrm{CH}$ & 10.000 & 10 & 610 & 230 & 508 & 508 & 3 & Parallel & 13.202 & 0.204 & 847.000 & & 3.90 \\
\hline 0.250 & Y & 20.000 & 7.000 & $\mathrm{CH}$ & 10.000 & 10 & 610 & 200 & 508 & 508 & 3 & Parallel & 12730 & 0.218 & 263.600 & & 3.60 \\
\hline 0.250 & Y & 20.000 & 7.000 & $\mathrm{CH}$ & 10.000 & 10 & 610 & 200 & 508 & 508 & 3 & Parallel & 11.565 & 0.220 & 244.800 & & 3.30 \\
\hline 0.250 & Y & 20.000 & 7.00 & $\mathrm{CH}$ & 10.000 & 1 & 610 & 200 & 50 & 508 & 3 & Parallel & 11.919 & 0.213 & 255.800 & & 3.40 \\
\hline 0.405 & Y & 11.300 & 10.000 & $\mathrm{CH}$ & 500 & 20 & 610 & 193 & 508 & 508 & 3 & Parallel & 4.628 & 0.374 & 490.000 & & 2.80 \\
\hline 0.405 & Y & 11.300 & 10.000 & $\mathrm{CH}$ & 25.000 & 56 & 610 & 197 & 508 & 508 & 3 & Parallel & 4.310 & 0.383 & 458.000 & & 2.20 \\
\hline 0.405 & $\mathrm{~N}$ & 11.300 & 10.000 & $\mathrm{CH}$ & 25.000 & 56 & 610 & 196 & 508 & 508 & 3 & Parallel & 5.451 & 0.355 & 530.000 & & 2.40 \\
\hline 0.590 & $y$ & 2.700 & 30.000 & $\mathrm{CH}$ & 10.000 & (n) & 610 & 204 & 508 & 508 & 3 & Parallel & 2.582 & 0.303 & 215.600 & & 1.10 \\
\hline
\end{tabular}




\begin{tabular}{|c|c|c|c|c|c|c|c|c|c|c|c|c|c|c|c|c|c|}
\hline $\begin{array}{c}\text { Open } \\
\text { Circuit } \\
\text { Voltage ph- } \\
\text { ph }(\mathrm{kV})\end{array}$ & $\begin{array}{c}\text { System } \\
\text { Grounded. } \\
-Y, N, \\
\text { HRG }\end{array}$ & $\begin{array}{l}\text { Bolted } \\
\text { fault } \\
\text { current } \\
\text { (KA) }\end{array}$ & XRRatio & $\begin{array}{l}\text { Electrode } \\
\text { material } \\
S S, A L, \\
\text { CH,CS }\end{array}$ & $\begin{array}{c}\text { Gap } \\
\text { between } \\
\text { electrodes } \\
\text { (mm) }\end{array}$ & $\begin{array}{c}\text { Gap } \\
\text { electrodes } \\
\text { to box (mm) }\end{array}$ & $\begin{array}{c}\text { Distance } \\
\text { from arcto } \\
\text { calorimeters } \\
(\mathrm{mm})\end{array}$ & $\begin{array}{l}\text { Arc Duratior } \\
\text { (msec) }\end{array}$ & $\begin{array}{c}\text { Box } \\
\text { width + } \\
\text { height2 } \\
\text { (mm) }\end{array}$ & $\begin{array}{l}\text { Box } \\
\text { depth } \\
\text { (mm) }\end{array}$ & $\begin{array}{l}\text { No. of } \\
\text { phases }\end{array}$ & $\begin{array}{c}\text { Electrode } \\
\text { configuration } \\
\text { (Parallel or } \\
\text { Inline) }\end{array}$ & $\begin{array}{l}\text { Arc } \\
\text { Current } \\
(\mathrm{KA})\end{array}$ & $\begin{array}{c}\text { Arc } \\
\text { Voltage } \\
\text { L-L (KV) }\end{array}$ & $\begin{array}{c}\text { Arc energy } \\
(\mathrm{k})\end{array}$ & $\begin{array}{c}\text { energy, the } \\
\text { mean of } 7 \\
\text { calorimeters } \\
\left(\mathrm{cal} / \mathrm{cm}^{2}\right)\end{array}$ & $\begin{array}{l}\text { energy, the } \\
\text { max of } 7 \\
\text { calorimeters } \\
\left(\mathrm{call}^{2} \mathrm{~cm}^{2}\right)\end{array}$ \\
\hline 0.590 & Y & 2700 & 30.000 & $\mathrm{CH}$ & 10.000 & 10 & 610 & 204 & 508 & 508 & 3 & Parallel & 2.582 & 0.303 & 215.600 & & 1.10 \\
\hline 0.590 & Y & 2.700 & 30.000 & $\mathrm{CH}$ & 10.000 & 10 & 610 & 199 & 508 & 508 & 3 & Parallel & 2.552 & 0.324 & 226.000 & & .90 \\
\hline 0.590 & Y & 2.700 & 30.000 & $\mathrm{CH}$ & 10.000 & 10 & 610 & 201 & 508 & 508 & 3 & Parallel & 2.521 & 0.327 & 229.000 & & 0.90 \\
\hline 0.590 & N & 2.700 & 30.000 & $\mathrm{CH}$ & 40.000 & 10 & 610 & 201 & 508 & 508 & 3 & Parallel & 2.413 & 0.348 & 255.000 & & 1.10 \\
\hline 0.590 & N & 2.700 & 30.000 & $\mathrm{CH}$ & 40.000 & 10 & 610 & 203 & 508 & 508 & 3 & Parallel & 2.391 & 0.357 & 264.000 & & 10 \\
\hline 0.590 & $\mathrm{~N}$ & 2700 & 30.000 & $\mathrm{CH}$ & 40.000 & 10 & 610 & 202 & 508 & 508 & 3 & Parallel & 2385 & 0.352 & 261.000 & & 0.90 \\
\hline 0.590 & Y & 2.700 & 30.000 & $\mathrm{CH}$ & 40.000 & 102 & 610 & 202 & 508 & 508 & 3 & Parallel & 2.244 & 0.381 & 270.000 & & 0.90 \\
\hline 0.590 & $Y$ & 2700 & 30.000 & $\mathrm{CH}$ & 40.000 & 102 & 610 & 407 & 508 & 508 & 3 & Parallel & 2.336 & 0.345 & 508.000 & & 2.20 \\
\hline 0.590 & Y & 2.700 & 30.000 & $\mathrm{CH}$ & 40.000 & 102 & 610 & 407 & 508 & 508 & 3 & Parallel & 2.300 & 0.343 & 502.000 & & 1.70 \\
\hline 0.590 & Y & 2.700 & 30.000 & $\mathrm{CH}$ & 40.000 & 102 & 610 & 407 & 508 & 508 & 3 & Parallel & 2.382 & 0.333 & 503.000 & & 1.60 \\
\hline 0.590 & N & 2.700 & 30.000 & $\mathrm{CH}$ & 10.000 & 102 & 610 & 407 & 508 & 508 & 3 & Parallel & 2.538 & 0.294 & 426.000 & & 1.50 \\
\hline 0.590 & $\mathrm{~N}$ & 2.700 & 30.000 & $\mathrm{CH}$ & 10.000 & 102 & 610 & 407 & 508 & 508 & 3 & Parallel & 2.582 & 0.265 & 416.000 & & 1.50 \\
\hline 0.590 & $N$ & 2.700 & 30.000 & $\mathrm{CH}$ & 10.000 & 102 & 610 & 407 & 508 & 508 & 3 & Parallel & 2.565 & 0.282 & 399.000 & & 1.20 \\
\hline 0.590 & $Y$ & 21.400 & 7.000 & $\mathrm{CH}$ & 10.000 & 102 & 610 & 207 & 508 & 508 & 3 & Parallel & 19.048 & 0.223 & 1487.000 & & 4.50 \\
\hline 0.590 & Y & 21.400 & 7.000 & $\mathrm{CH}$ & 10.000 & 102 & 610 & 211 & 508 & 508 & 3 & Parallel & 18.831 & 0.222 & 1484.000 & & 4.20 \\
\hline 0.590 & Y & 21.400 & 7.000 & $\mathrm{CH}$ & 10.000 & 102 & 610 & 211 & 508 & 508 & 3 & Parallel & 18.919 & 0.218 & 1461.000 & & 4.30 \\
\hline 0.590 & N & 21.400 & 7.000 & $\mathrm{CH}$ & 40.000 & 102 & 610 & 209 & 508 & 508 & 3 & Parallel & 16.459 & 0.334 & 1869.000 & & 5.80 \\
\hline 0.590 & $\mathrm{~N}$ & 21.400 & 7.000 & $\mathrm{CH}$ & 40.000 & 102 & 61 & 205 & 508 & 508 & 3 & Parallel & 16.722 & 0.326 & 1844.000 & & 5.50 \\
\hline 0.590 & $N$ & 21.400 & 7.000 & $\mathrm{CH}$ & 40.000 & 102 & 0 & 209 & 508 & 508 & 3 & Parallel & 16.924 & 0.317 & 1841.000 & & 6.00 \\
\hline 0.590 & $Y$ & 21.400 & 7.000 & $\mathrm{CH}$ & 40.000 & 10 & 610 & 212 & 508 & 508 & 3 & Parallel & 17.356 & 0.288 & 1730.000 & & 9.10 \\
\hline 0.590 & $Y$ & 21.400 & 7.000 & $\mathrm{CH}$ & 40.000 & 10 & 610 & 208 & 508 & 508 & 3 & Parallel & 17.532 & 0.288 & 1696.000 & & 8.50 \\
\hline 0.590 & Y & 21.400 & 7.000 & $\mathrm{CH}$ & 40.000 & 10 & 610 & 208 & 508 & 508 & 3 & Parallel & 17.305 & 0.291 & 1693.000 & & 8.30 \\
\hline 0.590 & N & 21.400 & 7.000 & $\mathrm{CH}$ & 10.000 & 10 & 61 & 208 & 508 & 508 & 3 & Parallel & 19.310 & 0.241 & 1574.000 & & 7.70 \\
\hline 0.590 & $\mathrm{~N}$ & 21.400 & 7.000 & $\mathrm{CH}$ & 10.000 & 10 & 0 & 21 & 508 & 508 & 3 & Parallel & 19.071 & 0.232 & 1597.000 & & 8.10 \\
\hline 0.590 & $N$ & 21.400 & 7.000 & $\mathrm{CH}$ & 10.000 & 10 & 0 & 213 & 508 & 508 & 3 & Parallel & 18.856 & 0.225 & 1495.000 & & 6.90 \\
\hline 0.606 & Y & 22.460 & 5.465 & CS & 38 & 38 & 611 & 00 & 330 & 191 & 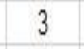 & Parallel & 18.110 & 0.235 & 637.600 & 1.18 & 1.50 \\
\hline 0.600 & $Y$ & 22.238 & 5.465 & CS & 38.100 & 38 & 610 & 106 & 330 & 191 & 3 & Parallel & 16.023 & 0.317 & 901.200 & 2.05 & 2.35 \\
\hline 0.600 & Y & 22.238 & 5.465 & CS & 38.100 & 38 & 610 & 105 & 330 & 191 & 3 & Parallel & 15.993 & 0.317 & 889.300 & 1.96 & 2.27 \\
\hline 0.400 & Y & 53.607 & 5.465 & CS & 19.050 & 38 & 61 & 10 & 330 & 191 & 3 & Parallel & 27.253 & 0.278 & 1349.000 & 2.92 & 3.60 \\
\hline 0.400 & $Y$ & 07 & 5.465 & CS & 18 & 38 & 6 & 10 & 33 & 191 & 3 & Parallel & 25.283 & 0.284 & 1279.900 & 2 & 3.26 \\
\hline 0.400 & Y & 53.607 & 5.465 & $C S$ & 10050 & 38 & 61 & 105 & 330 & 191 & 3 & Parallel & 23.082 & 0.284 & 3438.267 & 207 & 3.37 \\
\hline 0.400 & Y & 53.607 & 5.465 & CS & 19.050 & 38 & 305 & 68 & 330 & 191 & 3 & Parallel & 23.553 & 0.296 & 784.200 & 5.83 & 7.41 \\
\hline 0.400 & Y & 53.607 & 5.465 & CS & 19.050 & 38 & 305 & 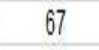 & 330 & 191 & 3 & Parallel & 24.920 & 0.289 & 806.300 & 5.34 & 7.27 \\
\hline 0.400 & Y & 53.607 & 5.465 & CS & 19.050 & 38 & 305 & 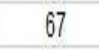 & 330 & 191 & 3 & Parallel & 26.543 & 0.277 & 818.200 & 5.94 & 8.21 \\
\hline 0.400 & Y & 53.607 & 5.465 & CS & 18 & 38 & 1829 & 10 & 330 & 191 & 3 & Parallel & 24.343 & 0.294 & 1282800 & 0.28 & 0.33 \\
\hline 0.400 & Y & 53.607 & 5.465 & CS & 19.050 & 38 & 182 & 53 & 330 & 191 & 3 & Parallel & 27.203 & 0.282 & 6922.000 & 5.0 & 5.71 \\
\hline 0.400 & Y & 53.607 & 5.465 & CS & 19.050 & 38 & 1829 & 180 & 330 & 191 & 3 & Parallel & 25.647 & 0.284 & 2171.800 & 0.93 & 1.13 \\
\hline 0.400 & Y & 53.607 & 5.465 & CS & 19.050 & 38 & 1829 & 178 & 330 & 191 & 3 & Parallel & 29.793 & 0.260 & 2283.000 & 0.61 & 0.74 \\
\hline 0.400 & $Y$ & 53.607 & 5.465 & CS & 19.050 & 38 & 1829 & 175 & 330 & 191 & 3 & Parallel & 28.327 & 0.269 & 2186.200 & 0.55 & 0.74 \\
\hline 0.400 & HRG & 53.607 & 5.465 & CS & 19.050 & 38 & 610 & 11 & 330 & 191 & 3 & Parallel & 28.043 & 0.279 & 1404.000 & 3.21 & 3.97 \\
\hline 0.400 & HRG & 53.607 & 5.465 & CS & 99.050 & 38 & 61 & 11 & 330 & 191 & 3 & Paralale| & 25.667 & 0.289 & 1347.400 & 2.88 & 3.46 \\
\hline 0.400 & HRG & 53.607 & 5.465 & CS & 19.050 & 38 & 610 & 112 & 330 & 191 & 3 & Parallel & 26.360 & 0.281 & 1331.900 & 0.41 & 0.50 \\
\hline
\end{tabular}




\begin{tabular}{|c|c|c|c|c|c|c|c|c|c|c|c|c|c|c|c|c|c|}
\hline $\begin{array}{c}\text { Open } \\
\text { Circuit } \\
\text { Voltage ph- } \\
\text { ph (KV) }\end{array}$ & $\begin{array}{c}\text { System } \\
\text { Grounded. } \\
-Y, N_{1} \\
\text { HRG }\end{array}$ & $\begin{array}{l}\text { Bolted } \\
\text { fault } \\
\text { current } \\
\text { (KA) }\end{array}$ & XRRatio & $\begin{array}{l}\text { Electrode } \\
\text { material } \\
S S, A L \text {, } \\
\text { CH,CS }\end{array}$ & $\begin{array}{c}\text { Gap } \\
\text { between } \\
\text { electrodes } \\
\text { (mm) }\end{array}$ & $\begin{array}{c}\text { Gap } \\
\text { electrodes } \\
\text { to box (mm) }\end{array}$ & $\begin{array}{c}\text { Distance } \\
\text { from arc to } \\
\text { calorimeters } \\
\text { (mm) }\end{array}$ & $\begin{array}{c}\text { Arc Duration } \\
\text { (msec) }\end{array}$ & $\begin{array}{c}\text { Box } \\
\text { width + } \\
\text { height2 } \\
\text { (mm) }\end{array}$ & $\begin{array}{l}\text { Box } \\
\text { depth } \\
\text { (mm) }\end{array}$ & $\begin{array}{l}\text { No. of } \\
\text { phases }\end{array}$ & $\begin{array}{l}\text { Electrode } \\
\text { configuration } \\
\text { (Parallel or } \\
\text { Inline) }\end{array}$ & $\begin{array}{l}\text { Arc } \\
\text { Current } \\
(\mathrm{KA})\end{array}$ & $\begin{array}{c}\text { Arc } \\
\text { Voltage } \\
\text { L-L (KV) }\end{array}$ & $\begin{array}{c}\text { Arc energy } \\
(\mathrm{k})\end{array}$ & $\begin{array}{l}\text { Incident } \\
\text { energy, the } \\
\text { mean of } 7 \\
\text { calorimeters } \\
(\text { callcm²) }\end{array}$ & $\begin{array}{l}\text { Incident } \\
\text { energy, the } \\
\text { max of } 7 \\
\text { calorimeters } \\
\left(\mathrm{call}^{2} \mathrm{~cm}^{2}\right)\end{array}$ \\
\hline 0.485 & HRG & 52.560 & 5.465 & CS & 19.050 & 38 & 610 & 108 & 330 & 191 & 3 & Parallel & 31.000 & 0.306 & 1726.200 & 3.83 & 4.37 \\
\hline 0.485 & HRG & 52.560 & 5.465 & CS & 19.050 & 38 & 610 & 106 & 330 & 191 & 3 & Parallel & 30.870 & 0.313 & 1732.600 & 4.24 & 4.81 \\
\hline 0.485 & HRG & 52.560 & 5.465 & $C S$ & 19.050 & 38 & 610 & 106 & 330 & 191 & 3 & Parallel & 31.030 & 0.310 & 1706.700 & 3.88 & 4.37 \\
\hline 0.400 & y & 54.186 & 5.797 & CS & 19.050 & 38 & 610 & 103 & 330 & 191 & 3 & Parallel & 25.773 & 0.286 & 1257.800 & 2.65 & 3.08 \\
\hline 0.400 & Y & 54.186 & 5.797 & $C S$ & 19.050 & 38 & 610 & 103 & 330 & 191 & 3 & Parallel & 25.287 & 0.289 & 1235.800 & 2.66 & 3.18 \\
\hline 0.400 & Y & 54.186 & 5.797 & $C S$ & 19.050 & 38 & 610 & 108 & 330 & 191 & 3 & Parallel & 24.990 & 0.287 & 1247.900 & & \\
\hline 0.400 & Y & 53.607 & 5.465 & $C S$ & 31.750 & 38 & 610 & 107 & 330 & 191 & 3 & Parallel & 24.337 & 0.297 & 1286.900 & 239 & 3.04 \\
\hline 0.400 & Y & 53.607 & 5.465 & $C S$ & 31.750 & 38 & 610 & 109 & 330 & 191 & 3 & Parallel & 22.137 & 0.306 & 1213.200 & 2.52 & 3.08 \\
\hline 0.400 & Y & 53.607 & 5.465 & CS & 31.750 & 38 & 610 & 104 & 330 & 191 & 3 & Parallel & 20.680 & 0.318 & 1130.500 & 2.36 & 2.82 \\
\hline 0.400 & Y & 103.340 & 5.465 & CS & 31.750 & 38 & 610 & 61 & 330 & 191 & 3 & Parallel & 26.853 & 0.342 & 943.100 & 2.02 & 2.41 \\
\hline 0.400 & Y & 103.340 & 5.465 & CS & 31.750 & 38 & 610 & 61 & 330 & 191 & 3 & Parallel & 27.297 & 0.340 & 941.500 & 1.95 & 2.31 \\
\hline 0.400 & Y & 103.340 & 5.465 & CS & 31.750 & 38 & 610 & 60 & 330 & 191 & 3 & Parallel & 28.660 & 0.335 & 964.200 & 2.04 & 2.42 \\
\hline 0.600 & Y & 100.594 & 5.167 & $C S$ & 31.750 & 38 & 610 & 63 & 330 & 191 & 3 & Parallel & 54.417 & 0.373 & 2124.000 & 5.85 & 7.64 \\
\hline 0.600 & Y & 100.594 & 5.167 & $C S$ & 31.750 & 38 & 610 & 63 & 330 & 191 & 3 & Parallel & 52.230 & 0.389 & 2078.900 & 86 & 7.65 \\
\hline 0.208 & Y & 87.500 & 6.169 & $C S$ & 12.700 & 38 & 61 & 72 & 330 & 191 & 3 & Parallel & 20.853 & 0.187 & 430.600 & 80 & 1.12 \\
\hline 0.400 & Y & 103.340 & 5.465 & $C S$ & 12.700 & 38 & 61 & 65 & 330 & 191 & 3 & Parallel & 35.900 & 0.313 & 1193.700 & 2.52 & 2.83 \\
\hline 0.400 & Y & 103.340 & 5.46 & CS & 12.700 & 38 & 61 & $b^{6}$ & 330 & 191 & 3 & Parallel & 44.570 & 0.285 & 1300.000 & 18 & 3.67 \\
\hline 0.405 & Y & 2.551 & 1.878 & $C S$ & 31.750 & 38 & 61 & 92 & 330 & 191 & 3 & Parallel & 2.122 & 0.175 & 9.582 & 04 & 0.05 \\
\hline 0.405 & Y & 2.551 & 1.878 & $C S$ & 31.750 & 38 & 61 & 31 & 330 & 191 & 3 & Parallel & 1.549 & 0.258 & 15.534 & 0.04 & 0.05 \\
\hline 0.610 & $\mathrm{~N}$ & 2.843 & 1.930 & $C S$ & 31.750 & 38 & 610 & 345 & 330 & 191 & 3 & Parallel & 2.058 & 0.266 & 306.680 & 0.56 & 0.68 \\
\hline 0.611 & $\mathrm{~N}$ & 2.848 & 1.930 & $C S$ & 31.750 & 38 & 610 & 808 & 330 & 191 & 3 & Parallel & 2.050 & 0.276 & 745.300 & 1.97 & 2.66 \\
\hline 0.611 & $\mathrm{~N}$ & 2.848 & 1.930 & $C S$ & 31.750 & 38 & 610 & 607 & 330 & 191 & 3 & Parallel & 2.031 & 0.282 & 564.600 & 1.74 & 2.46 \\
\hline 0.603 & $\mathrm{~N}$ & 3.063 & 0.776 & $C S$ & 31.750 & 38 & 610 & 526 & 330 & 191 & 3 & Parallel & 1.901 & 0.291 & 470.200 & 1.45 & 1.99 \\
\hline 0.603 & $\mathrm{~N}$ & 3.063 & 0.776 & $C S$ & 31.750 & 38 & 610 & 526 & 330 & 191 & 3 & Parallel & 1.894 & 0.295 & 474.700 & 1.63 & 230 \\
\hline 0.603 & $\mathrm{~N}$ & 3.063 & 0.776 & $C S$ & 31.750 & 38 & 61 & 526 & 330 & 191 & 3 & Parallel & 1.889 & 0.295 & 458.100 & 1.58 & 2.14 \\
\hline 0.606 & Y & 2.825 & 1.5 & $C S$ & 19.050 & 38 & 61 & 53 & 330 & 191 & 3 & Parallel & 2.063 & 0.271 & 443.300 & 38 & 1.86 \\
\hline 0.606 & Y & 2.825 & 1. & $C S$ & 19. & 38 & 61 & 5 & 330 & 191 & 3 & Parallel & 2.051 & 0.276 & 450.800 & 1.36 & 1 \\
\hline 0.606 & Y & 2.825 & & c & 19 & 38 & & 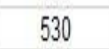 & 330 & 19 & 3 & |lel & 2.044 & 0.277 & 45 & & 1. \\
\hline 0.405 & Y & 2.551 & 0.567 & $C S$ & 7.112 & 9 & of & 531 & 330 & 191 & 3 & Parallel & 1.886 & 0.179 & 242.440 & 0.59 & 0.71 \\
\hline 0.405 & Y & 2.551 & 0.567 & $C S$ & 7.112 & 9 & 610 & 528 & 330 & 191 & 3 & Parallel & 1.835 & 0.187 & 243.710 & 0.56 & 0.78 \\
\hline 0.405 & Y & 2.551 & 0.567 & $C S$ & 7.112 & 9 & 610 & 531 & 330 & 191 & 3 & Parallel & 1.899 & 0.197 & 244.560 & 0.65 & 0.94 \\
\hline 0.609 & Y & 2.859 & 1.985 & $C S$ & 7.112 & 9 & 305 & 535 & 330 & 191 & 3 & Parallel & 2.189 & 0.260 & 431.400 & 1.77 & 2.62 \\
\hline 0.609 & Y & 2.859 & 1.985 & $C S$ & 7.112 & 9 & 305 & 536 & 330 & 191 & 3 & Parallel & 2.216 & 0.253 & 418.200 & 1.59 & 2.16 \\
\hline 0.609 & Y & 2.859 & 1.985 & $C S$ & 7.112 & 9 & 305 & 531 & 330 & 191 & 3 & Parallel & 2.196 & 0.262 & 419.500 & 1.66 & 2.23 \\
\hline 0.400 & Y & 103.340 & 5.465 & $C S$ & 7.112 & 38 & 610 & 70 & 330 & 191 & 3 & Parallel & 50.507 & 0.259 & 1480.500 & 4.12 & 4.83 \\
\hline 0.400 & $Y$ & 103.340 & 5.465 & $C S$ & 7.112 & 38 & 610 & 69 & 330 & 191 & 3 & Parallel & 45.977 & 0.276 & 1399.800 & 3.59 & 4.47 \\
\hline 0.400 & Y & 103.340 & 5.465 & $C S$ & 7.112 & 38 & 61 & 69 & 330 & 191 & 3 & Parallel & 48.377 & 0.265 & 1389.100 & 4.07 & 4.98 \\
\hline 0.606 & Y & 101.600 & 5.167 & $C S$ & 7.112 & 38 & 0 & 43 & 330 & 191 & 3 & Parallel & 65.160 & 0.293 & 1375.500 & 4.29 & 4.80 \\
\hline 0.450 & N & 79.600 & 10.750 & $\mathrm{CH}$ & 38.100 & 10000 & 610 & 216 & 10000 & 10000 & 3 & Parallel & 19.000 & 0.236 & 4066.000 & 66 & 10.62 \\
\hline 0.450 & $\mathrm{~N}$ & 79.600 & 10.750 & $\mathrm{CH}$ & 38.100 & 10000 & 670 & 217 & 10000 & 10000 & 3 & Parallel & 26.700 & 0.235 & 4446.000 & 8.49 & 11.92 \\
\hline 0.450 & $\mathrm{~N}$ & 79.600 & 10.750 & $\mathrm{CH}$ & 38.100 & 10000 & 610 & 217 & 10000 & 10000 & 3 & Parallel & 20.100 & 0.233 & 4580.000 & 8.88 & 12.33 \\
\hline 2.382 & $\mathrm{~N}$ & 2.577 & & $\mathrm{CH}$ & 102.000 & 152 & 610 & 204 & 953 & 762 & 3 & Parallel & 2.523 & 0.663 & * & 0.66 & 0.77 \\
\hline
\end{tabular}




\begin{tabular}{|c|c|c|c|c|c|c|c|c|c|c|c|c|c|c|c|c|c|}
\hline $\begin{array}{c}\text { Open } \\
\text { Circuit } \\
\text { Voltage ph- } \\
\text { ph }(\mathrm{kV})\end{array}$ & $\begin{array}{c}\text { System } \\
\text { Grounded- } \\
-Y, N \\
\text { HRG }\end{array}$ & $\begin{array}{l}\text { Bolted } \\
\text { fault } \\
\text { current } \\
\text { (KA) }\end{array}$ & XRRatio & $\begin{array}{l}\text { Electrode } \\
\text { material } \\
S S, A L \text {, } \\
C H, C S\end{array}$ & $\begin{array}{c}\text { Gap } \\
\text { between } \\
\text { electrodes } \\
(\mathrm{mm})\end{array}$ & $\begin{array}{c}\text { Gap } \\
\text { electrodes } \\
\text { to box (mm) }\end{array}$ & $\begin{array}{c}\text { Distance } \\
\text { from arc to } \\
\text { calorimeters } \\
\text { (mm) }\end{array}$ & $\begin{array}{l}\text { Arc Duration } \\
\text { (msec) }\end{array}$ & $\begin{array}{c}\text { Box } \\
\text { width + } \\
\text { height2 } \\
\text { (mm) }\end{array}$ & $\begin{array}{l}\text { Box } \\
\text { depth } \\
(m m)\end{array}$ & $\begin{array}{c}\text { No. of } \\
\text { phases }\end{array}$ & $\begin{array}{c}\text { Electrode } \\
\text { configuration } \\
\text { (Parallel or } \\
\text { Inline) }\end{array}$ & $\begin{array}{l}\text { Arc } \\
\text { Current } \\
(\mathrm{KA})\end{array}$ & $\begin{array}{c}\text { Arc } \\
\text { Voltage } \\
L-L(K V)\end{array}$ & $\begin{array}{l}\text { Arc energy } \\
(\mathrm{k})\end{array}$ & $\begin{array}{l}\text { Incident } \\
\text { energy, the } \\
\text { mean of } 7 \\
\text { calorimeters } \\
(\text { callcm²) }\end{array}$ & $\begin{array}{l}\text { Incident } \\
\text { energy, the } \\
\text { max of7 } \\
\text { calorimeters } \\
\text { (call/cm²) }\end{array}$ \\
\hline 2.382 & $N$ & 2.577 & & $\mathrm{CH}$ & 102.000 & 152 & 610 & 199 & 953 & 762 & 3 & Parallel & 2.557 & 0.581 & 459.100 & 0.53 & 0.62 \\
\hline 2.382 & N & 2.577 & & $\mathrm{CH}$ & 102.000 & 152 & 610 & 203 & 953 & 762 & 3 & Parallel & 2.567 & 0.552 & 453.000 & 0.57 & 0.66 \\
\hline 2.382 & N & 2.577 & & $\mathrm{CH}$ & 102.000 & 152 & 610 & 202 & 953 & 762 & 3 & Parallel & 2.577 & 0.598 & * & 0.54 & 0.62 \\
\hline 2.380 & N & 4.873 & & $\mathrm{CH}$ & 102.000 & 152 & 610 & 198 & 953 & 762 & 3 & Parallel & 4.807 & 0.661 & * & 1.12 & 1.22 \\
\hline 2.378 & N & 4.873 & & $\mathrm{CH}$ & 102.000 & 152 & 610 & 194 & 953 & 762 & 3 & Parallel & 4.803 & 0.664 & * & 1.00 & 1.11 \\
\hline 2.376 & N & 4.873 & & $\mathrm{CH}$ & 102.000 & 152 & 610 & 192 & 953 & 762 & 3 & Parallel & 4.880 & 0.684 & 963.150 & 1.15 & 1.22 \\
\hline 2.373 & N & 4.873 & & $\mathrm{CH}$ & 102.000 & 152 & 610 & 190 & 953 & 762 & 3 & Parallel & 4.753 & 0.710 & 985.840 & 1.10 & 1.19 \\
\hline 2.376 & $N$ & 6.953 & & $\mathrm{CH}$ & 102.000 & 152 & 610 & 197 & 953 & 762 & 3 & Parallel & 6.737 & 0.691 & 1446.610 & 1.65 & 1.78 \\
\hline 2.373 & $N$ & 6.953 & & $\mathrm{CH}$ & 102.000 & 152 & 610 & 194 & 953 & 762 & 3 & Parallel & 6.713 & 0.706 & 1438.870 & 1.62 & 1.74 \\
\hline 2.373 & N & 6.953 & & $\mathrm{CH}$ & 102.000 & 152 & 610 & 197 & 953 & 762 & 3 & Parallel & 6.777 & 0.738 & 1547.660 & 1.73 & 1.89 \\
\hline 2.373 & N & 6.953 & & $\mathrm{CH}$ & 102.000 & 152 & 610 & 195 & 953 & 762 & 3 & Parallel & 6.797 & 0.729 & 1507.380 & 1.76 & 1.86 \\
\hline 2.378 & $\mathrm{~N}$ & 11.637 & & $\mathrm{CH}$ & 102.000 & 152 & 610 & 191 & 953 & 762 & 3 & Parallel & 11.107 & 0.710 & 2443.860 & 2.78 & 3.04 \\
\hline 2.371 & N & 11.637 & & $\mathrm{CH}$ & 102.000 & 152 & 610 & 187 & 953 & 762 & 3 & Parallel & 11.167 & 0.700 & 2330.730 & 2.64 & 2.93 \\
\hline 2.368 & N & 11.637 & & $\mathrm{CH}$ & 102.000 & 152 & 610 & 194 & 953 & 762 & 3 & Parallel & 10.993 & 0.742 & 2497.650 & 2.69 & 2.98 \\
\hline 2.371 & N & 11.637 & & $\mathrm{CH}$ & 102.000 & 152 & 610 & 200 & 953 & 762 & 3 & Parallel & 11.010 & 0.778 & 2719.460 & 2.95 & 3.25 \\
\hline 2.369 & $\mathrm{~N}$ & 5.583 & & $\mathrm{CH}$ & 102.000 & 152 & 610 & 198 & 953 & 762 & 3 & Parallel & 5.583 & * & * & 1.65 & 1.89 \\
\hline 2.369 & $\mathrm{~N}$ & 5.583 & & $\mathrm{CH}$ & 102.000 & 152 & 610 & 198 & 953 & 762 & 3 & Parallel & 5.340 & * & * & 1.68 & 1.84 \\
\hline 2.371 & $\mathrm{~N}$ & 5.583 & & $\mathrm{CH}$ & 102.000 & 152 & 610 & 199 & 953 & 762 & 3 & Parallel & 5.890 & * & * & 1.51 & 1.80 \\
\hline 2.378 & $\mathrm{~N}$ & 5.583 & & $\mathrm{CH}$ & 102.000 & 152 & 610 & 196 & 953 & 762 & 3 & Parallel & 5.627 & * & * & 1.45 & 1.61 \\
\hline 2.375 & $\mathrm{~N}$ & 14.517 & & C & 102.000 & 152 & 610 & 207 & 953 & 762 & 3 & el & 13.700 & 0.792 & 3629.290 & 4.29 & 52 \\
\hline 2.382 & N & 14.517 & & c & 102.000 & 152 & 610 & 208 & 953 & 762 & 3 & el & 13.720 & 0.736 & 3387.880 & 3.53 & 93 \\
\hline 2.378 & $\mathrm{~N}$ & 14.517 & & C & 102.00 & 152 & 610 & 214 & 953 & 762 & 3 & el & 13.673 & 0.716 & 3359.000 & 8 & 04 \\
\hline 2.380 & $\mathrm{~N}$ & 14.517 & & $\mathrm{CH}$ & 102.00 & 152 & 610 & 203 & 953 & 762 & 3 & el & 13.733 & 0.701 & 3194.790 & 46 & 3.63 \\
\hline 2.340 & N & 16.210 & & $\mathrm{CH}$ & 102.00 & 15 & & 212 & 953 & 762 & 3 & |lel & 03 & 0.785 & 413 & 4.73 & 5.05 \\
\hline 2.338 & N & 16.210 & & $\mathrm{CH}$ & 102.000 & 152 & 61 & 212 & 953 & 762 & 3 & rallel & 15.143 & 0.786 & 4087.420 & 4.20 & 4.62 \\
\hline 2.338 & N & 16.210 & & $\mathrm{CH}$ & 102.000 & 152 & 610 & 209 & 953 & 762 & 3 & rallel & 15.227 & 0.761 & 3881.610 & 4.60 & 5.04 \\
\hline 2.335 & $\mathrm{~N}$ & 16.210 & & $\mathrm{CH}$ & 102.000 & 152 & 610 & 212 & 953 & 762 & 3 & frallel & 15.167 & 0.728 & 3775.250 & 4.47 & 4.82 \\
\hline 2.369 & N & 11.637 & & $\mathrm{CH}$ & 102.000 & 152 & 61 & 1 & 953 & 762 & 3 & rallel & 11.093 & 0.599 & 2269.850 & 3.94 & 4.95 \\
\hline 2.373 & $\mathrm{~N}$ & 11.637 & & $\mathrm{CH}$ & 102.000 & 152 & 61 & 211 & 953 & 762 & 3 & rallel & 11.020 & 0.610 & 329.800 & 37 & 14 \\
\hline 2.380 & $\mathrm{~N}$ & 11.637 & & $\mathrm{CH}$ & 102.000 & 152 & 61 & 20 & 953 & 762 & 3 & frallel & 11.197 & 0.599 & 236.470 & 6 & 28 \\
\hline 2.373 & N & 11.637 & & $\mathrm{CH}$ & 102.000 & 15. & & 8 & 953 & 762 & 3 & rallel & 11.133 & 0.580 & 186.960 & 2 & 19 \\
\hline 2.331 & N & 6.810 & & $\mathrm{CH}$ & .000 & 15. & & 210 & 953 & 762 & 3 & rallel & 13 & 0.591 & 1310.850 & 8 & 47 \\
\hline 2.333 & $\mathrm{~N}$ & 6.810 & & $\mathrm{CH}$ & 102.000 & 152 & 61 & 201 & 953 & 762 & 3 & allel & 23 & 0.609 & 1322.880 & 77 & 54 \\
\hline 2.328 & $N$ & 6.810 & & C & 102.000 & 152 & 610 & 207 & 953 & 762 & 3 & Parallel & 70 & 0.613 & 1348.230 & 70 & 35 \\
\hline 2.336 & $\mathrm{~N}$ & 6.810 & & C & 102.000 & 152 & 610 & 220 & 953 & 762 & 3 & Parallel & 6.593 & 0.610 & 1416.760 & 95 & 83 \\
\hline 2.335 & $\mathrm{~N}$ & 4.787 & & $\mathrm{CH}$ & 102.000 & 152 & 610 & 211 & 953 & 762 & 3 & Parallel & 4.700 & 0.590 & 932.410 & 02 & 2.69 \\
\hline 2.335 & $\mathrm{~N}$ & 4.787 & & $\mathrm{CH}$ & 102.000 & 152 & 610 & 212 & 953 & 762 & 3 & Parallel & 4.697 & 0.596 & 941.960 & 13 & 2.81 \\
\hline 2.333 & $\mathrm{~N}$ & 4.787 & & $\mathrm{CH}$ & 102.000 & 152 & 610 & 215 & 953 & 762 & 3 & Parallel & 4.690 & 0.588 & 942.500 & 2.14 & 2.66 \\
\hline 2.336 & $\mathrm{~N}$ & 4.787 & & $\mathrm{CH}$ & 102.000 & 152 & 610 & 213 & 953 & 762 & 3 & Parallel & 4.700 & 0.610 & 982.370 & 2.12 & 2.81 \\
\hline 2.336 & N & 2.527 & & $\mathrm{CH}$ & 102.000 & 152 & 610 & 212 & 953 & 762 & 3 & Parallel & 2.527 & 0.546 & 453.190 & 1.13 & 1.35 \\
\hline 2.338 & N & 2.527 & & $\mathrm{CH}$ & 102.000 & 152 & 610 & 204 & 953 & 762 & 3 & Parallel & 2.487 & 0.511 & 422.190 & 0.96 & 1.16 \\
\hline 2.340 & N & 2.527 & & $\mathrm{CH}$ & 102.000 & 152 & 610 & 209 & 953 & 762 & 3 & Parallel & 2.493 & 0.536 & 436.100 & 1.07 & 1.42 \\
\hline
\end{tabular}




\begin{tabular}{|c|c|c|c|c|c|c|c|c|c|c|c|c|c|c|c|c|c|}
\hline $\begin{array}{c}\text { Open } \\
\text { Circuit } \\
\text { Voltage ph- } \\
\text { ph }(\mathrm{KV})\end{array}$ & $\begin{array}{c}\text { System } \\
\text { Grounded. } \\
-Y, N \\
\text { HRG }\end{array}$ & $\begin{array}{l}\text { Bolted } \\
\text { fault } \\
\text { current } \\
\text { (KA) }\end{array}$ & XRRatio & $\begin{array}{l}\text { Electrode } \\
\text { material } \\
S S, A L, \\
C H, C S\end{array}$ & $\begin{array}{c}\text { Gap } \\
\text { between } \\
\text { electrodes } \\
\text { (mm) }\end{array}$ & $\begin{array}{c}\text { Gap } \\
\text { electrodes } \\
\text { to box (mm) }\end{array}$ & $\begin{array}{c}\text { Distance } \\
\text { from arc to } \\
\text { calorimeters } \\
(\mathrm{mm})\end{array}$ & $\begin{array}{l}\text { Arc Duration } \\
\text { (msec) }\end{array}$ & $\begin{array}{c}\text { Box } \\
\text { wioth + } \\
\text { height2 } \\
(\mathrm{mm})\end{array}$ & $\begin{array}{l}\text { Box } \\
\text { depth } \\
\text { (mm) }\end{array}$ & $\begin{array}{c}\text { No. of } \\
\text { phases }\end{array}$ & $\begin{array}{l}\text { Electrode } \\
\text { configuration } \\
\text { (Parallel or } \\
\text { Inline) }\end{array}$ & $\begin{array}{l}\text { Arc } \\
\text { Current } \\
\text { (KA) }\end{array}$ & $\begin{array}{c}\text { Arc } \\
\text { Voltage } \\
\text { L-L(KV) }\end{array}$ & $\begin{array}{l}\text { Arc energy } \\
\text { (ki) }\end{array}$ & $\begin{array}{l}\text { Incident } \\
\text { energy, the } \\
\text { mean of } 7 \\
\text { calorimeters } \\
\left(\mathrm{cal} / \mathrm{cm}^{2}\right)\end{array}$ & $\begin{array}{l}\text { Incident } \\
\text { energy, the } \\
\text { max of } 7 \\
\text { calorimeters } \\
(\text { call/cm²) }\end{array}$ \\
\hline 2366 & N & 2.527 & & $\mathrm{CH}$ & 102.000 & 152 & 610 & 197 & 953 & 762 & 3 & Parallel & 2.540 & 0.511 & 409.980 & 1.23 & 1.46 \\
\hline 2.361 & N & 16.403 & & $\mathrm{CH}$ & 102.000 & 152 & 610 & 207 & 953 & 762 & 3 & Parallel & 15.517 & 0.585 & 3016.430 & 4.43 & 5.78 \\
\hline 2.357 & N & 16.403 & & $\mathrm{CH}$ & 102.000 & 152 & 610 & 205 & 953 & 762 & 3 & Parallel & 15.640 & 0.590 & 3021.010 & 4.56 & 5.36 \\
\hline 2.362 & N & 16.403 & & $\mathrm{CH}$ & 102.000 & 152 & 610 & 206 & 953 & 762 & 3 & Parallel & 15.580 & 0.618 & 3284.500 & 4.40 & 5.66 \\
\hline 2.359 & N & 16.403 & & $\mathrm{CH}$ & 102.000 & 152 & 610 & 212 & 953 & 762 & 3 & Parallel & 15.417 & 0.638 & 3418.960 & 4.47 & 6.06 \\
\hline 2.369 & N & 14.400 & & $\mathrm{CH}$ & 102.000 & 152 & 610 & 219 & 953 & 762 & 3 & Parallel & 13.727 & 0.545 & 2571.560 & 5.93 & 6.67 \\
\hline 2.371 & $\mathrm{~N}$ & 14.400 & & $\mathrm{CH}$ & 102.000 & 152 & 610 & 213 & 953 & 762 & 3 & Parallel & 13.767 & 0.585 & 2729.070 & 5.35 & 6.09 \\
\hline 2.369 & N & 14.400 & & $\mathrm{CH}$ & 102.000 & 152 & 610 & 211 & 953 & 762 & 3 & Parallel & 13.600 & 0.609 & 2876.410 & 4.49 & 6.29 \\
\hline 2.368 & N & 14.400 & & $\mathrm{CH}$ & 102.000 & 152 & 610 & 215 & 953 & 762 & 3 & Parallel & 13.700 & 0.601 & 2898.210 & 3.98 & 5.45 \\
\hline 2.369 & N & 13.000 & & $\mathrm{CH}$ & 102.000 & 152 & 610 & 201 & 953 & 762 & 2 & Parallel & 7.760 & & * & 3.36 & 4.50 \\
\hline 2.369 & N & 13.000 & & $\mathrm{CH}$ & 102.000 & 152 & 610 & 198 & 953 & 762 & 2 & Parallel & 7.680 & & ${ }^{*}$ & 3.08 & 3.83 \\
\hline 2.368 & N & 13.000 & & $\mathrm{CH}$ & 102.000 & 152 & 610 & 207 & 953 & 762 & 2 & Parallel & 7.753 & & * & 3.58 & 4.44 \\
\hline 2.369 & $\mathrm{~N}$ & 13.000 & & $\mathrm{CH}$ & 102.000 & 152 & 610 & 200 & 953 & 762 & 2 & Parallel & 7.873 & & * & 3.49 & 4.46 \\
\hline 2.352 & N & 15.000 & & $\mathrm{CH}$ & 102.000 & 152 & 762 & 210 & 953 & 762 & 3 & Parallel & 13.503 & 0.612 & 2796.050 & 3.15 & 4.52 \\
\hline 2.357 & $\mathrm{~N}$ & 15.000 & & $\mathrm{CH}$ & 102.000 & 152 & 762 & 205 & 953 & 762 & 3 & Parallel & 13.560 & 0.628 & 2841.130 & 3.44 & 4.89 \\
\hline 2.350 & N & 15.000 & & $\mathrm{CH}$ & 102.000 & 152 & 762 & 201 & 953 & 762 & 3 & Parallel & 13.550 & 0.639 & 2836.600 & 3.35 & 4.52 \\
\hline 2.352 & $N$ & 15.000 & & $\mathrm{CH}$ & 102.000 & 152 & 762 & 206 & 953 & 762 & 3 & Parallel & 13.603 & 0.643 & 2981.160 & 3.31 & 4.77 \\
\hline 2.349 & N & 15.000 & & $\mathrm{CH}$ & 102.000 & 152 & 914 & 206 & 953 & 762 & 3 & Parallel & 13.417 & 0.643 & 2906.240 & 2.83 & 4.00 \\
\hline 2.343 & N & 15.000 & & $\mathrm{CH}$ & 102.000 & 152 & 914 & 206 & 953 & 762 & 3 & Parallel & 13.527 & 0.618 & 2843.380 & 2.94 & 4.09 \\
\hline 2.343 & $N$ & 15.000 & & $\mathrm{CH}$ & 102.000 & 152 & 914 & 213 & 953 & 762 & 3 & Parallel & 13.560 & 0.616 & 2942.830 & 2.81 & 3.93 \\
\hline 2.342 & N & 15.000 & & $\mathrm{CH}$ & 102.000 & 152 & 914 & 208 & 953 & 762 & 3 & Parallel & 13.397 & 0.626 & 2847.160 & 256 & 3.86 \\
\hline 2.335 & N & 15.000 & & $\mathrm{CH}$ & 102.000 & 152 & 1219 & 205 & 953 & 762 & 3 & Parallel & 13.660 & 0.592 & 2667.260 & 1.94 & 2.75 \\
\hline 2.335 & N & 15.000 & & $\mathrm{CH}$ & 102.000 & 152 & 1219 & 210 & 953 & 762 & 3 & Parallel & 13.463 & 0.609 & 2814.370 & 2.18 & 3.09 \\
\hline 2.335 & $\mathrm{~N}$ & 15.000 & & $\mathrm{CH}$ & 102.000 & 152 & 1219 & 232 & 953 & 762 & 3 & Parallel & 13.353 & 0.655 & 3297.730 & 2.49 & 3.73 \\
\hline 2.338 & N & 15.000 & & $\mathrm{CH}$ & 102.000 & 152 & 1219 & 228 & 953 & 762 & 3 & Parallel & 13.487 & 0.600 & 2984.040 & 2.09 & 2.93 \\
\hline 2.338 & N & 15.000 & & $\mathrm{CH}$ & 102.000 & 152 & 1524 & 229 & 953 & 762 & 3 & Parallel & 13.507 & 0.609 & 3069.870 & 1.85 & 2.96 \\
\hline 2.340 & N & 15.000 & & $\mathrm{CH}$ & 102.000 & 152 & 1524 & 222 & 953 & 762 & 3 & Parallel & 13.577 & 0.597 & 2924.560 & 1.79 & 2.57 \\
\hline 2.336 & $N$ & 15.000 & & $\mathrm{CH}$ & 102.000 & 152 & 1524 & 236 & 953 & 762 & 3 & Parallel & 13.593 & 0.599 & 3123.690 & 1.89 & 2.47 \\
\hline 2.338 & $\mathrm{~N}$ & 15.000 & & $\mathrm{CH}$ & 102.000 & 152 & 1524 & 182 & 953 & 762 & 3 & Parallel & 13.487 & 0.608 & 2443.860 & 1.55 & 2.21 \\
\hline 2.345 & N & 15.000 & & $\mathrm{CH}$ & 102.000 & 152 & 457 & 186 & 953 & 762 & 3 & Parallel & 13.480 & 0.584 & 2408.030 & 4.46 & 5.68 \\
\hline 2.343 & N & 15.000 & & $\mathrm{CH}$ & 102.000 & 152 & 457 & 194 & 953 & 762 & 3 & Parallel & 13.597 & 0.591 & 2550.310 & 4.50 & 5.47 \\
\hline 2.349 & $\mathrm{~N}$ & 15.000 & & $\mathrm{CH}$ & 102.000 & 152 & 457 & 194 & 953 & 762 & 3 & Parallel & 13.713 & 0.574 & 2446.390 & 4.35 & 5.93 \\
\hline 2.347 & N & 15.000 & & $\mathrm{CH}$ & 102.000 & 152 & 457 & 194 & 953 & 762 & 3 & Parallel & 13.537 & 0.603 & 2537.840 & 4.46 & 5.18 \\
\hline 2.352 & N & 15.000 & & $\mathrm{CH}$ & 102.000 & 152 & 457 & 192 & 953 & 762 & 3 & Parallel & 13.610 & 0.623 & 2528.900 & 4.74 & 5.95 \\
\hline 2.350 & N & 15.000 & & $\mathrm{CH}$ & 102.000 & 152 & 457 & 191 & 953 & 762 & 3 & Parallel & 13.730 & 0.593 & 2448.050 & 4.53 & 5.68 \\
\hline 4.160 & N & 5.440 & 47.383 & $\mathrm{CH}$ & 102.000 & 10000 & 483 & 215 & 10000 & 10000 & 3 & Parallel & 5.277 & * & 2164.000 & 1.50 & 1.80 \\
\hline 4.160 & N & 5.440 & 47.383 & $\mathrm{CH}$ & 102.000 & 10000 & 483 & 216 & 10000 & 10000 & 3 & Parallel & 5.337 & * & 2284.000 & 1.37 & 1.57 \\
\hline 4.160 & $\mathrm{~N}$ & 5.440 & 47.383 & $\mathrm{CH}$ & 102.000 & 10000 & 483 & 217 & 10000 & 10000 & 3 & Parallel & 5.343 & * & 2352.000 & 1.76 & 2.17 \\
\hline 4.160 & $\mathrm{~N}$ & 5.440 & 47.383 & $\mathrm{CH}$ & 102.000 & 10000 & 483 & 214 & 10000 & 10000 & 3 & Parallel & 5.217 & * & 2135.000 & 1.31 & 1.62 \\
\hline 4.160 & $\mathrm{~N}$ & 5.440 & 47.383 & $\mathrm{CH}$ & 102.000 & 10000 & 483 & 216 & 10000 & 10000 & 3 & Parallel & 5.293 & * & 2416.000 & 1.63 & 2.00 \\
\hline 4.160 & N & 6.110 & 43.092 & $\mathrm{CH}$ & 102.000 & 10000 & 483 & 214 & 10000 & 10000 & 3 & Parallel & 5.830 & & 2660.000 & 1.73 & 2.05 \\
\hline 4.160 & $\mathrm{N}$ & 6.110 & 43.092 & $\mathrm{CH}$ & 102.000 & 10000 & 483 & 215 & 10000 & 10000 & 3 & Parallel & 5.890 & & 2658.000 & 1.77 & 2.21 \\
\hline
\end{tabular}




\begin{tabular}{|c|c|c|c|c|c|c|c|c|c|c|c|c|c|c|c|c|c|}
\hline $\begin{array}{c}\text { Open } \\
\text { Circuit } \\
\text { Voltage ph- } \\
\text { ph (kV) }\end{array}$ & $\begin{array}{c}\text { System } \\
\text { Grounded } \\
-\quad-Y, N, \\
\text { HRG }\end{array}$ & $\begin{array}{l}\text { Bolted } \\
\text { fault } \\
\text { current } \\
(\mathrm{KA})\end{array}$ & XRRatio & $\begin{array}{l}\text { Electrode } \\
\text { material } \\
\mathrm{SS}, \mathrm{AL}, \\
\mathrm{CH}, \mathrm{CS}\end{array}$ & $\begin{array}{c}\text { Gap } \\
\text { between } \\
\text { electrodes } \\
\text { (mm) }\end{array}$ & $\begin{array}{c}\text { Gap } \\
\text { electrodes } \\
\text { to box (mm) }\end{array}$ & $\begin{array}{c}\text { Distance } \\
\text { from arc to } \\
\text { calorimeters } \\
(\mathrm{mm})\end{array}$ & $\begin{array}{l}\text { Arc Duration } \\
\text { (msec) }\end{array}$ & $\begin{array}{c}\text { Box } \\
\text { width+ } \\
\text { height2 } \\
(\mathrm{mm})\end{array}$ & $\begin{array}{l}\text { Box } \\
\text { depth } \\
(\mathrm{mm})\end{array}$ & $\begin{array}{l}\text { No. of } \\
\text { phases }\end{array}$ & $\begin{array}{l}\text { Electrode } \\
\text { configuration } \\
\text { (Parallel or } \\
\text { Inline) }\end{array}$ & $\begin{array}{l}\text { Arc } \\
\text { Current } \\
\text { (kA) }\end{array}$ & $\begin{array}{c}\text { Arc } \\
\text { Voltage } \\
\mathrm{L}-\mathrm{L}(\mathrm{KV})\end{array}$ & $\begin{array}{l}\text { Arc energy } \\
(\mathrm{kj})\end{array}$ & $\begin{array}{l}\text { Incident } \\
\text { energy, the } \\
\text { mean of } 7 \\
\text { calorimeters } \\
\left(\mathrm{call} \mathrm{cm}^{2}\right)\end{array}$ & $\begin{array}{l}\text { Incident } \\
\text { energy, the } \\
\text { max of } 7 \\
\text { calorimeters } \\
\text { (call/(m²) }\end{array}$ \\
\hline 4.160 & $\mathrm{~N}$ & 6.110 & 43.092 & $\mathrm{CH}$ & 102.000 & 10000 & 483 & 214 & 10000 & 10000 & 3 & Parallel & 5.880 & & 2464.000 & 1.70 & 1.97 \\
\hline 4.160 & $\mathrm{~N}$ & 6.110 & 43.092 & $\mathrm{CH}$ & 102.000 & 10000 & 483 & 215 & 10000 & 10000 & 3 & Parallel & 5.930 & & 2533.000 & 1.66 & 1.96 \\
\hline 4.160 & $\mathrm{~N}$ & 6.110 & 43.092 & $\mathrm{CH}$ & 102.000 & 10000 & 483 & 215 & 10000 & 10000 & 3 & Parallel & 5.940 & & 2580.000 & 1.44 & 1.70 \\
\hline 4.160 & $\mathrm{~N}$ & 6.110 & 43.092 & $\mathrm{CH}$ & 102.000 & 10000 & 483 & 215 & 10000 & 10000 & 3 & Parallel & 5.990 & & 2606.000 & 1.89 & 2.23 \\
\hline 4.160 & $\mathrm{~N}$ & 9.947 & & $\mathrm{CH}$ & 102.000 & 10000 & 610 & 215 & 10000 & 10000 & 3 & Parallel & 9.687 & * & 4460.000 & 2.57 & 2.98 \\
\hline 4.160 & $\mathrm{~N}$ & 9.947 & & $\mathrm{CH}$ & 102.000 & 10000 & 610 & 216 & 10000 & 10000 & 3 & Parallel & 9.947 & * & 4910.000 & 2.69 & 3.39 \\
\hline 4.160 & $\mathrm{~N}$ & 9.947 & & $\mathrm{CH}$ & 102.000 & 10000 & 610 & 216 & 10000 & 10000 & 3 & Parallel & 9.983 & * & 4750.000 & 2.36 & 2.66 \\
\hline 4.160 & $\mathrm{~N}$ & 9.947 & & $\mathrm{CH}$ & 102.000 & 10000 & 610 & 215 & 10000 & 10000 & 3 & Parallel & 9.780 & * & 4660.000 & 2.75 & 3.20 \\
\hline 4.160 & $\mathrm{~N}$ & 19.833 & 36.350 & $\mathrm{CH}$ & 102.000 & 10000 & 610 & 216 & 10000 & 10000 & 3 & Parallel & 18.467 & * & 9880.000 & 5.60 & 6.45 \\
\hline 4.160 & $\mathrm{~N}$ & 19.833 & 36.350 & $\mathrm{CH}$ & 102.000 & 10000 & 610 & 216 & 10000 & 10000 & 3 & Parallel & 18.233 & * & 9580.000 & 5.95 & 7.16 \\
\hline 4.160 & $\mathrm{~N}$ & 19.833 & 36.350 & $\mathrm{CH}$ & 102.000 & 10000 & 610 & 216 & 10000 & 10000 & 3 & Parallel & 18.633 & $*$ & 9770.000 & 6.07 & 7.06 \\
\hline 4.160 & $\mathrm{~N}$ & 19.833 & 36.350 & $\mathrm{CH}$ & 102.000 & 10000 & 610 & 216 & 10000 & 10000 & 3 & Parallel & 18.800 & * & 10070.000 & 5.44 & 6.47 \\
\hline 4.160 & $\mathrm{~N}$ & 19.833 & 36.350 & $\mathrm{CH}$ & 102.000 & 10000 & 610 & 216 & 10000 & 10000 & 3 & Parallel & 23.033 & * & 8890.000 & 5.89 & 6.87 \\
\hline 4.160 & $\mathrm{~N}$ & 40.433 & 25.106 & $\mathrm{CH}$ & 102.000 & 10000 & 610 & 218 & 10000 & 10000 & 3 & Parallel & 38.400 & * & 19020.000 & 14.22 & 17.20 \\
\hline 4.160 & $\mathrm{~N}$ & 40.433 & 25.106 & $\mathrm{CH}$ & 102.000 & 10000 & 610 & 217 & 10000 & 10000 & 3 & Parallel & 30.000 & * & 15390.000 & 14.34 & 17.25 \\
\hline 4.160 & $\mathrm{~N}$ & 40.433 & 25.106 & $\mathrm{CH}$ & 102.000 & 10000 & 610 & 217 & 10000 & 10000 & 3 & Parallel & 38.067 & * & 19770.000 & 15.10 & 17.29 \\
\hline 4.160 & $\mathrm{~N}$ & 40.433 & 25.106 & $\mathrm{CH}$ & 102.000 & 10000 & 610 & 217 & 10000 & 10000 & 3 & Parallel & 37.633 & * & 20650.000 & 14.71 & 17.37 \\
\hline 4.160 & $\mathrm{~N}$ & 19.833 & 36.350 & $\mathrm{CH}$ & 102.000 & 10000 & 610 & 61 & 10000 & 10000 & 3 & Parallel & 19.500 & * & 2355.000 & 1.50 & 1.81 \\
\hline 4.160 & $\mathrm{~N}$ & 19.833 & 36.350 & $\mathrm{CH}$ & 102.000 & 10000 & 610 & 55 & 10000 & 10000 & 3 & Parallel & 18.933 & * & 2176.000 & 1.32 & 1.58 \\
\hline 4.160 & $\mathrm{~N}$ & 19.833 & 36.350 & $\mathrm{CH}$ & 102.000 & 10000 & 610 & 52 & 10000 & 10000 & 3 & Parallel & 19.200 & * & 2113.000 & 1.41 & 1.63 \\
\hline 4.160 & $\mathrm{~N}$ & 19.833 & 36.350 & $\mathrm{CH}$ & 102.000 & 10000 & 610 & 103 & 10000 & 10000 & 3 & Parallel & 18.900 & * & 3990.000 & 2.68 & 3.17 \\
\hline 4.160 & $\mathrm{~N}$ & 19.833 & 36.350 & $\mathrm{CH}$ & 102.000 & 10000 & 610 & 103 & 10000 & 10000 & 3 & Parallel & 19.767 & * & 4210.000 & 2.40 & 2.85 \\
\hline 4.160 & $\mathrm{~N}$ & 19.833 & 36.350 & $\mathrm{CH}$ & 102.000 & 10000 & 610 & 103 & 10000 & 10000 & 3 & Parallel & 19.367 & * & 3970.000 & 2.23 & 2.62 \\
\hline 4.160 & $\mathrm{~N}$ & 19.833 & 36.350 & $\mathrm{CH}$ & 102.000 & 10000 & 610 & 103 & 10000 & 10000 & 3 & Parallel & 19.500 & * & 42900.000 & 2.96 & 3.58 \\
\hline 4.160 & $\mathrm{~N}$ & 19.833 & 36.350 & $\mathrm{CH}$ & 102.000 & 10000 & 610 & 508 & 10000 & 10000 & 3 & Parallel & 19.133 & * & 20190.000 & 13.36 & 15.84 \\
\hline 4.160 & $\mathrm{~N}$ & 19.833 & 36.350 & $\mathrm{CH}$ & 102.000 & 10000 & 610 & 514 & 10000 & 10000 & 3 & Parallel & 19.400 & 1.572 & 23160.000 & 14.48 & 17.21 \\
\hline 4.160 & $\mathrm{~N}$ & 19.833 & 36.350 & $\mathrm{CH}$ & 102.000 & 10000 & 610 & 513 & 10000 & 10000 & 3 & Parallel & 19.367 & 1.487 & 22220.000 & 13.74 & 16.93 \\
\hline 4.160 & $\mathrm{~N}$ & 19.833 & 36.350 & $\mathrm{CH}$ & 102.000 & 10000 & 610 & 515 & 10000 & 10000 & 3 & Parallel & 19.433 & 1.612 & 23430.000 & 13.66 & 16.82 \\
\hline 13.800 & $\mathrm{~N}$ & 5.710 & 81.295 & $\mathrm{CH}$ & 152.000 & 10000 & 762 & 205 & 10000 & 10000 & 3 & Parallel & 5.617 & 1.585 & 2771.000 & 1.03 & 1.12 \\
\hline 13.800 & $\mathrm{~N}$ & 5.710 & 81.295 & $\mathrm{CH}$ & 152.000 & 10000 & 762 & 206 & 10000 & 10000 & 3 & Parallel & 5.643 & 1.886 & 2937.000 & 0.96 & 1.07 \\
\hline 13.800 & $\mathrm{~N}$ & 5.710 & 81.295 & $\mathrm{CH}$ & 152.000 & 10000 & 762 & 207 & 10000 & 10000 & 3 & Parallel & 5.693 & 1.758 & 2793.000 & 1.11 & 1.19 \\
\hline 13.800 & $\mathrm{~N}$ & 5.710 & 81.295 & $\mathrm{CH}$ & 152.000 & 10000 & 762 & 208 & 10000 & 10000 & 3 & Parallel & 5.660 & 1.730 & 2880.000 & 0.98 & 1.11 \\
\hline 13.800 & $\mathrm{~N}$ & 5.710 & 81.295 & $\mathrm{CH}$ & 152.000 & 10000 & 762 & 206 & 10000 & 10000 & 3 & Parallel & 5.640 & 1.632 & 2854.000 & 1.04 & 1.12 \\
\hline 13.800 & $\mathrm{~N}$ & 10.000 & 89.280 & $\mathrm{CH}$ & 152.000 & 10000 & 762 & 206 & 10000 & 10000 & 3 & Parallel & 9.990 & 1.740 & * & 1.66 & 1.90 \\
\hline 13.800 & $\mathrm{~N}$ & 10.000 & 89.280 & $\mathrm{CH}$ & 152.000 & 10000 & 762 & 206 & 10000 & 10000 & 3 & Parallel & 9.927 & 1.783 & 5480.000 & 1.84 & 1.98 \\
\hline 13.800 & $\mathrm{~N}$ & 10.000 & 89.280 & $\mathrm{CH}$ & 152.000 & 10000 & 762 & 207 & 10000 & 10000 & 3 & Parallel & 10.027 & 1.777 & 5490.000 & 1.84 & 1.98 \\
\hline 13.800 & $\mathrm{~N}$ & 10.000 & 89.280 & $\mathrm{CH}$ & 152.000 & 10000 & 762 & 206 & 10000 & 10000 & 3 & Parallel & 10.030 & 1.681 & 5160.000 & 1.77 & 1.94 \\
\hline 13.800 & $\mathrm{~N}$ & 20.100 & 51.011 & $\mathrm{CH}$ & 152.000 & 10000 & 762 & 207 & 10000 & 10000 & 3 & Parallel & 20.200 & 1.533 & 9300.000 & 4.20 & 4.47 \\
\hline 13.800 & $\mathrm{~N}$ & 20.100 & 51.011 & $\mathrm{CH}$ & 152.000 & 10000 & 762 & 208 & 10000 & 10000 & 3 & Parallel & 20.033 & 1.491 & * & 3.53 & 3.85 \\
\hline 13.800 & $\mathrm{~N}$ & 20.100 & 51.011 & $\mathrm{CH}$ & 152.000 & 10000 & 762 & 208 & 10000 & 10000 & 3 & Parallel & 20.167 & 1.479 & 8850.000 & 3.86 & 4.16 \\
\hline 13.800 & $\mathrm{~N}$ & 20.100 & 51.011 & $\mathrm{CH}$ & 152.000 & 10000 & 762 & 206 & 10000 & 10000 & 3 & Parallel & 20.100 & 1.417 & 8450.000 & 2.63 & 2.89 \\
\hline 13.800 & $\mathrm{~N}$ & 40.800 & 33.769 & $\mathrm{CH}$ & 152.000 & 10000 & 762 & 207 & 10000 & 10000 & 3 & Parallel & 40.000 & 1.718 & 18660.000 & 9.08 & 9.90 \\
\hline
\end{tabular}




\begin{tabular}{|c|c|c|c|c|c|c|c|c|c|c|c|c|c|c|c|c|c|}
\hline $\begin{array}{l}\text { Open } \\
\text { Circuit }\end{array}$ & $\begin{array}{l}\text { System } \\
\text { Grounded. }\end{array}$ & $\begin{array}{l}\text { Bolted } \\
\text { fault }\end{array}$ & & $\begin{array}{l}\text { Electrode } \\
\text { material }\end{array}$ & $\begin{array}{l}\text { Gap } \\
\text { between }\end{array}$ & Gap & $\begin{array}{l}\text { Distance } \\
\text { from arcto }\end{array}$ & & $\begin{array}{l}\text { Box } \\
\text { widh + }\end{array}$ & Box & & $\begin{array}{l}\text { Eleccrooe } \\
\text { configuration }\end{array}$ & Arc & Arc & & $\begin{array}{l}\text { Incident } \\
\text { energy, the } \\
\text { mean of }\end{array}$ & $\begin{array}{l}\text { Incident } \\
\text { energy, the } \\
\text { max of }\end{array}$ \\
\hline gge ph- & $-Y_{,} N_{1}$ & current & & $S S_{, A L}$ & electrodes & electrodes & calorimeters & Arc Curation & 1 height2 & depth & No. of & (Parallel or & Current & Voltage & Arcenergy & calorimeters & calorimeters \\
\hline ph $(K M)$ & HRG & $(\mathrm{KA})$ & XRRatio & CH,CS & (mm) & to box $(\mathrm{mm})$ & $(\mathrm{mm})$ & (msec) & $(\mathrm{mm})$ & $(\mathrm{mm}) \mathrm{p}$ & phases & (ninine) & $(\mathrm{k} A)$ & $L L L(K M)$ & (ki) & $\left(\mathrm{cal} / \mathrm{cm}^{2}\right)$ & $\left(\mathrm{cal} / \mathrm{cm}^{2}\right)$ \\
\hline 13.800 & N & 40.800 & 33769 & $\mathrm{CH}$ & 152.000 & 10000 & 762 & 208 & 10000 & 10000 & 3 & Parallel & 40.467 & 1.663 & 18800.000 & 9.26 & 10.23 \\
\hline 13.800 & N & 40,800 & 33769 & $\mathrm{CH}$ & 152.000 & 10000 & 762 & 209 & 10000 & 10000 & 3 & Parallel & 39.867 & 1.659 & 18700.000 & 9.42 & 46 \\
\hline 13.800 & N & 40.800 & 33.769 & $\mathrm{CH}$ & 152.000 & 1000 & 762 & 207 & 10000 & 10000 & 3 & Parallel & 40.333 & 1.647 & 18690.000 & 9.71 & 10.83 \\
\hline 13.800 & N & 40.8 & 33.769 & $\mathrm{CH}$ & 152.000 & 10000 & 762 & 207 & 10000 & 10000 & 3 & Par & 40.400 & 1.753 & 18900.000 & 9.95 & 189 \\
\hline 13.800 & N & 20. & 011 & $\mathrm{CH}$ & 152.000 & 10000 & 762 & & 10000 & 10000 & 3 & Parallel & 00 & 1.837 & 3 & 1 & \\
\hline 13.800 & N & & 51.011 & $\mathrm{CH}$ & 152.000 & & & & 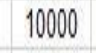 & 10000 & 3 & |lel & 00 & 1.697 & 30. & 0.99 & 1.09 \\
\hline 13.800 & N & 20. & 1.011 & $\mathrm{CH}$ & 152.000 & 10000 & 762 & 5 & 10000 & 10000 & 3 & allel & 300 & 1.776 & 301 & 1.36 & 1.51 \\
\hline 13.800 & N & 20. & 51.011 & $\mathrm{CH}$ & 152.000 & 10 & 762 & 105 & 10000 & 10000 & 3 & allel & 20.000 & 1.781 & 5400 & 233 & 50 \\
\hline 13.800 & N & 20. & 51.011 & Ch & 152.000 & 100 & 762 & 10 & 10000 & 10000 & 3 & yrlelel & 20.000 & 1.784 & 5530 & 2.43 & 2.61 \\
\hline 13.800 & N & 20.1 & 51.011 & $\mathrm{CH}$ & 152.000 & 10 & 762 & 105 & 10000 & 10000 & 3 & |r|llel & 19.900 & 1.754 & 5320.000 & 2.34 & 2.52 \\
\hline 13.800 & N & 20.100 & 51.011 & $\mathrm{CH}$ & 152.000 & 10000 & 762 & 104 & 10000 & 10000 & 3 & Parallel & 20.000 & 1.632 & 5150.000 & 1.84 & 2.19 \\
\hline 13.800 & N & 20.100 & 51.011 & $\mathrm{Cl}$ & 152.000 & 100 & 762 & 252 & 10000 & 10000 & 3 & Parallel & 20.000 & 1.560 & 11060.000 & 4.80 & 5.44 \\
\hline 13.800 & N & 20.100 & 51.011 & $\mathrm{CH}$ & 152.000 & 10000 & 762 & 514 & 10000 & 10000 & 3 & Parallel & 20.000 & 1.453 & 20600.000 & 8.25 & 9.05 \\
\hline 13.800 & N & 20.100 & 51.011 & $\mathrm{CH}$ & 152.000 & 10000 & 762 & 516 & 10000 & 10000 & 3 & Parallel & 20.100 & 1.704 & 24670.000 & 10.81 & 11.95 \\
\hline 13.800 & N & 20.100 & 51.011 & $\mathrm{Cl}$ & 152.000 & 10000 & 762 & 515 & 10000 & 10000 & 3 & Parallel & 20.000 & 1.618 & 22960.000 & 9.49 & 10.98 \\
\hline 13.800 & N & 20.1 & 51.011 & $\mathrm{CH}$ & 152.000 & 10000 & 762 & 515 & 10000 & 10000 & 3 & allel & 20.100 & 1.538 & 22180.000 & 8.53 & 9.49 \\
\hline 13.800 & N & 20. & 51.0 & $\mathrm{CH}$ & 13.000 & 10000 & 762 & & 10000 & 10000 & 3 & |lel & 20.067 & 0.501 & 3018.000 & 0.86 & 0.95 \\
\hline 13.80 & N & 20.1 & $1.0^{-1}$ & 0 & 13.0 & & 762 & 2 & 10000 & 10000 & 3 & Patalle| & 20.033 & 0.531 & 2639.000 & 0.92 & 1.07 \\
\hline 13.800 & N & 20.1 & 01 & $\mathrm{Cl}$ & 13.000 & 1000 & 102 & 2 & 10000 & 10000 & 3 & Parallel & 20.2 & 0.631 & 3657.000 & 1.10 & 1.20 \\
\hline 13.800 & N & 20.1 & 51.011 & $\mathrm{CH}$ & 13.000 & 1000 & 762 & 2 & 10000 & 10000 & 3 & Parallet & 20.133 & $0.5 / 8$ & 3608.000 & 1.11 & 1.51 \\
\hline 13.800 & N & 20.100 & 51.011 & $\mathrm{CH}_{\mathrm{H}}$ & 13.000 & 10000 & 762 & 21 & 10000 & 10000 & 3 & Parallel & 20.167 & 0.693 & 4080.000 & 1.25 & 1.43 \\
\hline
\end{tabular}

